\title{
Role Development of Nurses Supervising Exercise Tolerance Tests
}

A dissertation submitted in partial fulfilment

of the requirements for the Degree

of Master of Health Sciences

in the University of Canterbury

by Judith Ann Ward

University of Canterbury 


\section{Table of Contents}

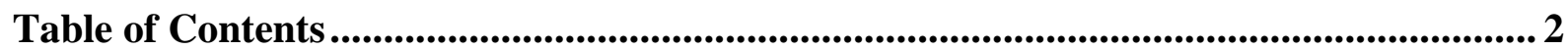

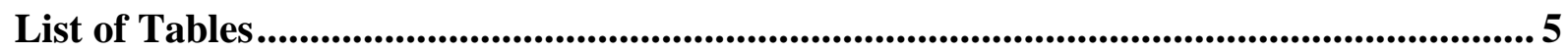

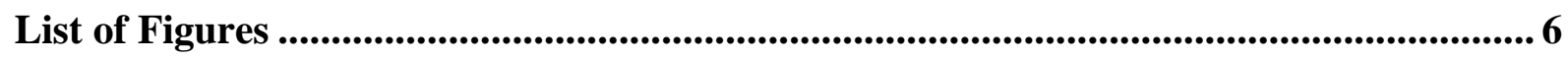

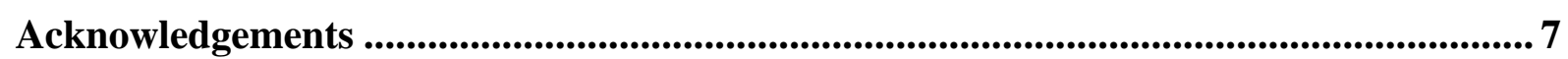

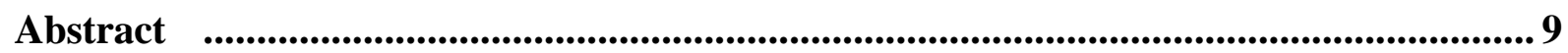

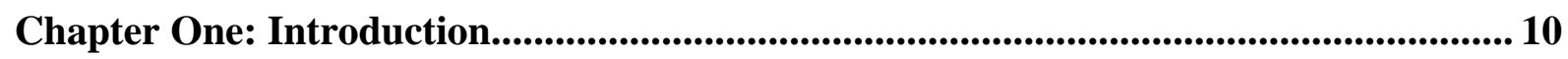

The Exercise Tolerance Test ............................................................................... 10

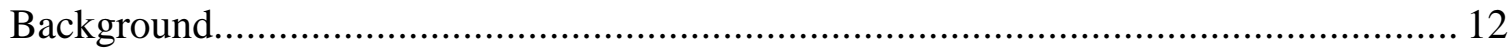

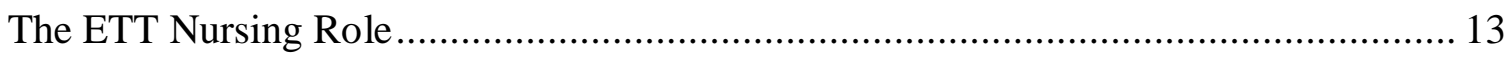

Development of Advanced Nursing Roles in New Zealand ...................................... 13

Advancing Cardiovascular Nursing Roles and Role Expansion ................................. 15

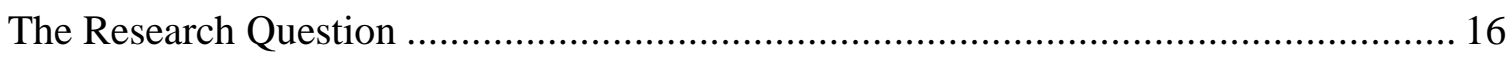

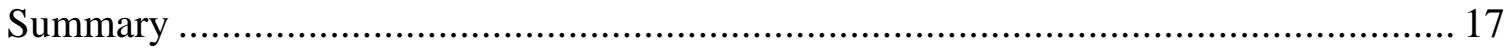

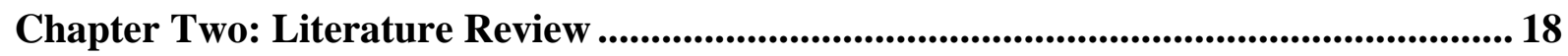

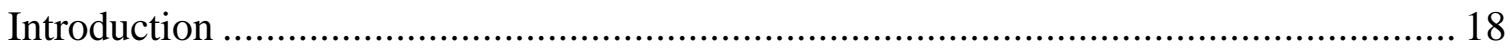

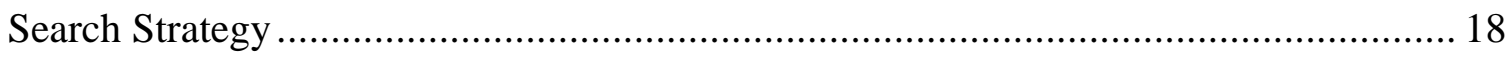

Historical Development of the ETT Nurse …....................................................... 19

Advancing Cardiovascular Nursing and Role expansion........................................ 27

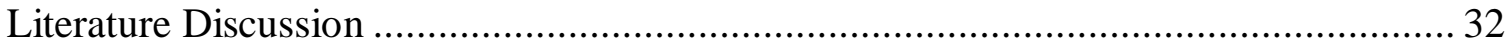

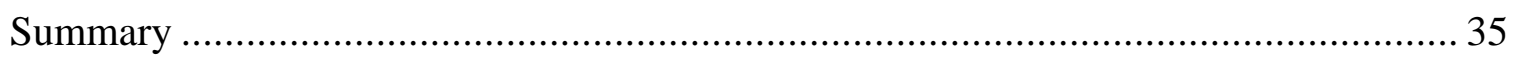

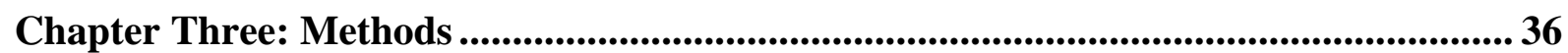

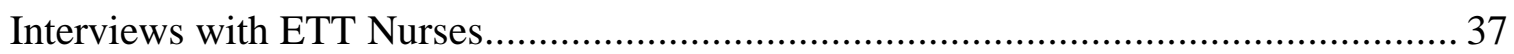

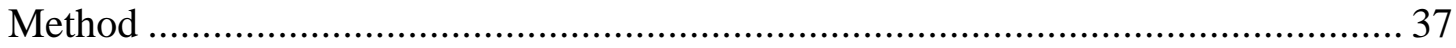

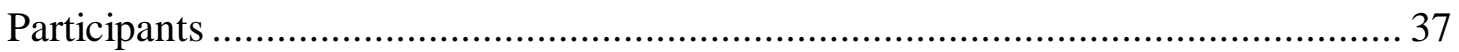

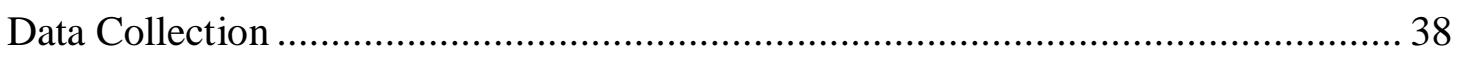

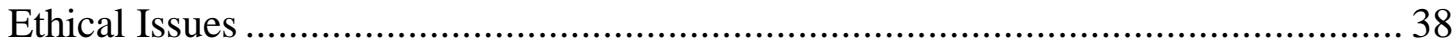

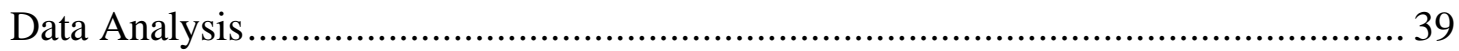

Interview with Clinical Director of Cardiology ....................................................... 40 


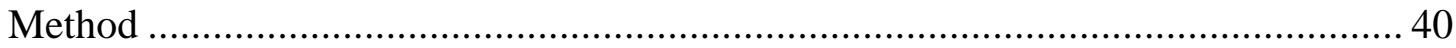

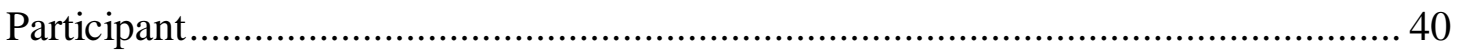

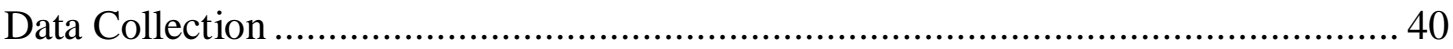

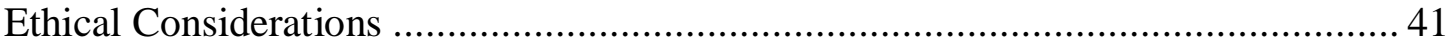

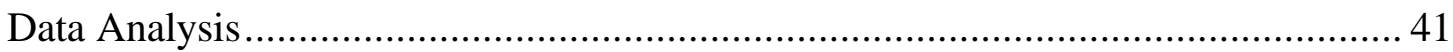

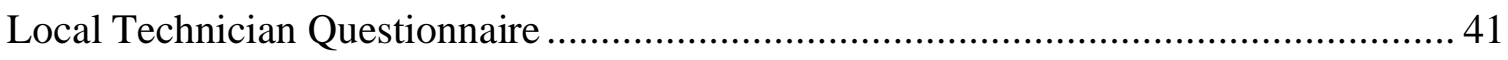

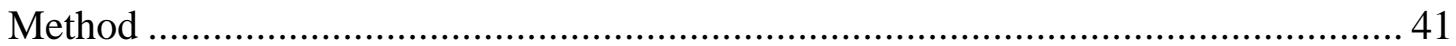

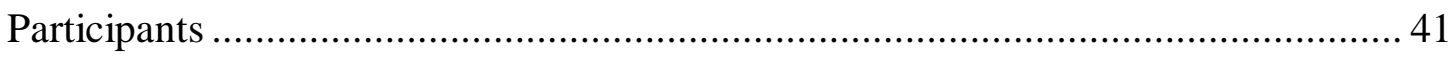

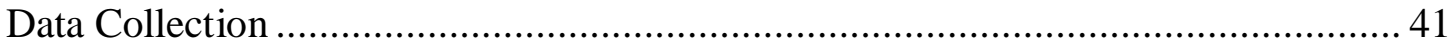

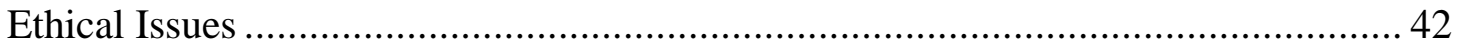

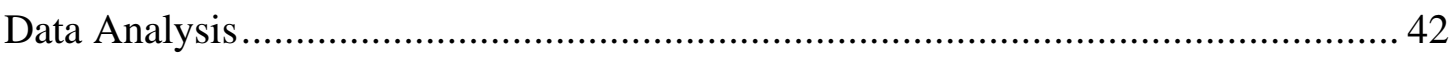

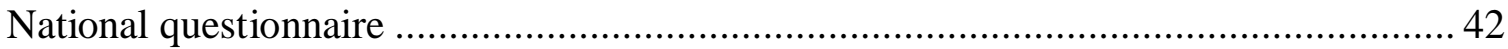

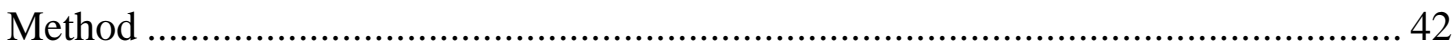

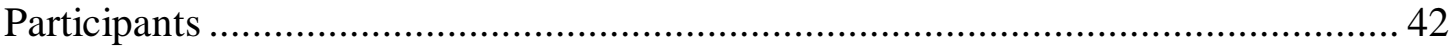

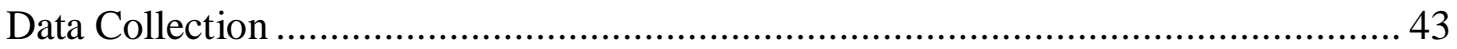

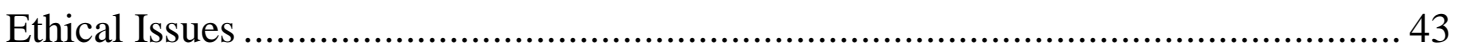

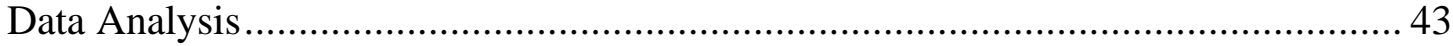

Chapter Four: Findings ............................................................................................................ 44

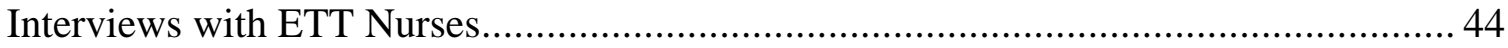

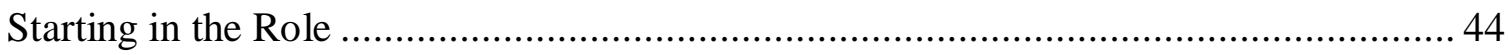

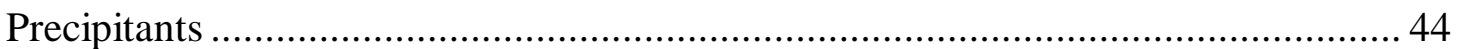

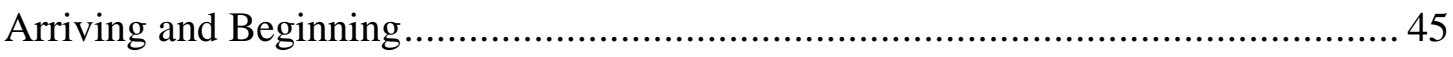

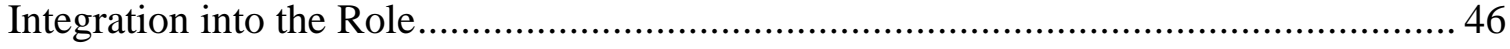

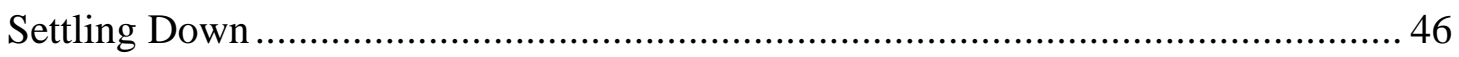

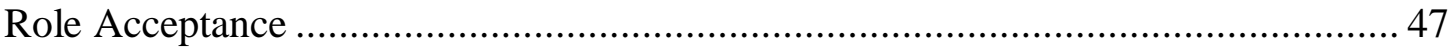

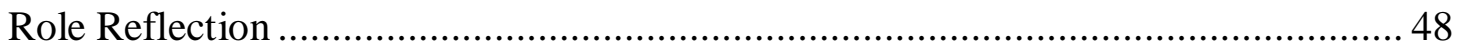

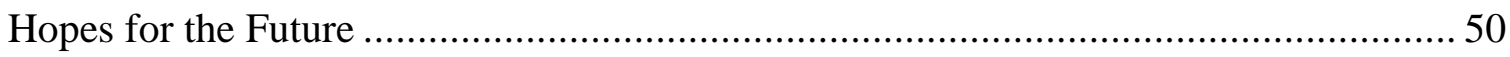

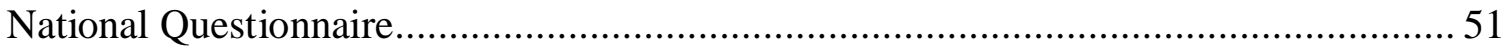

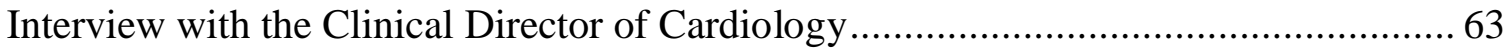

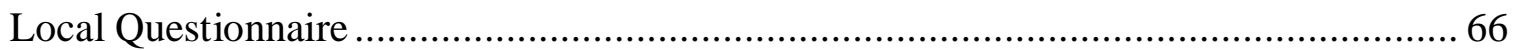

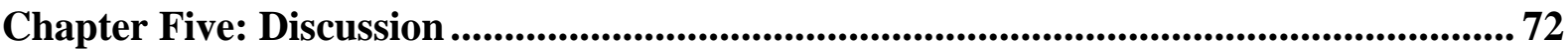




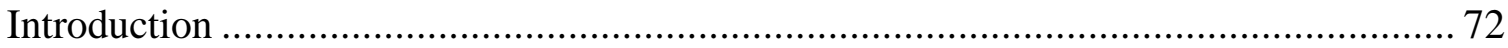

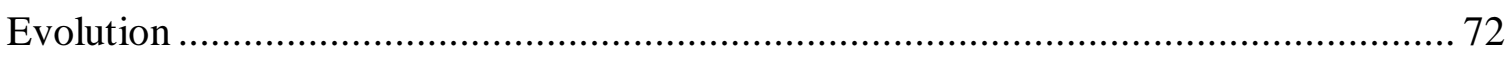

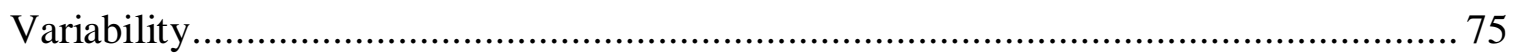

Developmental Process for the ETT Nurse …....................................................... 78

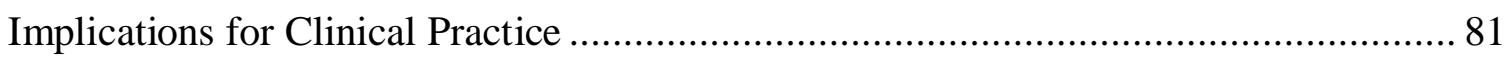

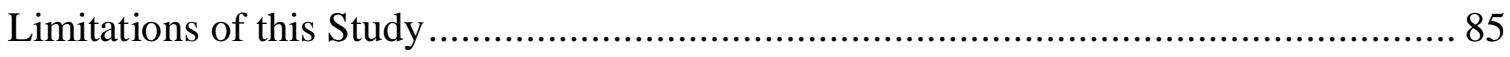

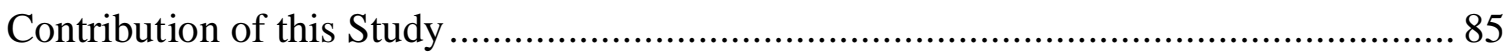

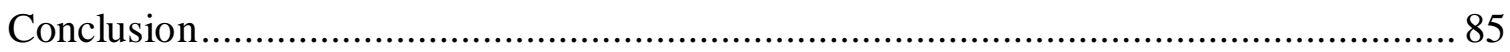

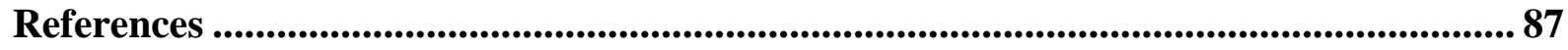

Appendix 1: Information Sheet - Nurses..................................................................... 92

Appendix 2: Consent Form - Nurses ................................................................................. 94

Appendix 3: Interview Guide - Nurses ...................................................................................96

Appendix 4: Information Sheet - Clinical Director of Cardiology ..................................97

Appendix 5: Consent Form - Clinical Director of Cardiology .......................................... 99

Appendix 6: Interview Guide - Clinical Director of Cardiology ................................... 101

Appendix 7: Information Sheet • Technicians......................................................... 102

Appendix 8: Questionnaire -Technicians .......................................................................... 104

Appendix 9: Information Sheet - National............................................................ 106

Appendix 10: Questionnaire - National.......................................................................... 108

Appendix 11: Maori Health - Consultation ........................................................... 112

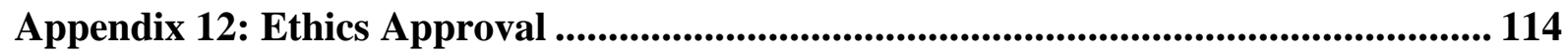

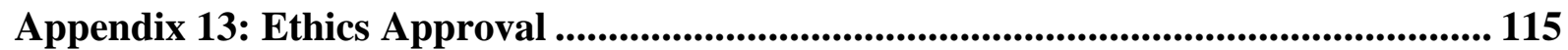




\section{List of Tables}

Table 1: Themes from interviews with ETT nurses........................................................ 44

Table 2: Hospitals within the 21 DHBs where questionnaires sent and responses ....... 52

Table 3: Hospitals where ETTs are performed.......................................................5 53

Table 4: Supervising personnel ...............................................................................................5 54

Table 5: Prerequisite experiences........................................................................5 56

Table 6: Prerequisite qualifications.....................................................................5 57

Table 7: Ongoing training responses .....................................................................58

Table 8: Presence of quality documents in regards to training and competency assessment ........................................................................................................59

Table 9: Other tests that ETT nurses are involved with.........................................6 60

Table 10: Hospitals where ETT nurses work alongside cardiac technicians .................... 61

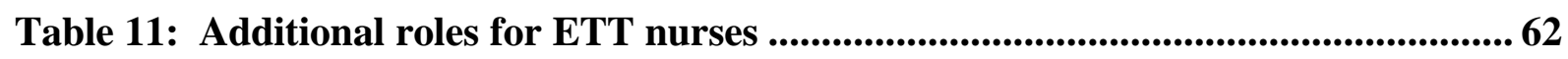

Table 12: Hospitals that apply CSANZ Guidelines .................................................6 63

Table 13: Strengths of doctor supervision..................................................................67

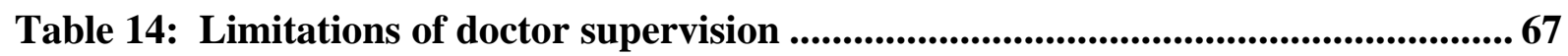

Table 15: Strengths of nurse supervision ....................................................................68

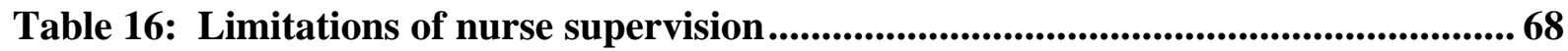

Table 17: Possibilities of service development and implications ................................... 69

Table 18: Technician contribution to nurse es role development .................................... 70

Table 19: Additional comments........................................................................... 70 


\section{List of Figures}

Figure 1: Days of the week ETTs are performed by hospital ...................................53

Figure 2: Number of nurses supervising at each hospital ..............................................55

Figure 3: Year that nurses began supervising ETTs...............................................55

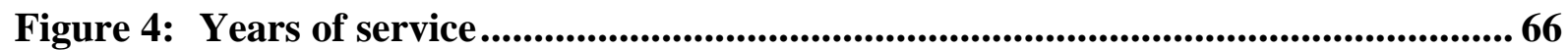




\section{Acknowledgements}

The process of inquiry and learning about everything I needed to know to complete this research study has been a special journey. My progress to completion would not have been possible without the support, guidance and encouragement of many people.

I would like to acknowledge the support given to me by the Volunteer group at Christchurch Hospital who in addition to their generous contribution, have maintained an ongoing interest in this study.

I would like to acknowledge the variety of support given to me by the Department of Nursing at Christchurch Hospital. Your generous support, including study leave has made it possible to continue study while remaining in clinical practice.

To Jeff and Paul my supervisors and mentors, your ongoing guidance; wisdom, patience and support have been the essential ingredients to keep my momentum up on this journey. I have valued our unique supervision relationship. Both of you have reinforced my nursing philosophy and assisted me to give something back to my colleagues and nursing.

Most importantly I thank the participants who participated in this study through interviews and surveys. Without your contribution, this study would not have progressed.

To my colleagues, clinical educator and manager in my workplace, I thank you for your ongoing encouragement and support. I have very much appreciated this through times of considerable organisational change.

To the library staff at Otago University (Christchurch Campus) and Canterbury University, I very much appreciate all your support and assistance given to me.

To all my friends and family who have given me constant and regular support, you have been a life line for me. Your encouragement, practical support and wise counsel have helped maintain important vision throughout this journey. 
Finally, I wish to thank all the staff and fellow students at Waimari (Health Sciences Centre) who have supported me in this academic journey. The interprofessional relationships and sharing of knowledge have been invaluable. I give special thanks to Cecilia, Philippa and Jenny for all their practical help and encouragement. 


\section{Abstract}

Exercise Tolerance Testing (ETT) is widely accepted as an important diagnostic and prognostic tool and its primary purpose is to assess patients with known or suspected coronary artery disease. Previous studies have focused on concordance between doctors and other supervising personnel in regards to safety outcomes. ETTs are increasingly supervised by nurses now as a result of medical devolvement in this role. This study contributes a new perspective to international literature and focuses on understanding the process of role development for cardiac nurses who supervise ETTs.

The overall aim was to gain greater understanding of how cardiac nurses have developed in the role of supervising ETTs and what their process has been. This is a mixed methods study that has utilised both qualitative descriptive techniques and descriptive quantitative data. These data were obtained by individual interviews with ETT nurses and the Clinical Director of Cardiology, and a survey of technicians who work alongside the ETT nurses at a tertiary hospital. Data were also obtained from a national survey of cardiac centres in New Zealand. Both methods were employed to give greater depth to the subject and place local findings in context with national data and international literature.

Findings show there have been a number of international and local evolutionary factors contributing to the emergence of the ETT nurse•s role over time. Specific themes emerged from the interviews that describe individual process of role development. Technicians identified that the ETT service has improved as a consequence of having -dedicated ETT nurses $\bullet$ Variability in regards to work place practices, training and assessment were found in the national survey.

There is further potential for both increasing the number of nurses practicing as ETT nurses and further expansion of the role, however continued fragmentation, inconsistent service delivery and variation in national standards for practice in New Zealand may be barriers to collective and individual role development. 


\section{Chapter One: Introduction}

The reasons for undertaking research into the role development of cardiac nurses who supervise exercise tolerance tests (ETTs) are outlined in this chapter. In addition to being the primary researcher, I also work in the clinical role as an ETT nurse. Reflecting on my own experiences precipitated my inquiry and formulation of the research question as to $\bullet$ what is the process of role development for cardiac nurses who supervise exercise tolerance tests?• On initial inquiry, I found only a small amount of literature pertaining to nurses and ETTs. The majority of this literature focused on safety outcomes for patients. No literature was found about the nurse•s role development in an ETT setting. Currently no comprehensive data base exists in New Zealand about ETT nurse demographics. It is for these reasons that I have utilised mixed methods to gather information that will add breadth to the phenomenon in question. Finally, this research will add a new perspective to current literature.

\section{The Exercise Tolerance Test}

Cardiovascular disease remains a predominant cause of mortality and morbidity impacting on health services. In New Zealand, $40 \%$ of deaths annually are cardiac in origin (Heart Foundation, 2010). Considerable research in the past fifty years has focused on not only risk factors and efficacy of treatments, but importantly, effectiveness of assessment tools in detecting cardiac disease. Understanding the physiology of vascular response to exercise has led to exercise stress testing being increasingly used as a prognostic and diagnostic tool in a controlled clinical environment. An Exercise Tolerance Test (ETT) is also commonly known as an Exercise Stress Test (EST) and involves exercising a client on a motorised and calibrated treadmill whilst attached to an electrocardiographic device via electrodes in a clinical environment. The speed and gradient at which the client begins and ends on is defined by a number of specific international protocols, The Bruce protocol is the most widely adopted protocol and has been extensively validated $f$ (Hill \& Timmis, 2002, p. 1084). This protocol has seven stages; each lasting three minutes with speed and incline increasing incrementally. The premise is that increasing energy expenditure places increasing workload on the heart. Evidence of ischemia is detected by electrographic changes and reported patient symptoms. , Exercise testing has a sensitivity of $78 \%$ and a specificity of $70 \%$ for detecting coronary artery disease $f$ (Hill \& Timmis, 2002, p. 
1084), and therefore strictly speaking as a test, is considered to be prognostic rather than diagnostic. A positive test is a precursor to other clinical investigations such as cardiac angiography in order to make accurate diagnosis and treat accordingly. Conclusive exclusion of coronary artery disease by a combination of blood tests and an ETT does however allow for safe and expedient discharge from in-patient services. ETTs are therefore frequently used as a first line assessment for people who present to an emergency department with chest pain.

Patients are commonly referred from within an acute hospital that has facilities or via community referral from GPs. In my experience, patients who are admitted to an emergency department with chest pain are screened using a chest pain pathway protocol. This protocol involves testing for cardiac bio-markers, assessment of symptoms and possible ECG changes. Following exclusion of these markers and a full physical assessment, inpatients are referred at the earliest opportunity for an ETT. Referrals may also come from the inpatient wards where the ETT nurse will make further assessment. Outpatients that are referred are commonly waiting for an outpatient assessment in clinic and require Cardiologist approval for their ETT. Patients are generally categorised as low to moderate risk for having a cardiac event and therefore considered $\bullet$ safe $\bullet$ to do the test. Higher risk patients require a medical officer also be in attendance for the supervision of the test.

The ETT nurse referral process in the clinical setting where I work involves checking the patient॰s biochemistry and cardiac enzyme results. The patient is interviewed regarding physical ability to perform the test and a brief history of cardiac risk factors is taken. The patient has an opportunity to ask questions and prepare psychologically for the impending test. Once in the exercise room, the patient is given specific explanation as to what to expect during the test and is consented. The patient is also advised of their responsibility to report any symptoms and difficulty experienced during the test such as discomfort or dizziness. The patient॰s blood pressure is checked by the ETT nurse, and their skin prepared for the electrodes by the technician. Before commencing the test, the patient is reminded that the treadmill will increase in speed and incline every three minutes and that their primary goal is to continue as long as possible so that a good workload is achieved. The patient continues on the treadmill until reaching end point criteria or they request to stop. After stopping the test, the patient is observed closely by 
the ETT nurse as complications such as angina and arrhythmias may occur in this period. The medical team is informed about patients who have a positive test as usually they will require further medical attention. A positive test is one where specific endpoint criteria are reached that strongly suggest cardiac ischemia or another cardiac anomaly. End point criteria refer to ST segment changes or a life threatening arrhythmia. The wave form of electrical conduction as seen on electrocardiographic equipment is represented as PQRST waves. These patients may also be symptomatic, requiring life saving measures such as intravenous medications and in the worst case scenario, cardiac defibrillation. During the recovery period the patient has an opportunity to discuss any pressing health concerns, receive health information and confirm follow-up appointments.

\section{Background}

Although this test is non-invasive, there is risk of mortality. A recent clinical report from the Cardiac Society of Australia and New Zealand (2008) refers to the risk of sudden death as approximately one in 10,000 tests, while two to three in 10,000 tests result in other morbid events such as myocardial infarction and major arrhythmias where resuscitation is required.

Cardiologists worldwide have been utilising ETTs for at least the last sixty years. Internationally, ETTs are conducted according to clinical and best practice guidelines as set out by various professional bodies (Gibbons et al. 2002; British Cardiovascular Society, 2008; Cardiac Society of Australia and New Zealand, 2008). Historically, a trained physician, who had experience in interpreting electrocardiographic data and able to respond to sudden adverse events, was considered the appropriate supervising attendant.

A growing global crisis of staff shortages in the health workforce has resulted in changes in the way health professionals and particularly, nurses work. This includes the adopting and sharing of roles. (Buchanan, 2009; Thompson, 2009). Over the last thirty years, other trained health professionals with specific training and experience have been supervising ETTs in the absence of a medical physician. These health professionals include registered nurses and cardiac technicians with specific cardiology experience. The New Zealand experience to date has no documented information on who 
specifically is supervising tests, although in most main centres, cardiac nurses have assumed this role (undocumented). Nurses in New Zealand have been involved in this role since approximately 2004 (undocumented Christchurch experience).

The subject of supervising personnel has been the focus of professional discussions because traditionally the medical discipline assumed this responsibility. Since part medical devolvement of this role, international studies have focused on concordance between nurses, technicians and medical staff in regards to safety outcomes and consistencies in the interpretation of tests. The literature review in chapter two will detail more fully outcomes of those studies.

\section{The ETT Nursing Role}

The ETT nurse role involves pre and post assessment and clinical supervision of the ETT. International guidelines recommend that supervising personnel who are not medical practitioners must have appropriate training (Cardiac Society of Australia and New Zealand, 2008). This means that that the supervising personnel not only have considerable cardiology experience, but specific experience and knowledge related to understanding the physiology of exercise and interpretation of electrographic data. The supervising nurse is required to have advanced resuscitation skills in the event of an adverse event, and demonstrate strong collaborative and communication skills with other staff. The exceptions to non medical staff supervising ETTs require that a medical officer be accessible in emergencies.

For the duration of the test, the supervising nurse is assimilating and integrating observation of the patient and data on the screen. Documentation and clinical decisionmaking are essential skills in the supervisory responsibilities. Professional and personal skills are also important, as essentially, the supervising nurse is the only registered nurse present in the test room. Currently, the guidelines do not refer to desirable interpersonal qualities that may be important to the role.

\section{Development of Advanced Nursing Roles in New Zealand}

While the ETT nursing role is considered to be an extended role for nurses, it remains within the scope of a registered nurse. With this emerging group of nurses who work with a particular focus, it is important to consider what is happening with nursing on a wider scale in New Zealand. Changing demographics, complexity of care and workforce 
issues have all contributed to the changing face of the New Zealand health workforce. Trying to understand and define different levels of practice and areas which nurses work in has been a complex challenge. During the 1990s, nurses in New Zealand were being appointed to various positions with various titles. However, , these titles lacked national consistency and links to education and competencef (Wilkinson, 2008, p. 10). In the following decade, trying to establish consensus about advancing nursing practice roles remained central to regulatory bodies because of the Health Practitioners Competence Assurance Act (2003). The primary purpose of the act is to protect the public and ensure that nurses are practicing within a recognisable scope of practice. Advancing practice roles are those where aspects of the role require additional specialist knowledge and skills. The literature also reports that advanced nursing roles in New Zealand were developed as , part of a government policy on primary health care provision and Maori health $f$ (Ministry of Health, 1988 cited in Duffield, Gardner, Chang \& Catling-Paul, 2009, p.59).

The first nurse practitioner was appointed in New Zealand in 2002. A nurse practitioner is one whose title is legally protected by the nursing council of New Zealand. The nurse practitioner is considered to be an expert nurse who is practising at a level, incorporating advanced knowledge and skills (New Zealand National Nursing Organisations, 2009). At this time there were also a number of nurses identifying as -specialty• nurses as well as those working in formalised nurse specialist positions. The latter refers to a nurse in an advancing role who has a broader focus of clinical practice, whilst a specialty nurses is someone who has a, greater knowledge in a specific area of practice $f$ (Holloway, Baker \& Lumby, 2010, p. 271). An attempt to view issues within an academic framework led to some discourse with unions, resulting in the issue being placed with the Nursing Council of New Zealand (Wilkinson, 2008). The council•s aim of developing an appropriate framework was influenced by the need to ensure public safety. The development of models for practice roles and related education were perceived to be outside the domain of Council responsibilities (Wilkinson, 2008). However, the Nursing Council did become involved in particular development of roles such as the Nurses Practitioners because there was considerable tension between the union, professional colleges and the Nursing Council. In 2009 the Nursing Council of New Zealand also initiated a consultation process about extended practice for registered nurses (Nursing Council of New Zealand, 2009). Head (2009), comments that the 
outcome of this will have long term effects on nursing, where the nursing workforce will stand relative to other professions and health workers and in terms of costs, pay and conditions, mobility, education and employment opportunities $f$ (p. 25).

Prior experiences around the conflicts that arose when establishing the nurse practitioner title may well have paved the way to look for different ways to understand and acknowledge other emerging roles such as the ETT nurse. There is a perception that the final outcome from the Nursing Counciløs consultation process will affect nursing in many ways. Head (2009) believes the nurse of tomorrow needs to be significantly flexible to respond to the changing needs of health consumers. It would seem that the ETT nursing role has been one of those reflexive responses to an increased demand for services.

\section{Advancing Cardiovascular Nursing Roles and Role Expansion}

Exploring other nursing roles in regards to expansion and specialisation will also be important in viewing how the ETT nurse role has developed. This is because there are similarities in process between different groups of nurses. Nurses contribute to the largest part of the health workforce and therefore there are common traits and experiences reported within this discipline. Nurses have been appointed to supervise ETTs generally as a primary role rather than supervising occasionally and intermittently as doctors may have done historically. The establishment of the ETT nurse role is perceived to be an advanced cardiovascular nursing role because of the level of skills and knowledge required and historically this was an established medical role. This interface between nursing and previous delegated medical roles has precipitated some debate amongst nurses. One of the issues fuelling that debate is a concern about potential for fragmentation of roles as with some earlier advanced roles such as , early nurse practitioner roles in the USA in terms of taking over devolved tasks and not the holistic care of the patient $f$ (Smith, 2002, p. 19). Despite this, exploring expanding roles for nurses provides some clarity and a reference point for potential new roles that benefits both managers and nurses. Some of those benefits are perceived to be fiscally orientated. Exploring the barriers and opportunities that have contributed to the establishment of such roles paves the way for the establishment of future cardiac nursing roles. 
Nurses work in collaborative relationships with other disciplines and their clients. Exploring these relationships also offers another perspective to individual role development. Understanding these processes may help identify ongoing educational and professional development training goals. This is important as multidisciplinary training within teams is perceived to improve patient outcomes (Clements, Dault \& Priest, 2007).

There have been some proven benefits to nurses working in roles in ETT services because of their broad holistic and seamless approach to health care delivery (Thompson, Quinn \& Stewart, 2002). ETT nurses appear to have developed a more holistic approach to this service than their medical counterparts in the ETT setting (Pottle, 2005). Recognition of the knowledge, skills and a degree of autonomy in the ETT nurse $\bullet$ role will be critical in retaining nurses. Undertaking research in this phenomena aims to provide evidence that will support nurses to train in this area.

\section{The Research Question}

Prior to defining my research question, I reflected on my integration into the role as I wanted to explore what influences and factors had contributed to my own development as an ETT nurse. A desire to be more autonomous and develop new clinical skills was the strongest precipitants to working in the role. During my formative time in the role, I continuously felt anxious about making the right decisions. My confidence, knowledge and skills of observation increased with experience. This process of reflection on my own development enabled me to consider possibilities for the future of the actual ETT role. These reflections contributed to my research question: What is the process of role development of cardiac nurses who supervise ETTs? In order to answer this question I developed specific aims:

B To determine what is currently known about the practice of ETT internationally (This involves reviewing the international literature).

B To describe the role development of nurses who supervise ETTs at a tertiary hospital in New Zealand (This involves interviewing a sample of ETT nurses).

B To gather an interdisciplinary perspective about the role development of a group of ETT nurses at a tertiary hospital in New Zealand (This involves interviewing the clinical director of the service and surveying the cardiac technicians in this setting). 
B To determine the extent to which nurses are involved in the supervision of ETTs in the public sector of New Zealand (This involves surveying all cardiac centres in the public health sector of New Zealand).

\section{Summary}

This chapter has highlighted some important reasons for focusing on research that provides more depth to the inquiry and will offer a new perspective to the literature focusing on role development for cardiac nurses who supervise ETTs. Researching nursing role development is important for the nursing profession, particularly in this era of changing and advancing roles. Understanding a nursing perspective makes a contribution to the interdisciplinary environment in which we work in today. The following chapter reviews the international literature about nurse involvement in the ETT supervisory role. 


\section{Chapter Two: Literature Review}

\section{Introduction}

Cardiovascular disease remains a major cause of death and illness. Considerable research in the past fifty years has focused not only on risk factors, but which assessment tools are useful in determining a definitive cardiac diagnosis. Clinical exercise tolerance testing (ETT), also known as exercise stress testing (EST) is considered to be , an established non-invasive procedure that provides diagnostic and prognostic information for the evaluation of several pathologies, the most common of which is coronary heart disease $f$ (British Cardiovascular Society, 2008, p. 2).

Whilst being an established procedure, the subject of supervising personnel has precipitated some debate over time. Registered nurses have been involved in supervising ETTs for at least the last 35 years as reported in an Australian study (Zecchin et al., 1999). Although there is a considerable body of literature on evaluating effectiveness of tests and safety outcomes for patients, the literature is sparse about nurses involvement in these tests. The following literature provides an historical perspective on the emergence of the ETT nurse supervisor amongst other personnel. The overall aim of this literature review is to determine what is known about the practice of nurses who supervise ETTs internationally.

\section{Search Strategy}

A literature search was carried out to identify what is known about how nurses came to be involved as supervisors of exercise tolerance testing and what common threads have contributed to their development. Initial literature found was limited, and therefore the search strategy was extended beyond 15 years. The lack of New Zealand literature on the subject of nurses and exercise tolerance testing was evident, and therefore the first section of the literature review focuses on international studies.

The following databases were searched: Ovid technologies (OVID); Cumulative Index of Nursing and Allied Health Literature (CINAHL); Medline; Science Direct; Web of Science and Google Scholar. References of retrieved articles were also searched but journals were not hand searched. Articles were restricted to English but open dates were searched around supervising personnel due to the paucity of publications. Reference lists of retrieved articles were also searched. 
The following Key words, mesh terms and Boolean phrases were used, •exercise tolerance testing •; •exercise stress testing•; •Cardiac nurses and roles $\bullet$; advancing

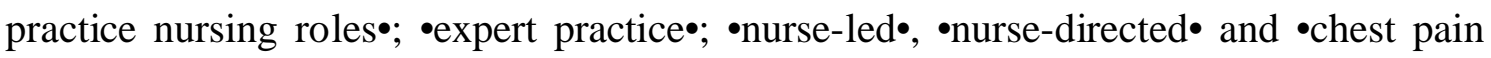
units $\bullet$ where ETT•s are commonly conducted. A total of 23 articles that specifically referred or alluded to the nursing role as an ETT supervisor or similar, were found and selected. Other articles selected were focused on the expanding cardiac nursing role and aspects regarding role development in the clinical environment.

\section{Historical Development of the ETT Nurse}

This first section of the literature review describes the historical development of the emerging ETT nurse in chronological order of publications. Lem, Krivokapich and Child (1985) refer to nurses taking on increasing responsibility in various areas of patient cares. This American study refers to the importance of the 1979 American Heart Association guidelines review. The exceptions to when other non medical staff might supervise tests were reviewed and amended. Physicians were initially involved as the primary supervisor to ensure patient safety, but this role was later extended to other personnel who had experience in a cardiology setting. These personnel were expected not only to understand the pathophysiology and the technical running of the tests, but also to respond to any sudden and unexpected emergencies. Some of these personnel included technologists, cardiac physiologists and cardiac nurses. Utilising nurses in such roles may have served a variety of purposes and benefits, not then evaluated. Specific registration boards, recognised the expanding roles of RNs and the existence of overlapping functions between physicians and nurses $f$ (Lem, et al., 1985, p. 280). Nurses as early as 1974 were becoming involved in testing procedures and consequently amendments to their practice act was required to provide protection for such new roles (Lem, et al., 1985).

Inconsistencies between supervisors in their interpretation of data and changing clinical rotation of doctors may have precipitated the concept of the establishment of $\bullet$ dedicated personnel•. Lem, et al. (1985), describe a treadmill laboratory where a clinical nurse specialist with a Masters degree was employed. Subsequent perceived success in this appointment, resulted in a review of policies and procedures. Lem, et al. (1985), argue that the concept of non-physician supervision should not be a medico legal issue, nor diminish the need for physician support in emergencies. They suggest that it is 
important to consider what are important qualities and skills an ETT supervisor might possess. They add that the actual personnel, who are regularly involved in the supervision of ETTs, plus the quality of their training, were thought to be factors contributing to ensuring high standards of safety during tests (Lem, et al., 1985).

Universally, patient safety is considered to be paramount and it is the simultaneous process of maintaining patient safety while collecting data in exercise testing, which is considered important (Lem, et al., 1985). Complication rates were reviewed over an arbitrary 13 month period within the three year period when a nurse specialist was supervising tests. A sample group of $70.7 \%$ of patients were supervised by the nurse and the other $6.5 \%$ were supervised by a cardiology fellow. The overall complication rate was considered low at $0.3 \%$ although $22.8 \%$ of this group were not reported on (Lem, et al., 1985). This study does not identify what discipline supervised the latter group. As a consequence of this study, it was identified that there were many advantages having -dedicated • nurses in this role. These included consistency and uniformity of tests, convenience and reduced need for medical staff and overall cost containment through cost savings (Lem, et al., 1985). Nurses were considered ideal to fulfil the supervising ETT role because of their background; education, experience and lower salaries (Lem, et al., 1985. The final recommendation was that, nurses can be effectively utilized in this role in lieu of a physicianf (Lem, et al., 1985, p. 284). A subsequent letter following this publication challenged this recommendation about suitability of nurses, citing limitations in their training regarding human physiology. It was suggested that exercise physiologists were perhaps more suited to the supervisor role because of their intensive understanding of electrophysiology (Richards, 1986). No consensus was established internationally at this time.

Knight, Laubach, Butcher and Menapace (1995) note the previous lack of literature on the subject of • other personnel involvement in ETTs. This American study reviewed the experiences of utilising a cardiac physiologist supervisor over a 13 year period. Few statistics were provided, but a high safety record was reported when cardiac physiologists were recruited into the role. Knowledge, experience and familiarity were cited as advantages in having dedicated personnel. One of the disadvantages of utilising cardiac physiologists was their inability to administer medications due to scope of practice. The centre involved in this study had utilised non-physicians for four years and 
this was, initially considered to free cardiologists for other clinical functions and to better standardise our approach to exercise testing $f$ (Knight, et al., 1995, p. 390). This study recommended that nurses and physicians could become more effective as supervisors but needed greater exposure to develop the necessary skills for this role (Knight, et al., 1995).

As more non-physicians and increasing numbers of nurses began supervising tests, cautious guidelines were put in place differentiating when a consultant must be present for ETTs. The issue of those high risk patients requiring physician supervision was also emphasised in a further American study (Franklin, Gordon, Timmis \& O•Neill, 1997). It was felt that complication rates should be carefully considered before any relaxation of old guidelines. Franklin, et al. (1997) also stress that, knowing $f$ is an important factor when considering whether or not to proceed with a test (p. 263). Along a similar vein, , expertise, rather than physician presence per se was the primary prerequisite to perform exercise testing $f$ (Ellestad, 1980, cited in Franklin, et al., 1997, p. 264).

A retrospective comparison of 250 exercise tests performed by cardiac technicians and 225 tests performed by GPs also found that there was a low complication and high diagnostic rates in the technician group (Davis, Ortloff, Reed, Worthington \& Roberts, 1998). Aims of this British study were to determine efficacy and safety in ETTs supervised independently by trained cardiac technicians. Final analysis suggested that although technicians were perhaps more cautious in their end-point criteria regarding when to stop a test, high levels of safety were maintained with this group. Protocols were specific about what constituted end-point criteria, such as ECG changes and reported symptoms of chest pain. Appropriate training rather than actual level of training was considered to be an important factor in enhancing the quality of the supervisor (Davis, et al., 1998). Similar results were obtained between other experienced personnel and a trained technician in the low-risk group of patients but it was suggested that patients were less likely to report symptoms of discomfort when supervised by a physician.

Cost and time constraints with a growing demand for services were perceived to be influential in the relaxation of some area guidelines. In addition, the ongoing debate about whether physician supervision was necessary continued (Franklin, et al., 1997). Despite policy requirements from insurers such as Medicare for physician presence, 
some countries such as the USA saw increasing use of Para-Medics involved with exercise testing.

During the late $1990 \bullet \mathrm{s}$ the debate has continued about whether other disciplines, including nurses were actually safe to supervise exercise tolerance tests that had been previously supervised by physicians. An American study reviewing safety of dobutamine stress echocardiography (DSE), supervised by Registered Nurse sonographers, saw similar complication rates to those of physicians (Bremer, Monahan, Stussy \& Miller, 1998). This retrospective study reviewed 1035 consecutive outpatients. The aim was, to prove that the safety of DSE was not compromised with the change of supervisionf (Bremer, et al., 1998, p. 601). Five hundred and sixteen outpatients were supervised by cardiologists and 519 outpatients were supervised by RN sonographers (Bremer, et al., 1998). As with earlier studies where dedicated personnel were involved in tests, there was more , timely and consistent supervision $f$ with the $\mathrm{RN}$ sonographers (Bremer, et al., 1998, p. 605). This initial group of RN sonographers went on to also supervise in-patient DSE tests, adding to the differing number of cardiac tests that nurses were now beginning to supervise.

The first Australasia publication about nurse involvement in ETTs describes a clinic that is nurse-led (Zecchin, et al., 1999). This study aimed to examine the safety complication rates of data during a 12 year period when nurses had supervised tests. This descriptive, retrospective audit of prospective data included 17,467 patients. The authors describe limitations with previous studies because of differences in the patient groups, both low and high risk categories, and variations in protocols and modalities used. No deaths and a relatively low complication rate were found as a result of nurses supervising tests (Zecchin, et al., 1999). The authors report that nurses have now been supervising tests since 1978 and thus had established a comprehensive training and competency assessment programme that has been developed over this period. This is the first literature that has focused specifically on the training for ETT nurses and acknowledges the influence of nursing frameworks (Zecchin, et al., 1999).

An audit of a technician run, open access exercise electrocardiography service was published in the United Kingdom (Agrawal, Danbauchi, Goodfellow, Robson \& Reid, 1999). General practitioners who utilised this service were invited to complete a questionnaire that aimed to evaluate safety, efficacy, accessibility and overall 
impressions of the initial experiences of this service (Agrawal, et al., 1999). Initiation of this service came about because of a perceived, burden on already overextended hospital cardiology servicesf (Agrawal et al., 1999, p. 378). The questionnaire was sent to 178 GPs, of which 147 responded. Of the total group, 269 patients were randomly selected over a 2.5 year period. This group of patients was part of 552 patients who were referred by GPs to the service run by technicians. The overall findings concluded that this type of service could be safely run by technicians and may in fact , have helped in the optimal utilisation of resources and prioritisation of patient management $f$ (Agrawal et al., 1999, p. 381).

The debate about concordance between emerging supervising personnel other than cardiologists and physicians continued, with increasing focus on public safety. There was also some interest within the medical discipline as to whether non-cardiologists were as accurate in their interpretations of ETTs as their cardiologist colleagues. Kirk, Turnipseed, Diercks, London and Amsterdam (2000) reported on a two year American study of 645 patients who were referred for exercise tests. All tests were over read by a cardiologist and any discrepancies were reinterpreted by an independent cardiologist who was blinded to the results. Strong concordance was found between the two groups and recommendations were made that cardiologist over reading for the purpose of quality assurance was unnecessary (Kirk, et al., 2000).

Looking at practice patterns of exercise testing was the focus of a large American study that surveyed 72 of the largest Veteran Affairs Medical Centres which had cardiology divisions. Seventy one questionnaires were returned relating to data from 75,828 tests performed over a one year period. The concept of $\bullet$ gate-keeping $\bullet$ to more expensive and invasive tests was cited as an important economic precursor to reviewing testing patterns (Marcus, Lowe, Froelicher \& Do, 1995, cited in Myers, Voodi, Umann, Froelicher, 2000). Findings in this multi centre American study also found low complication rates with tests supervised by trained non-physician personnel, and as a result physician requirement was only deemed necessary for high risk patients. Variability in equipment and protocols made it difficult to compare exercise testing from various regions.

Stein, et al. (2000) recommend that an ETT become an integral part of a treatment plan when triaging patients who present to an emergency department or specialised chest 
pain centres with chest pain. The aim of this American study was to interpret and summarise evidence of safety for patients who have an ETT following presentation to the emergency department (Stein, et al., 2000). Identifying patients who could be rapidly and effectively assessed and discharged early is considered to be an increasing and important economic consideration (Stein, et al., 2000). Following a review of literature, recommendations were made around criteria, end-point protocols that would further assist in triaging patients. Low risk patients were generally considered safe enough to be exercised in emergency departments (Stein, et al., 2000). The other significant recommendation was the reference to a taskforce statement from the American College of Cardiology that exercise testing could be , safely performed by properly trained nurses, exercise physiologists, physical therapists, or medical technicians $f$ (Stein, et al., 2000, p. 1466) with the proviso of close access to a physician in emergencies. The issue of quality of training had now entered into the debate on suitability of supervising staff.

Latus and Underwood, (2001) acknowledge the variability of training and personnel between centres. The authors add that the concept of •dedicated • personnel is becoming more the •norm, $\bullet$ and that medical supervision is becoming less common in the United Kingdom. The emergence of the •nurse supervisor was seen as a successful organisational strategy and had become increasingly acceptable in hospitals where ETTs were performed. Whilst technicians have become reputable as competent supervisors, nurses were seen as ideal supervisors because of their ability to administer prescribed drugs, and respond to emergencies. It was thought that nurses with their wide range of skills, could provide a seamless service in collaboration with others. Personnel attributes such as good clinical judgement and communication are emphasised as important attributes alongside having a good knowledge of exercise physiology (Fletcher et al., 2001).

A further prospective study in the UK assessing technician diagnostic accuracy, found a high standard of reporting particularly when employing pre specified endpoints (Muir, Jummun, Stewart \& Clark, 2002). Two hundred and forty-six consecutive technician supervised tests were evaluated. ,Each test was reported according to specified criteria by each investigator who was blinded to the clinical reports and to the reports of other investigators $f$ (Muir, et al., 2001, p. 381). Tests were excluded if they required medical 
supervision, $(\mathrm{n}=23)$, had presence of a bundle block branch $(\mathrm{n}=150)$, or if they were not being assessed for ischemia ( $\mathrm{n}=8$ ), (Muir, et al., 2002). In this particular setting utilising technicians was deemed to be effective and the regular auditing of test reports was recommended. Having clear guidelines and protocols were thought to enhance the overall safety of tests and contribute to consistency in decision-making by ETT supervisors.

Froelicher and Myers (2007) emphasise that deciding which indications and contraindications are considered to be important demonstrate good clinical judgement by an ETT supervisor. Endpoints are more specific and are contained within absolute guidelines that state indications of when to stop a test. Revision of these guidelines is becoming part of an ongoing process, presumably with an increased demand for exercise testing and a desire to improve quality and consistency of tests.

By the start of the millennium, the concept of chest pain centres and units were becoming more common. This was an attempt to effectively manage the increasing demand on cardiac services. In the UK, nurses were being increasingly utilised in new initiatives that were coined as •nurse-led• interventions. Thompson, et al. (2002) refer to the growing complexity of treatments and the need to optimise strategies that will improve health outcomes. Chest pain nurses in the UK were taking on regular responsibility for ETTs as well as providing expertise in the management of acute coronary syndromes (Goodacre, Morris, Campbell, Arnold \& Angelini, 2002). While acknowledging nurse-led interventions are increasingly effective, proper support and appropriate structures are deemed necessary to support nurses in such roles (Thompson, et al., 2002).

While utilising nurses in new roles such as exercise testing, cardiac assessment and rehabilitation, many issues remained unresolved. These include funding for such roles, scope of practice, pre requisite qualifications, ongoing training and finally integration of such roles into the health system. Lack of research around such roles and levels of research were seen as reasons why nurses were not always getting sufficient support to develop in these roles (Thompson, et al., 2002).

Pottle (2005) describes the experiences of the first three years of a nurse-led chest pain clinic in the UK. This paper reviewed the triage decisions made by a nurse consultant 
for 454 patients presenting with chest pain. Three hundred and twenty-four out of this group were exercised. Fifty-four (16.7\%) patients out of this group had positive tests for cardiac ischemia demonstrating consistent and appropriate decision making by the nurse consultant (Pottle, 2005). Other patients in the total group considered not appropriate for an ETT, were referred by the nurse consultant for other assessment procedures. A high level of satisfaction was reported by patients either about further recommended treatments or the tests they experienced. Experienced cardiac nurses and scientific officers were directly responsible for supervising tests but the nurse consultant had overall responsibility for ordering and referring for tests (Pottle, 2005). When reviewing chest pain pathways in New Zealand study, it was suggested that access for patients might be improved and length of stay shortened if appropriately trained coronary care nurses were involved in the supervision of tests (Edmond, et al., 2002).

Overall the concept of the $\bullet$ chest pain unit $\bullet$ was considered to be of significant benefit to those seeking health services within the National Health Service (NHS) in the UK. These benefits were recognised as a timely provision of treadmill testing for patients within a protocol driven process. Inclusion of nurses and a variety of other staff contributed to the effectiveness of a perceived, process of care, rather than a physical entity $f$ (Arnold, Goodacre \& Morris, 2007, p. 465). The concept of chest pain units are also seen as the gateway to a variety and possibility of assessment and treatments.

The process of evaluating effectiveness of the varying disciplines has continued as organisations look to improving health care. In a Canadian study, the reliability of a Nurse Practitioneres interpretation skills was measured against two cardiologists, and to a computer generated programme that produced concordance measurement results in a blinded study (Maier, Jensen, Sonnenberg \& Archer, 2008). A high level of concordance was found between the nurse consultant and the two cardiologists that supported recommendations of nurse involvement in the interpretation of tests. Some variability was found but this was related to lead selection and importantly no significant differences were found.

Kane, et al. (2008) also report similar levels of accuracy in an American study. Complication rates were measured when nurses were involved in supervising stress echocardiography tests. Low complication rates were found in this two year audit of 15,404 patients. Despite findings, the actual utilisation of non-physicians in the 
supervising role was seen to be less progressive. This was attributed to the complex protocols, use of pharmacological agents and actual •risk• of patients (Kane et al., 2008). However, growing demand on services has meant there has been consideration of training •other $f$ staff in order to provide services. Previous studies assessing nurses have all found similar results supporting the growing trend of nurses expanding from traditional cardiovascular roles.

Franklin, Fern, Fowler, Spring and deJong (2009) acknowledge that, the use of specialised exercise professionals for the supervision of exercise testing and training may represent a safe and cost effective alternative to many hospitals $f$ (p. 93). The authors argue that while the focus of this paper is about the exercise physiologist $\bullet$ contribution to services in America, the emergence of this type of specialist has created a need to educate health care providers specifically to the role. Experienced physiologists were considered to be the ideal mentors for those professional wanting to train in this role because of their in depth knowledge in electrophysiology (Franklin, et al., 2009). This section has reviewed the literature that describes the influences to the historical and international emergence of the ETT nursing role.

\section{Advancing Cardiovascular Nursing and Role Expansion}

This second section of the literature review focuses primarily but not exclusively on advancing cardiovascular nursing roles to illustrate parallel influences to new and emerging nursing roles. There is a wealth of literature on advancing and specialist roles but there is little written on the interpersonal processes that may help understand more fully the development of the ETT nurse role. Literature on practice development for advanced nursing and specialty roles was reviewed in order to place ETT nurse supervision within a New Zealand and international context.

Smith (2002) acknowledges that demands on cardiology services have precipitated a review of the way services are provided and personnel involved. Some of those demands include increasing complexity within health and need for cost containment amidst rationalisation of resources. These increasing pressures have resulted in opportunities for nurses to be involved with services previously led by other disciplines. The development of initiatives where nurses have taken on previous medically defined roles, have resulted in some scrutiny by other disciplines. This is despite their growing 
and proven effectiveness in a rapidly changing health environment. Areas where cardiac nurses have shown initiatives include chest-pain clinics, angiography laboratories, cardiac rehabilitation and exercise tolerance testing (Pottle, 2005; Smith, 2002; Thompson \& Stewart, 2002). Outside cardiovascular nursing, rural primary health initiatives are one example where nurses in New Zealand have advanced in their roles to fill a unique gap (Ross, 1999). Rural isolation and workforce issues have created opportunities for many of the nurse-led initiatives within New Zealand.

Research that has reviewed or compared nurse effectiveness in new roles is considered to be limited. Thompson and Stewart (2002) point out that most research around new roles has been focused on patient outcomes and little attention has been given to the ,important contextual factors such as the environmental, social, demographic, interpersonal and technical conditions in which interventions are delivered $f$ (p. 8). Supervising ETTs is one example where physicians in some areas were still supervising tests because of perceived complication rates, and yet previous studies show safety is not diminished with the involvement of non medical personnel (Lem, el., 1985; Zecchin, et al., 1999; Stein, et al., 2000., Maier, 2008). Traditional organisation requirements to have physician attendance for ETTs, have gradually relaxed as complication rates were reported as similar and equivocal.

Smith (2002) emphasises that support is fundamental to the development of new nursing roles if they are to succeed. A proportion of nurses have left positions because of restrictions on autonomy and lack of service development and training (Pryse-Hawkins, 2001). Cardiovascular nursing as a specialty is considered to be , undergoing immense changes $f$ (Riley, Bullock, West \& Shuldham, 2003, p. 283). These changes have also precipitated a review of the types of post graduate education required to equip nurses working in advanced roles (Riley, et al., 2003). Although many specialist nurse-led interventions have been successful, a number of unresolved issues have remained. Those issues include competency assessment; levels of autonomy; portability of roles, funding and support structures (Riley, et al., 2003).

Nurses constitute the largest part of the health service and it is possible that increased wages reflecting new roles with increased responsibilities have resulted in more scrutiny by managers (Thompson \& Stewart, 2002). Nursing as a discipline is keen to not only make impact with any new initiatives but also review effectiveness of newly established 
roles (Thompson \& Stewart, 2002). Thompson and Stewart (2002) report that, one of the challenges facing nurses and nursing, is extrapolating findings from research and applying them in practicef (p. 8). It would seem equally important that nurses are encouraged and supported to engage in research that reflects the practice setting that they work in. Seeking appropriate remuneration for advanced practice roles has been difficult particularly as nurses $\bullet$ wages have been traditionally low and formalisation of roles has been difficult.

While health teams may share similar goals such as wanting a seamless service for their clients, there is ongoing debate about how much autonomy nurses in advanced roles should have, and whether they should be directly linked to competencies. While there is a lack of consensus about competency frameworks, considerable variability in practice is likely. Lack of portability between organisations regarding competency frameworks is seen to be a disadvantage. Riley, Brodie and Shuldham, (2005) suggest that a development of a common national and international standard for competence may address concerns about safe and competent care in areas where nurses are advancing in their roles. They describe how a national competency based pathway was developed in conjunction with a national body that represented British cardiac nurses. They suggest this process would also enhance portability of competencies between hospitals (Riley, et al., 2005). They suggest there are difficulties and debate in trying to define those competencies. In addition they argue competency is more than having knowledge and performing tasks, but the development and integration of knowledge skills and personal attributes through practice experience. Different sets of competencies for varying areas of practice were thought to be useful and a basis for, discussion between practitioner and managerf (Riley, et al., 2005, p. 20). Discussing competencies not only provides a progressive pathway for achieving skills but provides a safety reassurance for an organisation. Individual and flexible frameworks were thought to be important for nurses who were advancing in roles rather than creating a , mass production of nurses who display competence at an advanced levelf (Riley, et al., 2005, p. 20).

The historical emergence of the nurse practitioner role coupled with social, political and economic factors contributed to diversity and lack of clear definition about advanced nursing roles (Furlong \& Smith, 2005). This social policy paper aimed to provide further clarity for the ongoing development of advanced practice roles. Despite diversity 
amongst nursing roles, it was felt that, practice experience and graduate education $f$ (Furlong \& Smith, 2005, p. 1060), are considered fundamental to progression in those roles. Policy, education and role development were some of the frameworks used to explore aspects of advancing nursing practice (Furlong \& Smith, 2005).

Advancing nursing roles has provided many opportunities to enhance interdisciplinary processes in health settings and much of the literature supports the importance of such nurses working in a more collaborative way. Furlong and Smith, (2005) emphasise that any model of practice needs to be patient outcome orientated. This was thought to be vital not only for the survival of nurses in certain roles, but for their managers, allied staff and consumer groups. Nurses are perceived to enhance interdisciplinary process because of their focus. One example is that, Nurse-led clinics are said to focus on health rather than illness, and an emphasis on life management rather than diagnosis and intervention $f$ (Anonymous, 2005).

Jones (2005) conducted a systematic literature review to identify qualitative studies that reported barriers and facilitators to role development for nurses in advancing roles. Fourteen studies from the United Kingdom were selected and refer to interpersonal relationships, role definitions and expectations as important factors. This range of factors was identified utilising a meta-analysis framework. The framework included personal characteristics, practitioners $\bullet$ previous experience, level of education and preparation for roles. Organisational culture and managerial issues are also thought to be contributing to nurses role development. Overall a range of factors were seen to be either barriers or facilitative of new cardiovascular roles. Most of the barriers centred on relationship difficulties and role ambiguity. It was felt any new and existing roles required clear definition and communication to other groups by the advanced practice nurse (Jones, 2005). Assisting others to understand function and role objectives are thought to be an important part of •paving the way• for any new role.

Analysing the concept of advancing nursing practice has been likened to , the Holy Grail as a mysterious object of search and as the ultimate source of knowledge $f$ (Callaghan, 2007, p. 206). This author suggests there is an expert development process which is ongoing and not necessarily concluded at mastery. Importantly, the author emphasises that expertise is a process that is , sharpened by way of dedication to lifelong learning $f$ (Callaghan, 2007, p. 207). Increasing professional autonomy comes with increased 
responsibility and thus nurses in advanced roles are required to rationalise their decision-making, and draw on intuition, past experiences and knowledge. A supportive and enabling organisational culture is also seen to be facilitative in promoting the advanced practice nurse (Callaghan, 2007). The development of strong leadership amongst advanced practice nurses is seen to be vital, in order to provide vision for the next generation of nurses (Callaghan, 2007).

Fragmentation and poorly coordinated training programmes are cited as providing an argument that $\bullet$ nursing $\bullet$ is also moving towards uncertainty (Srivastava, Tucker, Draper \& Milner, 2008). This review considered what policies have influenced advanced nursing roles in the UK. The authors suggest that studies that look at impact on patient outcomes would be more influential to nursing role development (Srivastava. et al., 2008). This is contrary to other author opinions who suggest there a range of other factors that can help explain professional development in clinical roles. This systematic review of literature identified that there was lack of clarity about role definitions and systematic and universal regulations. Research around autonomy is suggested as being useful to the development of new and existing advancing nursing roles (Srivastava et al., 2008). Trying to understand tension between professional groups was also suggested as crucial in any reformulation of current roles as interdisciplinary confusion could be a barrier to certain roles succeeding. In addition, , if localised initiatives are to be tested for their reliability and generalisability, a more robust evidence base is required $f$ (Srivastava. et al., 2008, p. 2678).

ETT nurses join the growing and diverse group of nurses who are perceived to be providing specialist services globally. , This global trend is an outcome of factors related to dynamic changes in healthcare services as well as in the nursing profession $f$ Sheer \& Wong, 2009, p. 208). Amongst this group there is variation in nursing titles of nurses who are working in advanced practice nursing roles (Sheer \& Wong, 2008). Nurse practitioner, clinical nurse specialist, case manager are among the titles given to nurses who have acquired expert knowledge specific to an area and are involved in complex decision-making. Lack of clarity about some roles and their titles has led to a perception of fragmentation by others. This ambiguity has also contributed to debate around titles and status for nurses practicing in advancing roles amongst other unresolved issues. Lack of support and funding are some of the factors contributing to the many unresolved 
issues around the status of specialist cardiovascular nurses internationally. Nurses in all areas, but particularly in cardiovascular nursing are invited to meet the challenges of growing global health demands (Thompson, 2009). This will mean looking at effectively using nurses within the health workforce. Sheer and Wong (2008) also refer to the importance of valuing multidisciplinary input and the valuable contributions that each discipline makes.

Bobay, Gentile and Hagle (2009) argue that , nurses working consistently with similar patient populations gain skills through increasing frequency of exposuref (p. 48). Experience is perceived to influence ongoing development although there is variable research to support this. The concept of intuitive decision-making that results from reflection on experience and trusting judgement in the moment, is considered to be very much characteristic of a nurse working in a specialised and advanced role. However there is a risk of habitualisation working in the same role and with a similar population despite the facts that roles are complex as described by an earlier paper (Heath, 1998). This author did add that the process of habitualisation can be positive when tasks are transferred into other roles.

An Australian study reviewing titles and scopes of practice saw international anomalies in the definitions and interpretations of titles (Duffield, et al., 2009). In addition, the authors found, specialist nurses focus on a specific-defined area of nursing whereas APNs operate at an autonomous level in a number of practice settings $f$ (p. 56).

\section{Literature Discussion}

Growing demand for expertise in all areas of health has precipitated a constant review of nursing roles and their efficacy. Demonstrating evidence of effectiveness alongside contribution to policy making has given nurses in advanced roles an opportunity to make an impact on the delivery of health services. Early literature around nursing involvement in exercise tolerance testing, show that their ad hoc development may have resulted from a lack of specific nursing evaluation and research. All initial reviews of nurse involvement in ETT have resulted in quantitative data only that focused on safety outcomes. There were limitations to these studies as they failed to include other multidimensional factors that contributed to supervisor safety records. Zecchin, et al., 
(1999) also noted difficulties with previous studies because of the lack of analysis using a nursing framework and variations in protocols used.

Early literature show attempts to engage in debate about suitability of supervising personnel was the primary focus. Reviewing complication rates was one way of providing evidence that nurses and other supervising personnel could safely perform ETTs. The success of utilising paramedical staff proved that complications were no higher with experienced personnel than with physicians. Similar results were found with technicians and exercise physiologists. Legal requirements and constraints within regulatory bodies may have contributed to the ongoing quest to validate nursing involvement in advanced roles. A paucity of research and literature focusing on the nurse supervisor may have contributed to the protracted nature of prior debate as to whether nurses are competent and safe to supervise ETTs.

The concept of a $\bullet$ dedicated $\bullet$ nurse and having a $\bullet$ dedicated $\bullet$ room has signalled that exercise tolerance testing has become a valuable first line tool in the assessment of cardiovascular disease (Davis, et al. 1997; Latus \& Underwood, 2001). Lem, et al. (1985) also makes reference to •dedicated personnel• and that this has shown to enhance patient safety. Evidence that repeated exposure to testing enhances patient safety was perhaps not observed when physicians previously supervised tests but later literature proved that patient safety levels were comparable (Bremer, et al., 1998; Zecchin, et., 1999).

The development of nurse-led clinics illustrates that the nursing profession has harnessed opportunities as a result of a growing demand for patient services. In promoting acceptance by others of specific nursing roles, it will be important to share findings of any new studies. This will serve to minimise barriers to acceptance of such roles. Thompson and Stewart (2002) refer to challenges facing nurses in the research arena and importantly applying findings to practice particularly if they want to be recognised as leaders in clinical practice.

Zecchin, et al., (1999) refers to , reflective nursing practicesf (p.1840), as integral to ongoing •quality improvement and auditing of safe practice. This is consistent with increasing autonomy and responsibility in advanced nursing roles. The ETT nurse is involved in a complex dynamic process where knowledge, reflection, knowing and 
critical thinking are part of advancing nurse practice. Reflecting on those experiences will help consolidate knowledge and contribute to confidence in the type decisionmaking required at any moment.

Nurses in advancing roles have demonstrated that their knowledge and expertise is multifaceted and that experience leads to developing expertise in some roles. A variety of theories such as Novice to Expert (Benner, 1984, cited in Lyneham, Parkinson \& Denholm, 2008) have been useful in understanding a nurse•s development through clinical experience. It is of course useful to revisit any theory and ask whether the concepts are clearly understood and appropriately fitting. The challenge will be to conduct research around how nurses in their ETT supervisory roles develop, which will add depth to existing quantitative data. Research in this area may provide greater understanding and contribute to any further developments of this role. It is also possible that nursing roles in this area may diminish as other health professionals become more involved in such clinical roles.

There has been some pressure for cardiovascular nurses to develop competency frameworks amongst other objectives as part of establishing credibility in new roles. Ironically, when physicians were involved in supervision of ETT tests, no formal training or competency framework existed. What did exist were guidelines set down by various Cardiology Boards and Societies that specified what skills and knowledge was required in order to supervise ETTs. Few organisations have focused on the interpersonal and professional requirements in order to perform specialist roles. This is because much of the research on ETTs focused on patient outcomes and risk management. One could argue that systematically exploring and analysing nurse experiences in roles such as the ETT nursing role will further help explain records of high safety rates for patient complications. Analysing role development may also assist other disciplines to adapt to such a role by understanding the complexity of skills required to perform the role safely. Despite the demand for ETT services, there has been no literature found since approximately 2008 regarding review of nurses in the ETT role (Kane, et al., 2008). 


\section{Summary}

This literature review has provided both a chronological historical perspective of how nurses became involved supervising ETTs and the influences to expanding nursing roles. Considerable evidence was found in the literature that supports nurses to be •safe• as ETT supervisors and yet professional debate has continued regarding their suitability. Growing demand for specialist knowledge has arisen out of the complexity of health care needs in the wider population. Despite this, there remains a lack of consensus about titles, levels of responsibility and autonomy for an ETT nurse. This appears parallel to global development of the nursing profession where there is also a lack of consensus regarding role definitions and competency frameworks. A wide range of influences, including political, social and economical are thought to have contributed to this variability. Future studies will be important in trying to understand the multifaceted dimensions to role development in the clinical ETT setting. Global demands for health services will undoubtedly increase, and it is assumed that nursing roles will expand as a result. 


\section{Chapter Three: Methods}

This chapter details the research methods undertaken in order to answer the research question: What is the process of role development of cardiac nurses who supervise exercise tolerance tests? A mixed methods study that utilised qualitative descriptive techniques and surveys was selected to add breadth to the subject matter and fulfil research aims. Those aims were:

B To determine what is currently known about the practice of nurses supervising ETTs internationally.

B To describe the role development of nurses who supervise ETTs at a regional tertiary hospital.

B To gather an interdisciplinary perspective about the role development of nurses and the ETT service at a regional tertiary hospital.

B To determine the extent to which nurses are involved in the supervision of ETTs within the public sector of New Zealand.

A mixed methods approach was appropriate for this research for a number of reasons. Firstly, a single method would have been insufficient to fulfil the different aims of this research. Secondly, employing different methods aims to increase accuracy of findings. This is because the combination of approaches brings about a more comprehensive understanding of the inquiry through a process of triangulation. Triangulation is a process of , seeking convergence and corroboration of findings from different methods that study the same phenomenon $f$ (Onwuegbuzie \& Leech, 2006, p. 480). Triangulation of different methods adds to the richness of multiple factors contributing to role development for ETT nurses. The multiple levels at which triangulation occurs, is both in the methods utilised and different forms of data analysis. Denzin (1978, cited in Johnson, Onweugbuzie \& Turner, 2007) comments that triangulation of a variety of sources is necessary in order to give greater depth on a subject matter. The process of triangulation also, reflects multiple methods or data sources to substantiate an outcome $f$ (Portney \& Watkins, 2009, p. 312). Thirdly, using both qualitative and quantitative approaches, add breadth to the understanding of the phenomena in question. The aims have also guided my selection of methods. For example, I was interested to know what were the similarities and differences in ETT nurse practice nationally, and so questions were both quantitative and qualitative in design. Quantitative data from the national 
survey places data obtained from local interviews within a national context. Informing the reader of an interdisciplinary perspective was obtained by surveying the technicians who work alongside the ETT nurses at a regional tertiary hospital, and interviewing the Clinical Director who has an overview of the service where participants were employed. This perspective was necessary as ETT nurses work in an interdisciplinary environment.

Prior to data collection, ethical approval was obtained by both from the Upper South B Regional Ethics Committee (Ministry of Health) and the Human Ethics Committee (University of Canterbury). Maori Health consultation also took place with Nga Ratonga Haura Maori as part of the process and acknowledgement that all research is of interest to Maori in New Zealand in keeping with the principles of the Treaty of Waitangi.

Aim 1: To determine what is currently known about the practice of nurses supervising ETTs internationally (covered in the literature review)

Aim 2: To describe the role development of nurses who supervise ETTs

A regional tertiary hospital where cardiac nurses had been supervising ETTs was selected. In order to describe individual role development of ETT nurses, it was necessary to find an adequate number of ETT nurses who had been supervising tests for at least five years. This group of nurses are a convenience sample of ETT nurses working in this setting.

\section{Interviews with ETT Nurses}

\section{Method}

Semi-structured qualitative interviews were chosen to provide structure suitable to collect data specific to the phenomenon in question. In addition it was important that all participants were exposed to the same questions. Face to face interviews allowed some rapport between the participants and myself through utilising a conversational style. The design of the interview guide (Appendix 3) included mainly open ended questions which sought to capture and describe participant reflections on their experiences.

\section{Participants}

Four ETT nurses were invited by myself to participate in individual face to face interviews. I approached each potential participant in the work place setting and discussed my research aims informally in the first instance. I gave each participant 
information sheet (Appendix 1) and consent form (Appendix 2). The time and location of each interview was individually negotiated with each participant. One interview was conducted in the workplace and the other interviews occurred in a private setting. Interviews took place between $24^{\text {th }}$ of October and the $27^{\text {th }}$ of November, 2009.

\section{Data Collection}

All interviews were audio-taped and participants were able to temporarily stop the interview at any point. Questions were semi- structured to allow participants to give individual reflective perspectives about integration into their role and about individual influences to role development. Some questions were closed such as how long have you been a registered nurse? Other questions asked for a description, describe important aspects to working in the role. Other questions were open ended such as how do you feel about working in the role now? (Appendix 3). Interviews lasted approximately 30 to 40 minutes. As primary researcher and as an ETT nurse myself, I needed to be mindful of my own preconceptions of participant answers and thus allowed each participant to answer questions fully in their own time. This process is also known as bracketing and means to keep separate one-s own thoughts within the interview process (Crotty, 1996; Gearing, 2004). After transcribing interviews, three of the participants were given their transcripts to check for accuracy. The fourth participant had left employment at this point and was not contactable. Only one participant made a minor correction.

\section{Ethical Issues}

The four participants were a convenience sample known to myself through professional work relationships. These relationships did not involve any line management power issues. Karnieli-Miller, Strier and Pessach (2009) describe a developmental trajectory where there is the potential for power relations to change at any stage between participants and the researcher. It is for that reason that I was very clear in my negotiation for interviews. Site approval was sought as a requirement to fulfil my ethics application process. All interviews were negotiated out of service hours so as to not interrupt service delivery. All participants signed a consent form prior to interviews (Appendix 2).

Participants were not identifiable by name to protect individual identity and subsequent transcripts were labelled alphabetically. Participants occasionally mentioned place names and dates but these were not used in the analysis of transcripts. 


\section{Data Analysis}

Transcripts were analysed using qualitative descriptive thematic analysis which is described by Sandelowski, $(2000,2010)$. In essence, this is a process of rewriting the data repeatedly and deductively an in order to find meaning from that data. The aim was to describe in more depth perspectives shared by the participants. Audio tapes were transcribed verbatim by myself as I was conscious of obtaining an accurate transcript of each interview. Three participants were offered their transcripts to check for errors. Only one participant made a minor grammatical correction. One participant had left employment at this stage. I repeatedly listened to each interview as described through the participant•s world view point. This involved separating my own bias about influences to my own role development and those of the participants. I highlighted responses that were of surprise. Part of the process was to continually look at responses and consider whether they had been expected. The process of being honest is important if I was to engage, with the analysis as faithful witness to their accounts in the dataf, (Starks \& Brown Trinidad, 2007, p. 1376). The process of bracketing at this stage was also a way of ensuring the process has been thorough and that outcomes were not predetermined by myself as the researcher.

The next stage was a systematic process of organising the data in a methodical way. Following transcription I wrote a brief description of what I thought each interview was meaning. I then read each transcript again separately and wrote an overall statement about each interview. I then compared the two statements for similarities and differences. In the next stage, I read the whole transcript again, looking for revealing statements about each nurse•s experience. For example I underlined these words and brief statements in a colour as a process of coding. Examples included, , needed a new change• (Transcript), $\bullet$ new challenge• (Transcript) I was also looking for common and unique themes. The importance of comparing and contrasting common and unique themes is a process that leads to the development of overriding themes. Unique themes included other possibilities contributing to each participantes experience that I had not considered, e.g., external pressure to $\bullet$ move with the times $\bullet$ (Transcript) and consumer expectations. I then looked at each transcript, line by line and asked specifically what was being described and coded this in another colour. The importance of coding statements was to ensure a systematic process, and to enable easy retrieval of data later. Following this I compared the two approaches and began to look for common groups of 
themes. All statements that were highlighted and coded in colour were then grouped into categories that formed the subthemes and eventually the three overall themes emerged through a process of deduction.

\section{Aim 3: To gather an interdisciplinary perspective about the role development of ETT nurses and the ETT service at a regional tertiary hospital}

This involved interviewing the clinical Director of Cardiology and surveying the technicians who worked in the department where exercise tests were conducted.

\section{Interview with Clinical Director of Cardiology}

\section{Method}

This participant was invited to participate in a semi-structured qualitative interview. The design of the interview guide included open ended questions as I sought to capture this participant॰s reflections on the ETT service in relation to pre and current nurse involvement (Appendix 6).

\section{Participant}

This participant (Clinical Director of Cardiology) was purposefully selected to provide another source of insight into the study of nurses• role development as ETT supervisors. In addition he was able to provide a managerial overview of the ETT service from both an interdisciplinary and historic perspective. This participant was approached by myself in the workplace and invited to be interviewed. After receiving and taking time to read an information sheet (Appendix 4), a consent form was signed (Appendix 5). A time and place for the interview was mutually negotiated. I discussed my proposal of research initially as a courtesy and as part of my ethics application. The participant asked to be interviewed in a private seminar room.

\section{Data Collection}

This interview was semi-structured and focused on influential antecedents to nurses starting in the ETT role in this setting. Questions were asked about perceptions of service pre nurse involvement and current service provision as a result of nurses involvement as ETT supervisors. This participant was also asked for thoughts about general service development for the future and implications for the ETT service (Appendix 6). This interview was audio-taped and transcribed by myself. 


\section{Ethical Considerations}

I discussed the fact that I was unable to guarantee total anonymity by the nature of the participantes title but that specific steps would be taken to protect personal information regarding the participant. This also involved deleting names of other health professionals where association could be made to the participant. These steps included not identifying names in the transcript. A copy of the transcript was offered to the participant to check for accuracy. This participant checked the transcript and returned it with no changes.

\section{Data Analysis}

The method of analysis for this interview was the same as described for the nurse interviews. This involved a systematic process of coding, labelling, and categorising data to develop themes. This transcript was compared and contrasted with data from the nurse transcripts and local questionnaire with the technicians in a process of triangulation. This was done in order to find convergence or divergence with views expressed.

\section{Local Technician Questionnaire}

\section{Method}

The design of the questionnaire was mixed with both closed and open-ended questions.

\section{Participants}

Eleven technicians worked in the ECG department where ETTs were conducted and they worked alongside the ETT nurses. I approached the charge technician of the department to explain the aims of the research. I inquired as a courtesy the preferred way to approach the other technicians. The charge technician agreed to discuss the proposed research at a meeting with technicians. I provided 11 information sheets (Appendix 7) and questionnaires (Appendix 8) plus a box to place completed questionnaires in. It was agreed between myself and the charge technician that the box awaiting completed questionnaires would remain in the charge•s office.

\section{Data Collection}

This questionnaire asked initially a closed demographic question about years of service. Other questions were open ended seeking subjective feedback about perceptions of the ETT service pre and current nurse involvement (Appendix 8). Some prompts were 
given so that some answers could be organised giving two different responses such as -strengths $\bullet$ and •weaknesses•. In addition, technicians were asked if they had contributed in any way to the nurse $\bullet$ s role development. The technicians were advised that the questionnaire would take approximately 10 minutes and on completion sealed questionnaires could be placed in the box provided. At the end of one week, there were 11 out of a possible 11 completed questionnaires in the box.

\section{Ethical Issues}

Participation was voluntary and completion of the questionnaire implied consent to participate. No specific time frame was given and names of participants were not asked for. There were no line management issues between myself and the participants.

\section{Data Analysis}

Data from this questionnaire were grouped and labelled under the headings relating to the questions. This data was presented in simple descriptive tables and figures. Findings from these data were compared and contrasted with the interviews with the Clinical Director and ETT nurses.

Aim 4: To determine the extent to which nurses are involved in the supervision of ETTs within the public hospital sector of New Zealand

\section{National Questionnaire}

\section{Method}

The design of this questionnaire included simple demographic and mainly closed questions, offering participants set choices in answers. There were some open questions where participants could write their own response.

\section{Participants}

Cardiac nurses who work as ETT nurses in public hospitals in New Zealand were the target population. At the commencement of this study, no complete data base existed on ETT nurses demographics. I addressed each questionnaire to the Cardiology Department of 26 public hospitals as I had no direct contact names. It was assumed that ETTs were being performed in these 26 hospitals, reflecting ETT activity amongst the 21 District Health Boards. To strengthen uptake of the questionnaire, I also e-mailed the secretary of the Affiliates group of the New Zealand branch of the Cardiac Society of Australia 
and New Zealand. My aim was to raise awareness of this research project and request that this information be disseminated nationally to affiliate members.

The inclusion criteria were all major public hospitals in New Zealand that had a cardiology department. My exclusion criteria were all private hospitals. My reason for this is that it is purported that technicians and doctors are mainly supervising ETTs in the private sector (undocumented discussion with a cardiologist and cardiac technicians).

\section{Data Collection}

An information sheet (Appendix 9) and questionnaire (Appendix 10) along with a stamped return address envelope, was sent to 26 hospitals in New Zealand. The design of the questionnaire included simple demographic questions, some closed questions where a range of answers were offered and some descriptive questions (Appendix 10). Questions initially asked whether ETTs were being performed at each hospital and then subsequent questions related to numbers, years of nurse involvement, training and educational requirements. No specific time was given for participants to return any completed questionnaires.

\section{Ethical Issues}

Participants were aware that data from the questionnaire would contribute to national findings. Providing a name and contact address was voluntary. Completion of the questionnaire implied consent.

\section{Data Analysis}

Data were collated and represented by both simple descriptive figures and tables under headings related to questions. In addition, this type of analysis seeks to give a descriptive picture of the target group. Descriptive statistics such as frequencies, percentages, ranges, means, medians and modes were used to describe the data. I grouped the hospital responses in geographic order from the top of the North Island to the bottom of South Island. These data were compared and contrasted in triangulation with the other data as part of a corroboration process. 


\section{Chapter Four: Findings}

\section{Interviews with ETT Nurses}

Four nurses were interviewed about their individual process of role development as ETT nurses. The aim was to describe role development of nurses who supervise ETTs at a regional tertiary hospital. Although the sample size is small, it represents all the ETT nurses working in this setting.

A method of qualitative descriptive thematic analysis was used to develop themes. Three main themes emerged from the interviews of the four ETT nurses. These themes were also supported by findings in the interview with the Clinical Director. The first theme was Starting in the Role which included two subthemes; precipitants, arriving and beginning. The second theme was Integration into the Role which contained three subthemes; settling down, role acceptance and role reflection. The third theme was Hopes for the Future, as participants expressed possibilities for the development of the ETT nurse role and ETT service as a whole.

Table 1: Themes from interviews with ETT nurses

\begin{tabular}{|l|l|}
\hline Themes & Subthemes \\
\hline Starting in the Role & $\begin{array}{l}\text { Precipitants } \\
\text { Arriving and Beginning }\end{array}$ \\
\hline Integration into the Role & $\begin{array}{l}\text { Settling Down } \\
\text { Role Acceptance } \\
\text { Role Reflection }\end{array}$ \\
\hline Hopes for the Future & \\
\hline
\end{tabular}

\section{Starting in the Role}

\section{Precipitants}

The participants described a range of clinical experience and levels of expertise working in Cardiology prior to entering into the role. Three participants described coincidental timing and service development as opportunities precipitating their entry into the ETT nurse role. This included being involved with setting up a nurse-led chest pain unit which resulted in increasing numbers of ETTs being performed. As a result, nurses were invited to be involved as ETT supervisors. One participant had become involved in a planned way as part of an opportunity to contribute to a service development and added , nurses are used to playing a pivotal role and having to adapt their rolesf (Transcript 
C, 2009, p. 6). Other precipitants were identified as boredom and frustration with existing clinical work in the wards. , I was feeling a little frustrated in the ward at the time. I thought it would give me some other interest as wellf (Transcript B, 2009, p. 2). ,I think the ward nursing role is fairly narrow, itfs a basic rolef (Transcript E, 2009, p. 2).

In contrast, expressing a passion for cardiology as a specialty in nursing was a motivating precipitant., I think my enthusiasm and my keenness for cardiology as a person were driving factors for me wanting to do ETT supervisionf (Transcript C, 2009, p. 5). A desire to work in a more autonomous role was considered a motivating factor. , I do like the autonomy that goes along with doing ETTs and that is something that attracted me to the role rather than doing the ward work, I did want something with a bit more autonomy and decision makingf (Transcript C, 2009, p. 4). Another participant echoed this, ,I volunteered; I thought it was time that I had something stimulating and new to do, something I could be autonomous in, so it was my suggestion that I would like to be an ETT nursef (Transcript A, 2009, p. 2).

One participant thought it would be helpful and complementary to working in the ward and contribute to some career progression as this would, advance me more in Cardiologyf (Transcript E, 2009, p. 1). Another participant thought being in the ETT nurse role, would result in enhanced ECG knowledge and as a consequence be , recognised as a bit more of an expertf (Transcript B, 2009, p. 2). Prior experience supervising ETTs was also identified as a precipitant for one participant who had been involved in planning an ETT service, I played quite a lead role in it actually with myself and medical physics peoplef. (Transcript C, 2009, p. 2). All participants described both the opportunity to enhance existing skills and have more clinical autonomy as overriding precipitants.

\section{Arriving and Beginning}

In regard to initial experiences, the participants described similar emotions such as feeling anxious; overwhelmed, scared and challenged. Anxiety was reported relating to increased responsibility and accountability such as, ,youfre the one who ultimately says wefre stopping or not stopping that felt quite scaryf, (Transcript B, 2009, p. 3). Fear and feeling challenged were related to the newness of that increased responsibility. One participant described feeling anxious because it was, it was a relatively new role for a 
nurses and it seemed to me a bit experimental, as I said, a new role for nurses to play, that doctors had done in the pastf (Transcript E, p. 1). When comparing prior experience, one participant identified immense challenges with the expectations of actually performing the role in this setting. , There is a lot more experience here in New Zealand, when I undertook this role, a lot more decision making, we are involved a lot more with interpreting the ECGsf (Transcript C, 2009, p. 3). This participant was surprised at the level of responsibility expected when starting in the role and felt that level was more fitting with a nurse specialist status. The level of responsibility for patient safety was of significant concern for several of the participants in the beginning, , being concerned that nothing went wrong or nobody came to any harmf (Transcript A, 2009, p. 2).

Adjusting to working with the technicians in the initial stage was reported as a challenge because of the diversity in personalities and perceived established individual rituals by the technicians, , You work with four different technicians a day and each one of them has a different way of doing thingsf (Transcript E. 2009, p. 2). All participants identified similar adjustment issues in regards to becoming familiar with individual technician differences and their approaches to exercise tolerance testing.

\section{Integration into the Role}

\section{Settling Down}

As the ETT nurses recalled the •settling down • period, their reflections focused on adjustment issues and feelings of increasing confidence. This was perceived as a direct result of seeing and doing more, , there is only a certain amount of training that you can do, then experience needs to take overf, (Transcript E, 2009, p. 3). Regular exposure to tests also contributed to adjustment to the role and increasing confidence. , I think itfs actually on the job experience and seeing a few potential situations where the test should be stopped or not done at all, and making decisions correct gives you a bit more confidence that youfve made the right decisionf (Transcript E, 2009, p. 2). Acknowledgement was made of the huge responsibility for patient safety and making the right decisions. One participant described her settling into the role as, , it just kind of grew and confidence came with the more that I did, the positive ones I saw, my confidence grew with my experience, (Transcript A, 2009, p. 3). Another participant acknowledged the value in identifying their first positive test by seeing $\bullet$ ST segment 
changes ${ }^{\bullet}$ on the screen indicating ischemia, and felt, chuffed as this is valuable knowledgef for her, (Transcript B, 2009, p. 4). One participant described, , Ifm feeling more comfortable now, there is a still an element of anxiety with regard to ensuring I donft miss important ECGs, or important pre test changes that would make me preclude a testf ( Transcript E 2009, P. 1). Generally, there was a perception this was a period of -steep learning•. ,I was constantly reading the books on rhythms and ECGs, and trying to find out all I couldf (Transcript A, 2009, p. 3). Learning about responsibilities and boundaries was ongoing, as reported by one participant, , more often than not, Ifm still groping around trying to find those boundaries and responsibilities, Ifve still got to bow to other peoplefs greater knowledge in many situations because Ifm still not that experiencedf, (Transcript E, 2009, p. 3). This was despite this participant reporting general increasing confidence at this stage.

Developing collaborative relationships with both the technicians and doctors were considered to be an important part of settling into the role for the nurses. All ETT nurses reported a very positive regard to the technicians whom they viewed as their collaborative partners in the service. Learning to trust, respect and listen to each other was considered important components in team development, Wefve both come to respect each other and talk to each other as wefre going along, about what it is, where as in the beginning, there was a little bit of friction going on that way until they learnt to trust that I knew what I was doingf (Transcript B, 2009, p. 4). Another participant described the ETT nurse role as a ,role where two different disciplines have to work together and consult each other and respect each otherfs knowledge and experience and work collaborativelyf (Transcript A, 2009, p. 9).

\section{Role Acceptance}

Learning how to communicate and relate to medical colleagues was described as an issue of concern in regards to being accepted in the ETT nurse role. Trying to understand and anticipate expectations from the doctors were a common concern, that would improve things really if we knew exactly what the consultants considered important from their point of view, because they do have differing opinionsf, (Transcript B, 2009, p. 6). This involved having to regularly and directly discuss findings from exercise tests with the doctors and discuss strategies around clinical incidents. This was perceived as different from situations in the ward setting, where nurses often discussed 
concerns amongst each other, before contacting medical staff. Dilemmas about making the right clinical decisions heightened initial concerns but this gradually relaxed with role acceptance, , Ifve been reasonably well received, I think by the registrars and most of the time my decisions, my reasons for calling have been right and very rarely have been wrong and often resulted in good outcomesf (Transcript E, 2009, p. 4). Another participant felt that time had contributed to acceptance by medical staff about the ETT nurse role.f Getting to know them, getting to know us as individuals and know that we are not being over anxious when we need themf (Transcript A, 2009, P. 8).

Over time the ETT nurses felt accepted by others and attributed this to their developing relationships with the technicians and the department॰s growing reputation as a positive team. In regards to working with the technicians, I think they werenft sure about my knowledge and being a new person in there, I think possibly they were learning to know me and trust me as well, I donft knowf (Transcript B, 2009, p. 4). This was also echoed by another participant in regards to beginning to work with a well established team, , $I$ also had to learn what my place was within that role and also learn how to interact with certain characters and people that already work there and so initially my angst was multi fold if you like, (Transcript E, 2009, p. 5).This participant felt this resolved relatively quickly and, the people interaction was quickly sorted outf (Transcript E, 2009, p. 5). Increasing acceptance over time by the doctors was attributed to their increasing understanding of the ETT nurse role, , they often have a bit more confidence in the reasons that Ifm ringingf (Transcript E, 2009, p. 5). One participant also perceived increasing respect from other colleagues from the ward for increased knowledge and skills around ECG analysis.

\section{Role Reflection}

Several of the ETT nurses felt that it was essential to have certain personal qualities in order to perform the role and function effectively in the environment. Having a sense of humour and •character were considered important traits. This was also viewed as a strategy to cope with the diversity of personalities within the ECG Department and the intense nature of the work. , Itfs just getting that relationship working so you are making decisions together, most of the timef (Transcript B, 2009, p. 6). At any one time, there is one ETT nurse and one cardiac technician in the room with the patient and thus 
communication was considered vital, we both work together and both listen to each other about whatfs going onf, (Transcript B, 2009, p. 6).

On reflecting about being in the ETT nurse role, one of the participants described diversity as one of the benefits to working in the role. This was in regard to both patient population, variation in clinical situations and interacting with other health professionals. Dealing with a wide range of people, having some autonomy and an opportunity to educate patients, were also seen as rewarding aspects of the role.

Growing confidence as a result of experience was a common perception amongst the ETT nurses. When asked about their current feelings regarding being in the role, one participant responded, , Ifm a positive person about my own knowledge and skills and being prepared to stand up for my judgement call, I didnft have the confidence to start with but I have developed it with experience and itfs made a tremendous impact on working down heref (Transcript B, 2009, p. 8). Developing confidence in decision making was considered an important factor in role development, , you also have to have the confidence to make good decisions repeatedly, under a reasonable amount of pressure $\bullet$, (Transcript E, 2009, p. 4). One participant recalled working in isolation at times on the weekend with only skeleton staff, and perceived this as a challenge. , There is unpredictability; you donft really know what is going to happen theref, (Transcript A, 2009, p. 3).

One participant commented that the role was also hard because of the repetitive nature of the tests and the requirement to concentrate on multiple things simultaneously, , By the time you get to ten or twelve tests, I think you can be quite jaded and itfs difficult to step up and continue concentratingf (Transcript E, 2009, p. 3). All the ETT nurses felt there were environmental limitations to the role, such as working in a very confined space and this was perceived to also impact on individual levels of concentration. As a consequence, having sufficient breaks were seen as a high priority. , It fs a hard physical place to be for eight hours, I think there needs to be more breaksf, (Transcript E, 2009 p. 6).

All four ETT nurses could not imagine returning to just working in the wards after having been in the role for a considerable period. As participants reflected on their growing confidence, the possibility of returning to nursing in the ward as a primary role 
was perceived as unattractive. ,I keep joking that if they turn the ward into a medical ward, I will work down here full-timef, (Transcript B, 2009, p. 8). One participant felt there were two distinct parts to integrating into the role, starting and learning. This participant thought they would never become an expert in ECG analysis but thought, , I can only develop and itfs important to recognise thatf (Transcript E, 2009, p. 5).

Team work was considered an important influence for individual role development, - you rely on team members anyway to perform to your maximum, you utilise their skills and knowledge and they utilise your skills and knowledge and you respect each otherf (Transcript C, 2009, p.6). All participants reported positively about the interdisciplinary environment that they worked in.

\section{Hopes for the Future}

In regards to the final theme, the ETT nurses hoped that their role would eventually expand more but were uncertain about specifics. , I can see the department expanding a bit but Ifm not sure I can see the role expanding particularly in anything other than an administrative rolef (Transcript E, 2009, p. 6). One participant thought that they may eventually , become self-redundant,f (Transcript E, 2009, p. 6) by only supervising ETTs and nothing else, as this might result in a narrowing of expertise. Another participant felt it was important to , move with the times and move with the demands of the patient, people are expecting more • (Transcript C, 2009, p. 6). This participant felt that consumer expectation was building, would ultimately shape service development, $I$ think there is a real cry for it definitely and itfs going to be a lot better for patients as wellf (Transcript C, 2009, p. 7). This participant expressed enthusiasm for the possibility of role expansion as a consequence. , I would love to see the role expand beyond what wefre doing now so that nurses can have a lot more responsibility if they choose tof (Transcript C, 2009, p. 9). The suggestion of the ETT nurses becoming more involved in the referral process and pre-test assessment was raised with the idea of , having some ownership in the patient journeyf (Transcript C, 2009, p. 7). One participant thought reviewing this process would result in an enhanced service as, more time could be spent on the referral process and possibly we could look at more of the patients that could possibly be ETTfd rather than a quick snapshot of doing the ones we dof (Transcript E, 2009 p. 7). 
Developing the role into a nurse specialist position was considered one possibility but the prospect of this happening was felt to be dependent on the, workload and politics of the hospitalf (Transcript E, 2009, p. 7). Perceived managerial and fiscal constraints were also seen as a block to ETT nurses being recognised as specialist nurses. , but itfs all down to money and costs, but itfs not that much more because if nurses could play a bigger role, then the consultant time is going to be freed upf, (Transcript, C, 2009, p. 7). One participant argued that the ETT role is a specialised role and warranted recognition. ,It would be nice to see in the future if it became the role of a specialist nurse, because it is a specialised rolef (Transcript A, 2009, p. 8). One participant could not see the service reverting to pre nurse involvement, , I canft see it going back to doctor assessment, just because of pressures on doctors as wellf, (Transcript B, 2009, p. 9).

In summary the participants identified varying stages of integration into ETT nurse role, alongside influences to their individual role development. The participants were able to clearly identify distinct stages that enabled them to identify association with time placed events such as arriving and settling down. The participants also alluded to environmental factors as having part influence to their role development. These included size and features of the room they worked in. All participants felt their involvement in a new nurse led initiative was influential to current service delivery and had implications for possibility of future service development. The collaborative nature of relationships between the participants and the ECG technicians was identified as a significant factor influencing individual ETT nurse role development. The participants described a process of accumulative confidence as a result of continually supervising tests on a regular basis. All the participants spoke with more authority and confidence towards the end of their interviews. This was in contrast with their expressed reflections of apprehension when first integrating into the ETT nurse role.

\section{National Questionnaire}

Completed questionnaires were received from 19 out of 26 hospitals. The following tables and figures relate to the sequential order of questions asked in the questionnaire 
Table 2: Hospitals within the 21 DHBs where questionnaires sent and responses

\begin{tabular}{|c|c|c|}
\hline DHBs & Hospitals & Returned \\
\hline Northland DHB & Whangarei Hospital & $"$ \\
\hline Waitemata DHB & $\begin{array}{l}\text { North Shore Hospital } \\
\text { Waitakere Hospital }\end{array}$ & $\begin{array}{l}, \quad, \\
, \quad,\end{array}$ \\
\hline Auckland DHB & Auckland Central Hospital &, \\
\hline Counties Manukau DHB & Middlemore Hospital &,$\ldots$ \\
\hline Bay of Plenty DHB & $\begin{array}{l}\text { Tauranga Hospital } \\
\text { Whakatane Hospital }\end{array}$ & $\begin{array}{ll}\cdots \\
\ldots\end{array}$ \\
\hline Waikato DHB & Waikato Hospital & 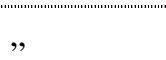 \\
\hline Tairawhiti DHB & Gisborne Hospital & , \\
\hline Taranaki DHB & Taranaki Base Hospital & , \\
\hline Hawkes Bay DHB & Hawkes Bay Hospital & 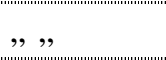 \\
\hline Whanganui DHB & Whanganui Hospital & 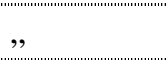 \\
\hline Lakes District DHB & Rotorua Hospital & $\ldots$ \\
\hline Mid Central DHB & Palmerston North Hospital & $\ldots$ \\
\hline Wairarapa DHB & Wairarapa Hospital & $\ldots$ \\
\hline Hutt DHB & Hutt Hospital &, \\
\hline Capital \& Coast DHB & Wellington Hospital & , \\
\hline Nelson Marlborough DHB & $\begin{array}{l}\text { Nelson Hospital, } \\
\text { Wairau Hospital }\end{array}$ & " \\
\hline West Coast DHB & Grey Base Hospital & 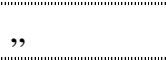 \\
\hline Canterbury DHB & $\begin{array}{l}\text { Christchurch Hospital } \\
\text { Ashburton Hospital }\end{array}$ & $\begin{array}{l}" \\
\ldots\end{array}$ \\
\hline South Canterbury DHB & Timaru Hospital & 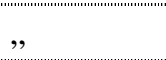 \\
\hline Otago DHB & Dunedin Hospital & , \\
\hline \multirow[t]{3}{*}{ Southland DHB } & $\begin{array}{l}\text { Lakes District Hospital } \\
\text { Southland Hospital }\end{array}$ & , \\
\hline & Unidentified Hospitals &,,,, \\
\hline & & 28 \\
\hline
\end{tabular}

Although questionnaires were sent to 26 hospitals, a total of 28 questionnaires were returned. These included four hospitals who sent an additional repsonse. Photocopies of the original letterhead were included in this group. Several hospitals contacted me to resend the questionnaire as they had mislaid the original questionnaire. I entered only one set of data from those hospitals that sent an additional response as I did not want to give extra weighting to any one hospital. In that selection of data, I made sure that there was consistency in the responses given. Variation in position title for respondants may have accounted for additional questionnaires being returned. Four returned questionnaires did not identify address or hospital. Two of those returned 
questionnaires were also not on official university letter head and therefore may have been a duplicate of one of the other identified hospitals. I have therefore chosen not include the four unidentifed responses in the data.

Question 1: Are exercise tolerance tests performed in your department?

Table 3: Hospitals where ETTs are performed

\begin{tabular}{|c|c|c|}
\hline $\begin{array}{l}\text { Exercise tests are } \\
\text { being performed } \\
\text { in these hospitals }\end{array}$ & $\begin{array}{l}\text { Whangarei; North Shore; Waitakere;Auckland; Middlemore; } \\
\text { Whakatane; Waikato; Gisborne;Taranaki; Hawkes Bay; } \\
\text { Whanganui; Hutt; Wellington; Nelson; Grey Base; } \\
\text { Christchurch; Timaru; Dunedin, Southland }\end{array}$ & 19 \\
\hline $\begin{array}{l}\text { Exercise tests are } \\
\text { not being } \\
\text { performed in this } \\
\text { hospital }\end{array}$ & Lakes District & 1 \\
\hline Uncertain & $\begin{array}{l}\text { Tauranga; Rotorua; Palmerston North; Wairarapa; Wairau, } \\
\text { Ashburton }\end{array}$ & 6 \\
\hline
\end{tabular}

Survey responses indicate Exercise Tolerance tests are performed in at least $19(73.0 \%)$ public hospitals surveyed in New Zealand. Twelve (63.1.2\%) of those hospitals are in the North Island where the population is greater. One (3.8\%) hospital is not providing ETT services. It is unknown whether six (23\%) hospitals are providing ETT services.

Question 2: How many days of the week are ETTs performed in your department?

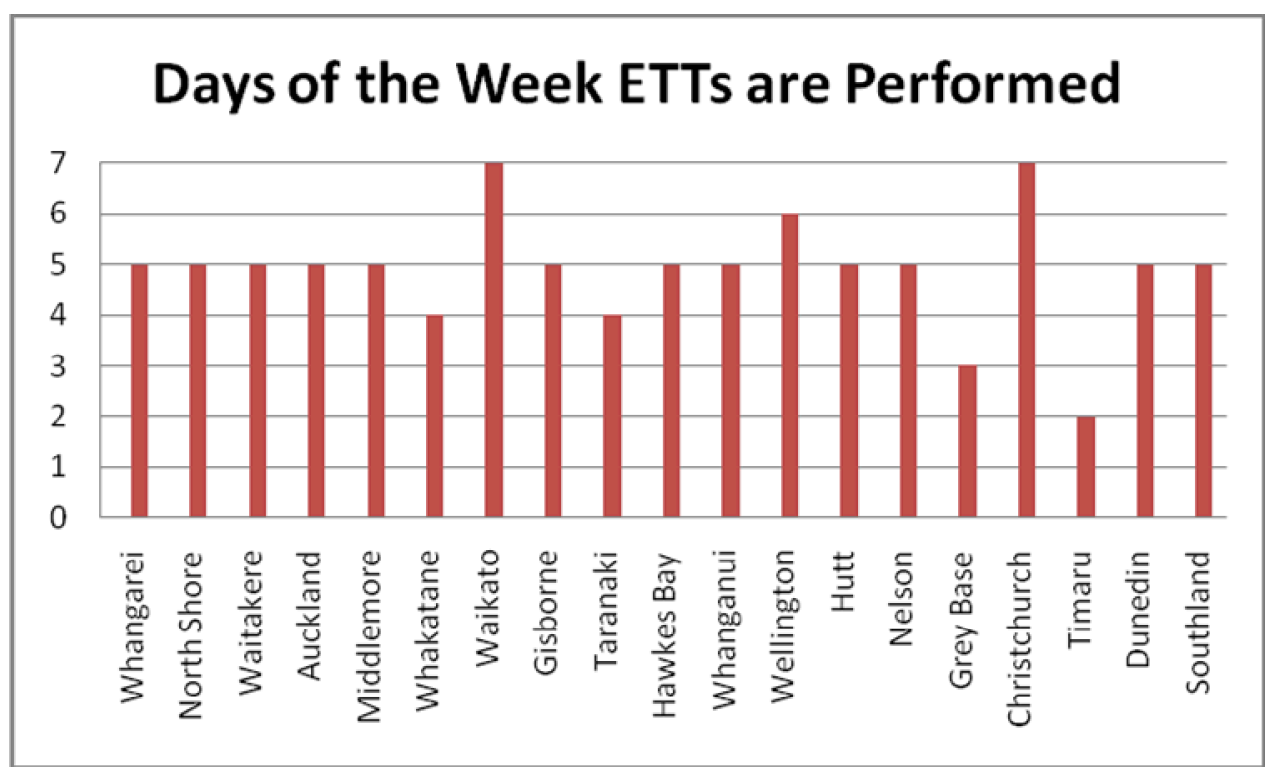

Figure 1: Days of the week ETTs are performed by hospital

ETTs are performed between two to seven days and on average are performed five days a week. 
Question 3: Which of the following personnel supervise exercise tolerance tests in your department?

Table 4: Supervising personnel

\begin{tabular}{|c|c|c|c|c|}
\hline Hospitals & Nurses & $\begin{array}{l}\text { Cardiologists } \\
\text { Consultants } \\
\text { Physicians }\end{array}$ & $\begin{array}{l}\text { Registrars } \\
\text { House } \\
\text { Surgeons }\end{array}$ & $\begin{array}{l}\text { Technicians } \\
\text { Technologists }\end{array}$ \\
\hline Whangarei &, &, &, & \\
\hline North Shore & 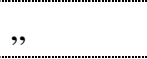 & & & $\%$ \\
\hline Waitakere &, & ,. & , & \\
\hline Auckland & &, & , & , \\
\hline Middlemore &. &, & 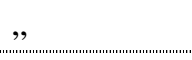 & .......... \\
\hline Whakatane & & 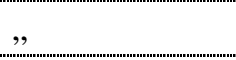 & , & \\
\hline Waikato &, & & , & \\
\hline Gisborne & &, & & , \\
\hline Taranaki &, & & , & \\
\hline Hawkes Bay &, & 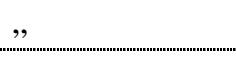 & & \\
\hline Whanganui & &, & & \\
\hline Wellington & & 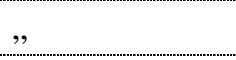 & , & \\
\hline Hutt &. &, &, & \\
\hline Nelson &, & ,., & & , \\
\hline Grey & & ,... & & \\
\hline Christchurch &, & & &, \\
\hline Timaru & , &, & & \\
\hline Dunedin &, & & & , \\
\hline \multirow[t]{2}{*}{ Southland } & & &, & , \\
\hline & 12 & 13 & 10 & 8 \\
\hline
\end{tabular}

Nurses are involved in supervising tests in 12 out of 19 (63.1\%) hospitals. All hospitals except Whanganui and Grey Hospital report using a combination of personnel. Whanganui and Grey Hospital utilise physicians only. Nurses are not involved in supervison of ETTs at five hospitals. Sixty three percent of the hospitals are utilising nurses to supervise ETTs. The trend is that most of the hospitals are now utilising nurses. 
Question 4: How many nurses are involved in supervising ETTs in your department?

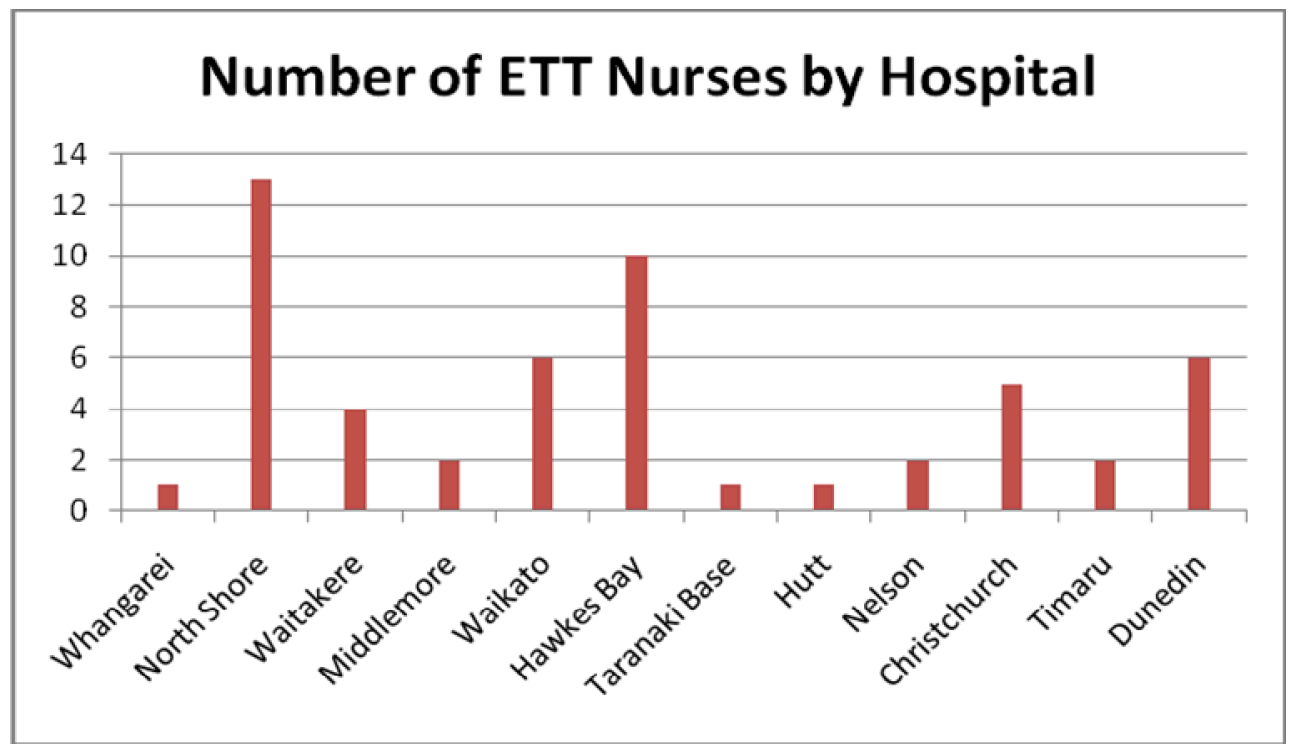

Figure 2: Number of nurses supervising at each hospital

The Range of nurses supervising by hospital is 12; mean/average 3.25, median is 2 and the mode is 2 .

Question 5: In what year did nurses become involved in the supervison of ETTs in your department?

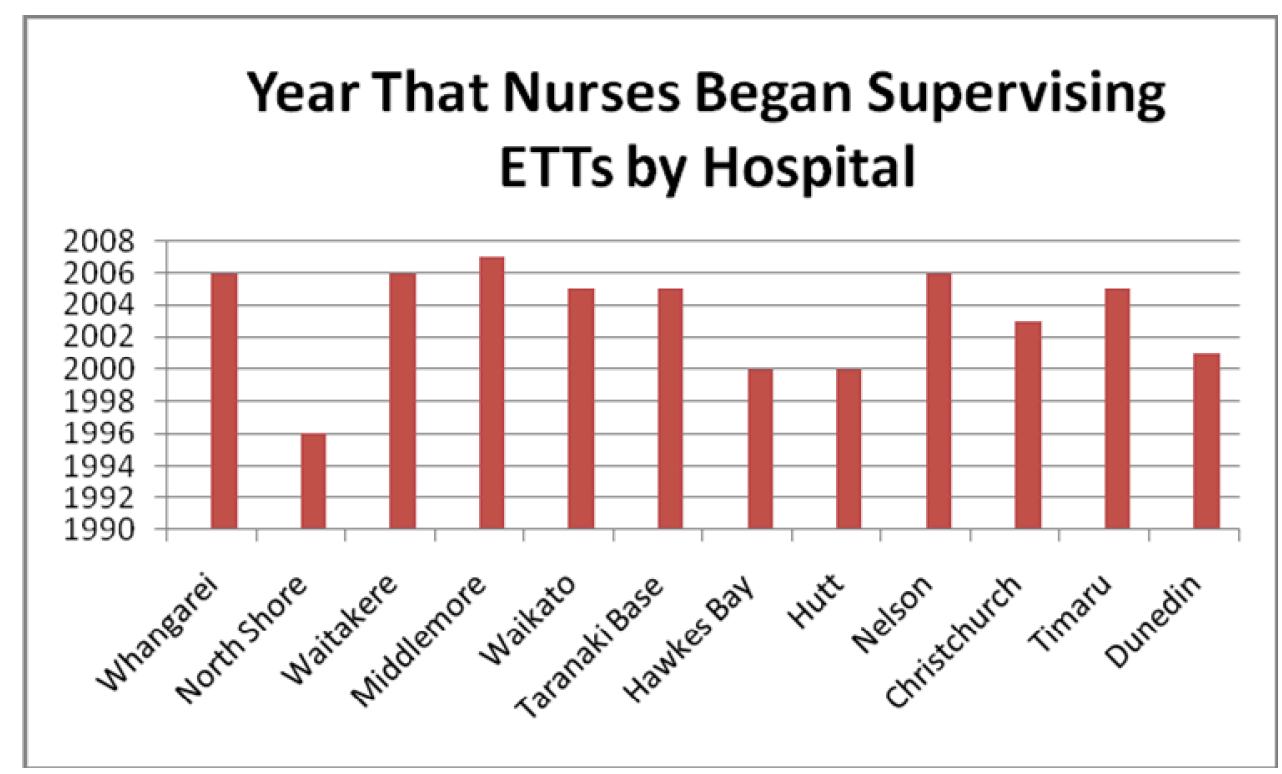

Figure 3: Year that nurses began supervising ETTs

Nurses began supervising ETTs in 1996 at North Shore Hospital. In 2005, nurses began supervising ETTs at three (25\%) hospitals. Since then nurses have been supervising at 
eight out of $12(66.6 \%)$ hospitals. The last reported year that nurses commenced supervising tests was 2007.

Question 6: What prior experience are nurses required to have before they supervise ETTs

Table 5: Prerequisite experiences

\begin{tabular}{|c|c|c|c|c|c|c|c|}
\hline Hospitals & Cardiology & $\begin{array}{l}* \mathrm{ACL} \\
\text { Level } \\
6\end{array}$ & $\begin{array}{l}\text { ETT } \\
\text { Nurses } \\
\text { Training }\end{array}$ & $\begin{array}{l}\text { Clinical } \\
\text { Nurse } \\
\text { Specialist }\end{array}$ & $\begin{array}{l}\text { ICU } \\
\text { CCU }\end{array}$ & $\begin{array}{l}\text { Chest } \\
\text { Pain } \\
\text { Clinic }\end{array}$ & $\begin{array}{l}* \mathrm{RN} \\
\text { Level } \\
3 \text { and } \\
\text { above }\end{array}$ \\
\hline Whangarei & , & & & & ", & & \\
\hline North Shore & , & & & & & & ", \\
\hline Waitakere & , & & & & & & \\
\hline Middlemore &, & & & & & & \\
\hline Waikato & , & , & & & & & \\
\hline Taranaki & , & & & & , & & \\
\hline Hawkes Bay & , & & , & & & & \\
\hline Hutt & , & & & & & & \\
\hline Nelson &, & & & , & & , & \\
\hline Christchurch &, & & & & & & \\
\hline Timaru & , & & & & & & \\
\hline Dunedin & , & & & & , & & \\
\hline & 12 & 1 & 1 & 1 & 3 & 1 & 1 \\
\hline
\end{tabular}

*ACL refers to Advanced Certificate in Life Support

*RN Level 3 refers to a senior registered nurses and in some areas is also known as (SN5)

A range of prerequsite experiences to training as an ETT nurse were described by 12 hospitals. They include having nursing experience in either cardiology or intensive/coronary care where nurses are expected to read and understand ECG tracings. In addition they are required to have experience and competency in emergency procedures (ACL). The most common prerequisite was to have clinical experience working in Cardiology (100\%). 
Question 7: What qualifications are nurses required to have before supervising ETTs

Table 6: Prerequisite qualifications

\begin{tabular}{|c|c|c|c|c|c|c|}
\hline Hospitals & None & $\begin{array}{l}\text { Advanced } \\
\text { Life } \\
\text { Support } \\
\text { Certificate }\end{array}$ & $\begin{array}{l}\text { Graduate } \\
\text { Certificate }\end{array}$ & $\begin{array}{l}\text { Post } \\
\text { Graduate } \\
\text { Certificate }\end{array}$ & $\begin{array}{l}\text { Masters } \\
\text { Degree }\end{array}$ & *Other \\
\hline Whangarei & & , & & & & $"$ \\
\hline North Shore & & ", & ", & & & \\
\hline Waitakere & & , & & & & \\
\hline Middlemore & & ", & & & & \\
\hline Waikato & & ", & & & & \\
\hline Taranaki & & , & & & & \\
\hline Hawkes Bay & & ", & & & & \\
\hline Hutt & & & & & & " \\
\hline Nelson & & ", & & " & & \\
\hline Christchurch & & " & & & & \\
\hline Timaru & , & & & & & \\
\hline \multirow[t]{2}{*}{ Dunedin } & & $"$ & & & & \\
\hline & 1 & 10 & 1 & 1 & 0 & 2 \\
\hline
\end{tabular}

*Those hospitals that gave an example of $\bullet$ other $\bullet$ included responses as $\bullet$ credentialing $\bullet$ and $\bullet$ nurse specialist $\bullet$

Respondents were given a range of set choices they could tick. Ten out of $12(83.3 \%)$ hospitals where nurses are supervising ETTs require an advanced life support certificate (qualification) prior to working in the role. One hospital has no prerequisite qualifications. One hospital required the ETT nurse to have a Graduate Certificate and one hospital required the ETT nurse to have a Post Graduate Certificate. No hospitals required the ETT nurse to have a Masters Degree. 
Question 8: What on going training do you see as being relevant for nurses supervising ETTs?

Table 7: Ongoing training responses

\begin{tabular}{|c|c|c|c|c|c|}
\hline Hospitals & $\begin{array}{l}\text { Cardiology } \\
\text { Study Days }\end{array}$ & Conferences & $\begin{array}{l}\text { Competency } \\
\text { Update Days }\end{array}$ & $\begin{array}{l}\text { Annual } \\
\text { ACL }\end{array}$ & $\begin{array}{l}\text { Training } \\
\text { with } \\
\text { Cardiologist }\end{array}$ \\
\hline Whangarei & " & & & ", & \\
\hline North Shore & , & & & " & \\
\hline Waitakere & " & & , & " & \\
\hline Middlemore & , & , & , & & \\
\hline Waikato & , & & & & \\
\hline Taranaki & & , & , & & , \\
\hline Hawkes Bay & & & & ", & , \\
\hline Hutt & & , & & & \\
\hline Nelson & " & & & & \\
\hline Christchurch & " & ", & , & & \\
\hline Timaru & , & " & & & \\
\hline \multirow[t]{2}{*}{ Dunedin } & & & , & & \\
\hline & 8 & 5 & 5 & 4 & 2 \\
\hline
\end{tabular}

Respondents were given examples of ongoing training but were able to choose their own responses. Eight out of twelve (66.6\%) hospitals recommended Cardiology Study Days as relevant to their position. Five $(41.6 \%)$ hospitals saw the relevance of ETT nurses to attending conferences. Five $(41.6 \%)$ hospitals also saw the relevance of ongoing competency update days. Four (33.3\%) hospitals saw the relevance of maintaining their advanced life support certification (ACL). Two (16.6\%) hospitals saw the relevance of ongoing training with a Cardiologist. 
Question 9: Do you have quality documents in regards to training ETT nurses in your department?

Question 10: Do you have quality documents in regards to assessing competencies of nurses who supervise ETTs?

Table 8: Presence of quality documents in regards to training and competency assessment

\begin{tabular}{|c|c|c|}
\hline Hospitals & $\begin{array}{l}\text { Quality Documents for } \\
\text { Training }\end{array}$ & $\begin{array}{l}\text { Quality Documents for } \\
\text { Competency } \\
\text { Assessment }\end{array}$ \\
\hline Whangarei & , & 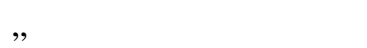 \\
\hline North Shore & , &, \\
\hline Waitakere & , & $\ldots$ \\
\hline Middlemore & " & 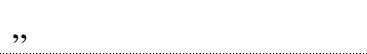 \\
\hline Waikato & , & 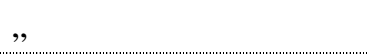 \\
\hline Taranaki & , & , \\
\hline Hawkes Bay & , & 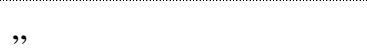 \\
\hline Hutt & $\ldots$ & $\ldots$ \\
\hline Nelson & In progress & $\ldots$ \\
\hline Christchurch & In progress & , \\
\hline Timaru & $\ldots$ & , \\
\hline Dunedin & , & , \\
\hline
\end{tabular}

Eight out of $12(66.6 \%)$ hospitals have quality training documents specific to training. Two (16.6\%) hospitals have documents in progress and two (16.6\%) hospitals do not have formal training documents. Nine $(75 \%)$ hospitals have quality documents in regards to assessing competency of nurses who supervise ETTs. Three (7.1\%) hospitals do not have documents in regards to competency assessment. 
Question 11: Are ETT nurses in your area involved in other tests?

\section{Table 9: Other tests that ETT nurses are involved with}

\begin{tabular}{|c|c|c|c|c|c|c|c|c|c|c|}
\hline Hospitals & 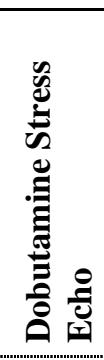 & 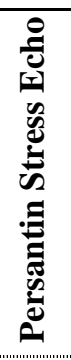 & 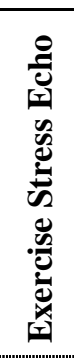 & 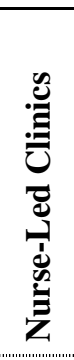 & 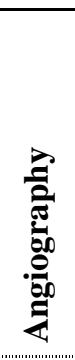 & 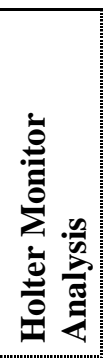 & 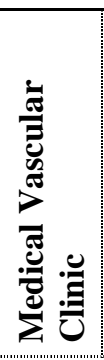 & 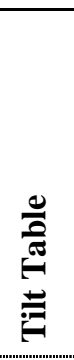 & 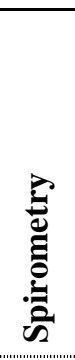 & 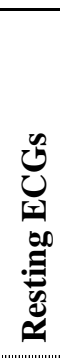 \\
\hline Whangarei & $"$ & & & & & & $"$ & & & \\
\hline North Shore & $"$ & & 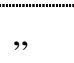 & & & & & $"$ & & \\
\hline Waitakere & $"$ & & $"$ & & & & & & & \\
\hline Waikato & $"$ & & & & & & & & & \\
\hline Taranaki & & & & & $"$ & & & & & \\
\hline Hawkes Bay & $"$ & $"$ & & & $"$ & ", & & & & \\
\hline Hutt & & & & , & & & & & & \\
\hline Nelson & & & & $"$ & & & & & & \\
\hline Christchurch & & & $"$ & & & & & & & \\
\hline Timaru & & & & & & " & " & & " & $"$ \\
\hline \multirow[t]{2}{*}{ Dunedin } & ", & & & & & & & & & \\
\hline & 6 & 1 & 3 & 2 & 2 & 2 & 2 & 1 & 1 & 1 \\
\hline
\end{tabular}

Eleven out of $12(91.6 \%)$ hospitals reported that their ETT nurses were also involved in supervising a range of other tests. ETT nurses are involved with nurse-led clinics at two hospitals. ETT nurse are not involved with other tests at one hospital. 
Question 12: Do technicians work alongside nurses supervising ETTs?

Table 10: Hospitals where ETT nurses work alongside cardiac technicians

\begin{tabular}{|l|l|l|}
\hline Hospitals & Yes & No \\
\hline Whangarei & & $\ldots$ \\
\hline North Shore &, & \\
\hline Waitakere &, & \\
\hline Middlemore &, & \\
\hline Waikato &, & \\
\hline Taranaki &, & \\
\hline Hawkes Bay & & $\ldots$ \\
\hline Hutt &, & \\
\hline Nelson &, \\
\hline Christchurch &, \\
\hline Timaru & \\
\hline Dunedin &, & \\
\hline & 9 & 3 \\
\hline
\end{tabular}

Cardiac technicians work alongside ETT nurses at nine out of $12(75 \%)$ hospitals. 
Question 13: Which of the following additional roles to supervising ETTs are nurses involved with?

Table 11: Additional roles for ETT nurses

\begin{tabular}{|c|c|c|c|c|c|c|}
\hline Hospitals & $\begin{array}{l}\text { Patient } \\
\text { Education }\end{array}$ & $\begin{array}{l}\text { Interpretation } \\
\text { of ETT } \\
\text { results }\end{array}$ & $\begin{array}{l}\text { Health } \\
\text { Promotion }\end{array}$ & $\begin{array}{l}\text { Referral } \\
\text { for } \\
\text { other } \\
\text { tests }\end{array}$ & $\begin{array}{l}\text { Cardiac } \\
\text { Examination }\end{array}$ & Other \\
\hline Whangarei & $"$ & " & , & & & \\
\hline North Shore & 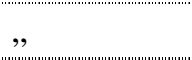 & 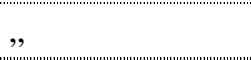 & 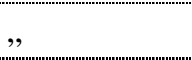 &, &, & \\
\hline Waitakere &, &, & , & &, & \\
\hline Middlemore & 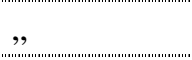 & , & 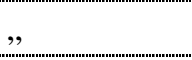 &, & & \\
\hline Waikato & , & 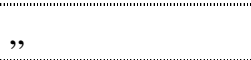 & 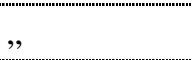 & 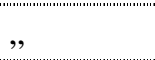 &, & \\
\hline Taranaki & , & & 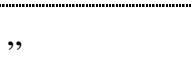 & 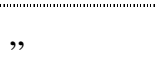 & & \\
\hline Hawkes Bay & , &, & 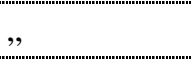 & & & \\
\hline Hutt & , & $"$ &, & , &, & \\
\hline Nelson &, & , &, & 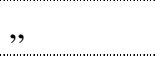 &, & \\
\hline Christchurch & 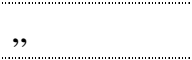 & & $\because$ & & & \\
\hline Timaru & 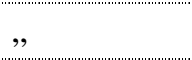 & & 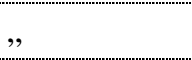 & & & \\
\hline \multirow[t]{2}{*}{ Dunedin } &, & & 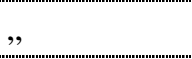 & & & , \\
\hline & 12 & 8 & 12 & 6 & 5 & 1 \\
\hline
\end{tabular}

ETT nurses are involved in patient education and health promotion in 12 hospitals. Eight out of $12(66.6 \%)$ hospitals report that their ETT nurses are involved in the formal interpretation of tests. Five (41.6\%) hospitals report that ETT nurses perform cardiac examination. Six (50\%) hospitals report that their ETT nurses directly refer for other tests. One $(8.3 \%)$ hospital reported that their ETT nurses are involved in the Heart Failure Clinic. 
Question 14: Does your area apply the guidelines (for supervision of Exercise Tolerance Testing) as set down by the Cardiac Society of Australia and New Zealand?

Table 12: Hospitals that apply CSANZ Guidelines

\begin{tabular}{|c|c|c|c|c|c|c|c|c|}
\hline Hospitals & Yes & No & Hospitals & Yes & No & Hospitals & Yes & No \\
\hline Whangarei & $"$ & & Gisborne & , & & Nelson & 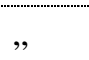 & \\
\hline North Shore & 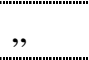 & & Taranaki & 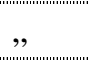 & & Grey Base & & $\ldots$ \\
\hline Waitakere & 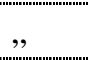 & & Hawkes Bay & 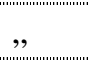 & & Christchurch & 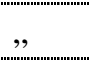 & \\
\hline Auckland & 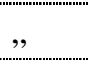 & & Whanganui & & $\ldots$ & Timaru & 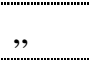 & \\
\hline Middlemore & $"$ & & Hutt & , & & Dunedin &, & \\
\hline Whakatane & 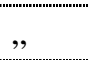 & & Wellington & 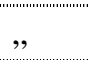 & & Southland &, & \\
\hline Waikato & " & & Nelson & , & & & & \\
\hline
\end{tabular}

Eighteen hospitals out of $20(90 \%)$ reported that they apply CSANZ guidelines as a reference point. Two hospitals reported that they did not.

In summary, responses were received from 20 public hospitals that provide descriptions about work place practices and simple demographic data regarding each service. Responses show that nurses have only been involved in the supervising role in New Zealand since 1996. Simple figures and tables represent information that provides a broad overview of ETT nurse activity in New Zealand.

\section{Interview with the Clinical Director of Cardiology}

The fifth participant was the Clinical Director who identified the need for change as the primary precipitant to how nurses became involved in the service. He had been in his role as Clinical Director for at least one year but had worked in Cardiology at this regional tertiary hospital for a number of years. He defined his role as having overall responsibility for that service. In context of having that overview, he described his style of leadership as reflective of the huge demands placed on services. , Sadly, one tends to be reactive these days to issues rather than proactive which is the nature of health services in $2009 f$ (Transcript D, 2009, p. 1). He reflected that the system of involving doctors in the ETT service as supervisors was less than effective to deal with the increasing volumes of patients requiring an exercise tolerance test. He recalled that nurses just started into the role in an ad-hoc way with no real training. He added that when the doctors were involved previously as ETT supervisors, , no one had any real expertise in itf (Transcript D, 2009, p. 2). He believed that extensive clinical experience 
and genuine interest expressed by the ETT nurses had facilitated their arrival into the ETT service. The opportunity for nurses to become involved in the service also coincided with a significant managerial push to expand the service. The result was that the ETT service as it was originally was, changed to being a $\bullet$ nurse-led service•

The Clinical Director recalled that there was considerable resistance from the professional body for Cardiology about the proposal to involve nurses in supervising ETTs, as this was considered contrary to traditional guidelines and had always been a medical role. , It was part of the duties of a doctor, because it had always been part of a duties of a doctor, not that anyone had any real expertise in itf, (Transcript D, 2009, p. 2).

Utilisation of the doctors• time was also a precipitant to change, we either needed to provide more house surgeons to become dedicated, the other thing was that the house surgeons were rotating every four months and they were rotating in and out of Cardiology and there was never any opportunity to get good at the taskf, (Transcript D, 2009 , p. 2). This participant reported feeling that the ETT nurses are an essential part of the service which has allowed for a greater flow of patients in regards to more tests being performed, , Itfs made it possible to function, I think without the nurses input, the whole system wouldfue come to an absolute haltf, (Transcript D, p. 4).

The Clinical Director was emphatic that experience was an important factor contributing to expertise in the role. He stressed that it is, important to know when you can take a risk and when you cannot, you canft train that, you canft learn that in a book or anybodyfs guidelines, itfs the fact of doing, itfs being experiencedf, (Transcript D, 2009, p. 4).

This participant reflected that there were some concerns expressed when nurses initially became involved with the ETT service, but then qualified further, , maybe not so much at *** Hospitalf, (Transcript D, 2009, p. 5). He attributed this to the fact that medicine is , very, very conservativef, (Transcript D, 2009, p. 5). This participant felt that , no one group is the repository of truth and that individuals become experts in their roles by performing the role, the academic part is only considered to be minorf, (Transcript D, 2009, p. 6). 
In regards to the future and whether the ETT role might develop further, he felt consulting the ETT nurses would be an important first step fthe first people you would ask are the nurses who have experience of exercise testingf. (Transcript D, 2009 p. 5). . He expressed concern about how the service responds to numbers and what expeditious ways of sorting them out, might exist. This participant identified that the ETT service now has considerable experience to consider risk stratification further and referred to the advent of chest pain clinics. , Wefre probably mature enough now to be able to risk stratifying patients further in that we do high risk and low risk, . A truly low risk person can probably be turned around in the emergency department and be sent home with an appointment for an exercise test $\bullet$, (Transcript D, p. 4). He identified financial constraints as a reason for shifting from a traditional model of care to consider team-led services where he envisaged nurses being involved as the primary care providers, ,I think it will be a team led service, I think nurses will be very important in being primary care providersf, (Transcript D, 2009, p. 5). Finally this participant acknowledged and looked forward to the possibility of a review and flexibility around protocols and standards , They are there to be modified if our experience is that itfs not workingf, (Transcript D, 2009, p. 6).

In summary, similar themes emerged as with the nurse interviews, except that they were more specifically related to when medical staff were supervising ETTs and precipitants to nurse involvement. Other themes reflected on the service as it currently is involving nurse supervisors and future service development possibilities. These reflections gave some insight into how changes came about. In his reflection, the Clinical Director of Cardiology was able to compare and contrast differences about the service related to the period of pre and current nurse involvement. He acknowledged that there was some anxiety initially about nurses taking on this role, but that these perceptions had became more positive over time. He expressed opinion about influences to developing in such a role such as •doing• the job to gain experience. He acknowledged that the service had changed as a result of nurse involvement and will continue to change as a result of future service development and consumer expectations. He commented that the service as a whole has improved as a result of having dedicated ETT nurses. His perceptions were that nurses will continue to contribute to future service development of cardiac services but as primary care providers in more of a team led approach to service delivery. 


\section{Local Questionnaire}

11 cardiac technicians who work along-side the ETT nurses at ***Hospital completed a questionnaire about the ETT service and nurse involvement.

Question 1: How many years have you been working at ***Hospital?

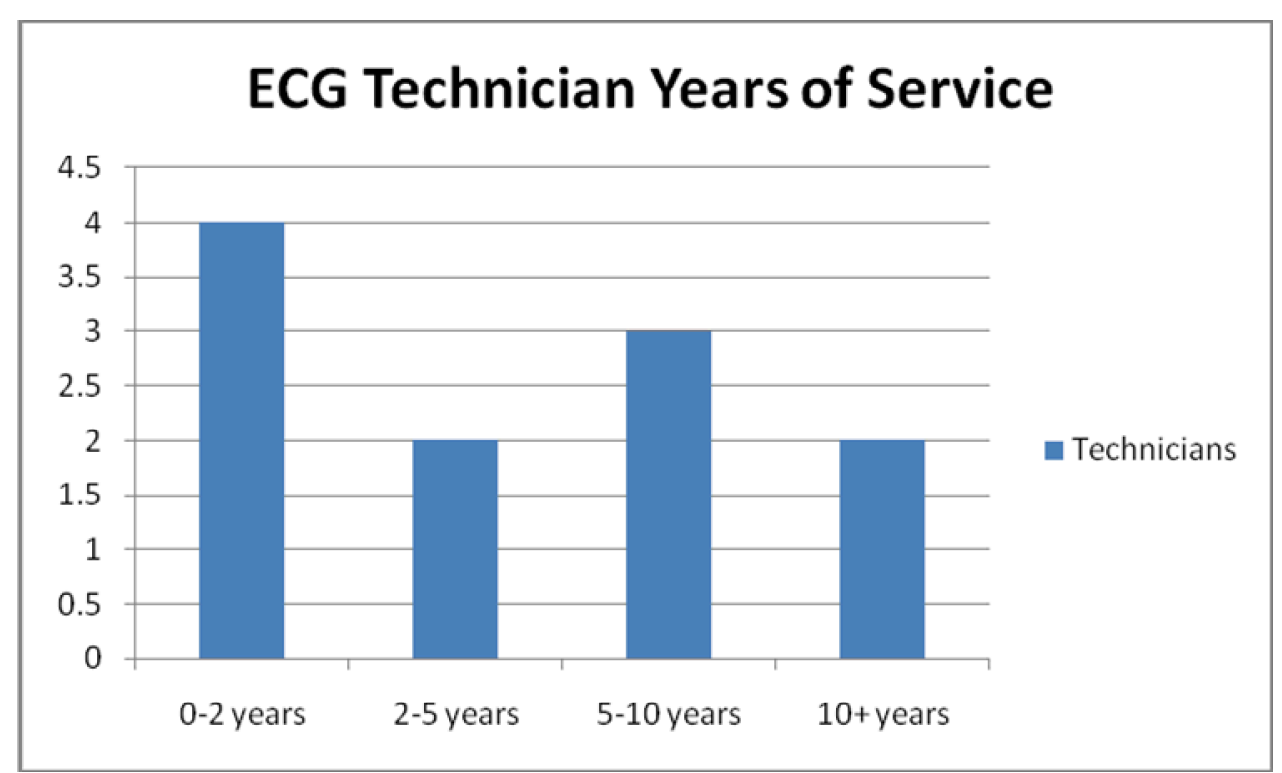

Figure 4: Years of service

Six of the technicians had been working between zero and five years. Three technicians had been working for between five and ten years. Only two technicians had been working for ten or more years $(18.1 \%)$.

*Nurses had been involved with the ETT services for the last six to seven years (20032010). 
Question 2: Have you been working at a time when there were no dedicated ETT nurses and a doctor supervised tests?

Six out of $11(54.5 \%)$ technicians had been working for five or more years and during the period of pre nurse involvement as ETT supervisors.

Question 3: If yes, what were the strengths and limitations of the way the ETT service was delivered when doctors supervised tests?

Table 13: Strengths of doctor supervision

\begin{tabular}{|l|}
\hline Medical presence in emergencies \\
\hline Medical knowledge \\
\hline Ability to admit patients and prescribe drugs \\
\hline Greater scope in conveying patient information \\
\hline Assessment skills \\
\hline Scope to discuss results \\
\hline
\end{tabular}

The technicians described a range of responses, identifying strengths and limitations of the medical supervision of ETTs. There was no predominate answer.

\section{Table 14: Limitations of doctor supervision}

\begin{tabular}{|l|}
\hline Unavailability/ Delay in clinic time \\
Limited ETT experience \\
Limited to specific teams \\
Being called away to emergencies \\
\hline
\end{tabular}

The technicians described a range of responses related to limitations of medical supervision of ETTs. The most common response was unavailability and delay in clinic time as a consequence. All technicians who worked in the department pre ETT nurses involvement identified this limitation. 
Question 4: What are the strengths and limitations of the way the ETT service is delivered now that nurses are supervising ETTS?

\section{Table 15: Strengths of nurse supervision}

\begin{tabular}{|l|l|l|l|}
\hline $\begin{array}{l}\text { Strong focus } \\
\text { Good pre test } \\
\text { familiarisation }\end{array}$ & $\begin{array}{l}\text { Clinics run on time } \\
\text { ETT nurse referrals }\end{array}$ & Eelpful & Eonsistency \\
\hline Emergency orientated & $\begin{array}{l}\text { Good nurse/tech } \\
\text { relationships }\end{array}$ & Cardiology focused & Patient safety focus \\
\hline $\begin{array}{l}\text { Fulfils all paper work } \\
\text { More efficient }\end{array}$ & $\begin{array}{l}\text { Well defined roles } \\
\text { Good ETT/ECG } \\
\text { knowledge }\end{array}$ & Constant presence & \\
\hline
\end{tabular}

The technicians identified a range of responses related to having nurses as ETT supervisors. The most common responses were good team relationships, clinics running on time and good ETT/ECG knowledge. These responses reflect the advantages to the service by having a $\bullet$ dedicated personnel• such as an ETT nurse who is assigned to the clinic for the day.

\section{Table 16: Limitations of nurse supervision}

\begin{tabular}{|l|}
\hline Nurses have to consult with medical colleagues \\
Not able to prescribe drugs \\
Not experts in ECG analysis \\
Unable to make final call \\
Do not supervise high risk patients on their own \\
Decision making abilities in emergencies \\
Clinical judgement in certain situations \\
\hline
\end{tabular}

The technician identified a range of responses related to limitations of nurse supervision. The most common response was contacting medical staff in emergencies and for further medical direction. Three technicians did not identify any limitations with nurse supervision. 
Question 5: How do you see the ETT service developing in the future?

Question 6: What would this mean for the role of the technicians?

Question 7: What will this mean for the nurses?

Table 17: Possibilities of service development and implications

\begin{tabular}{|c|c|c|}
\hline $\begin{array}{l}\text { Possibilities of Service } \\
\text { Development }\end{array}$ & Implications for technicians & Implications for nurses \\
\hline $\begin{array}{l}\text { Introduction of a technician- } \\
\text { led service }\end{array}$ & Will need extra staff & Nurses role becomes obsolete \\
\hline Need for more room & $\begin{array}{l}\text { Technicians will need a higher } \\
\text { emergency certificate }\end{array}$ & Nurses role increases \\
\hline $\begin{array}{l}\text { More flexibility around } \\
\text { guidelines }\end{array}$ & More responsibility/training & Nurses role remains the same \\
\hline Longer hours for the service & Taking on the supervisory role & Nurses role gradually decrease \\
\hline Extension of weekend hours & Working longer hours & Greater decision making \\
\hline $\begin{array}{l}\text { Separate rooms for } \\
\text { inpatients/outpatients }\end{array}$ & & $\begin{array}{l}\text { Nurses may have to advance } \\
\text { training }\end{array}$ \\
\hline No change & & $\begin{array}{l}\text { Nurses may have to familiarise } \\
\text { more with equipment }\end{array}$ \\
\hline Greater demand & & Demand for more ETT nurses \\
\hline
\end{tabular}

Technicians identified a range of responses regarding possibilities for the ETT service in the future and implications for both technicians and the nurses. The most common response regarding the service as a whole is that it may be a technician $\dagger$ led service. The most common response in regards to implications for technicians was increased responsibility. There were mixed responses to implications for nurses and these appeared to relate to responses regarding possibilities for future service development. 
Question 8: What role do technicians play in the role development of nurses who supervise exercise tolerance tests?

\section{Table 18: Technician contribution to nurse's role development}

\begin{tabular}{|l|}
\hline Multidisciplinary training and teamwork \\
Involvement in competency assessments \\
Initial development \\
Help familiarise with technical equipment and protocols \\
Sharing of experience \\
Collaboration re analysis \\
No contribution
\end{tabular}

Technicians identified a range of responses to the question asking whether they had contributed to the nurse's role development. The most common responses were teamwork and collaboration. Only one technician thought that they did not play any role in the role development of ETT nurses. One technician thought that they should be assessing ETT nurses in their competencies.

\section{Table 19: Additional comments}

\begin{tabular}{|l|}
\hline Nurses supervision has improved the service \\
Technicians enjoy working with dedicated nurses \\
Importance of each discipline appreciating each other \\
\hline Nurse supervised tests are safer than doctor supervision \\
\hline
\end{tabular}

Technicians were asked to make a final comment regarding nurses working for the ECG service where ETTs are conducted. A range of responses were identified by four technicians only. Those comments were positive about nurse involvement and related to the collaborative nature of relationships between the ETT nurses and ECG technicians. There was a consensus that the service had improved since nurse involvement.

In summary, just over half of the technician group had been working in the department prior to the introduction of cardiac nurses supervising exercise tolerance tests. Whilst identifying limitations in the scope of the nursing role such as not having prescribing rights etc, generally, the technicians felt the service had improved. Constancy and lack of disruption has meant that the service has run more efficiently. Technicians identified the interpersonal aspects such as the developing relationships as factors that enhanced the overall service. In the context of the current scope for the ETT nurse role, 
technicians identified limitations related to a reliance on medical staff for final clinical decisions. One technician identified ETT nurses as not being experts in ECG analysis and another commented on limitations in the nurse $\bullet$ clinical judgement. Overall, the technicians saw the potential for the service to both expand and change and identified implications for both ETT nurses and themselves. Technicians identified their contribution to the nurse s role development primarily in the context of their initial orientation and as collaborative partners. Technicians reported positively about work along-side nurses and that the service had improved with their involvement. 


\section{Chapter Five: Discussion}

\section{Introduction}

This study has provided the first •stock take• of nurses supervising ETTs in the public health sector, New Zealand. This study was undertaken to explore the process of role development for nurses who supervise ETTs. The rationale for selecting this process was to gain further understanding about the factors which have influenced the emergence of this clinical role for nurses. Those factors include both historical and socio-political influences as well as interpersonal and professional development within the nursing discipline as a whole. I utilised mixed methods to obtain data as this was necessary to place individual nurse•s experiences in context with other ETT nurse experiences and to add breadth to the subject matter. This study offers a new perspective on the international literature and serves as a platform for future studies. This chapter describes selected key issues that have arisen from the findings that warrant further discussion. Some of these issues may also form the basis for further research inquiry. Both strengths and limitations of the study are acknowledged alongside implications for nursing practice. Results from this New Zealand study show that the process of role development for cardiac nurses who supervise ETTs has been evolutionary and variable. In addition the experiences reported by nurse participants describe a developmental process which is similar to experiences described by nurses in other expanding and advanced clinical roles. Clinical experience; knowledge; decision making; autonomy and collaboration are some of those factors contributing to that process.

\section{Evolution}

Pressures on services to expand and become more efficient were a significant influence to the change of supervising personnel. The cardiac technicians in the local setting reported frustration with the way clinics were being run, when supervised by doctors. This was because the frequency of rotation was high and doctors had dual responsibilities. Delays in getting doctors to supervise ETTs meant that other clinics were delayed as a consequence. These factors were contributory to the solution of having •dedicated $\bullet$ nurses to supervise ETTs. Having to consider more expeditious ways of dealing with the increasing volume of patients requiring assessment was considered an increasing priority. Lem, et al., (1985) described cost containment as one of those pressures that led to looking at the suitability of nurses supervising ETTs. The move to 
establish dedicated personnel to supervise ETTs was seen as a significant influence to the evolution of the emerging ETT nurse role.

While there was initial concern expressed about nurses adopting this role in New Zealand, they have continued to increase in numbers, particularly between 2000 and 2007. This demonstrates an increasing acceptance by doctors to nurses working in a previously medical delegated role. It could also mean that efficiency of nurses in this role has shown to be a cost saving for organisations. Cardiac nurses have been working in the ETT nurse role internationally for at least 36 years and thus are an established role for nurses (Lem, et al., 1985). During this period, there was considerable debate about whether nurses were safe to continue supervising tests and under what conditions. Consensus about guidelines was agreed upon by cardiologists who specified that this role should remain under medical responsibility. This was despite growing evidence that nurses have a proven high safety record in regards to ensuring patient safety (Lem, et al., 1985; Maier, et al., 2008; Zecchin, et al., 1999). Those guidelines have subsequently relaxed to allow other health professionals to supervise without direct medical supervision. Ironically, there was no evidence that cardiac nurses had been invited to contribute to those consensus statements around personnel requirements.

The rising incidence of cardiac disease globally has put considerable pressure on services to consider different ways of managing patient workload. One result is that, cardiovascular science within cardiology has shifted to focus more on the technological and invasive procedures such as angiography and angioplasty. The advent of chest pain units were a precursor to nurses taking on new and additional roles as this freed up doctors to concentrate on the invasive procedures. One participant identified that despite this shift, the idea of nurses supervising ETTs was more of a solution to a less than effective system utilising doctors. Despite this, the introduction of the ETT nurse has been seen as an effective strategy to deal with increased patient workload. The advent of chest pain assessment units was set up primarily for those reasons where nurses were able to offer a brief total package for $\bullet$ low risk $\bullet$ patients. These packages include patient education and health promotion alongside an opportunity to have an ETT. , Chest pain clinical pathways have been designed to reduce the possibility of missing an infarction while facilitating early discharge of low risk patientsf (Aroney, Dunlevie \& Bett, 2003, 
p. 370). All the hospitals where nurses are supervising ETTs reported that those nurses are also involved in health promotion and patient education as part of the ETT role.

A global shortage of health professionals is cited as an important reason to consider more effective ways of utilising health workers, particularly with growing demands on services. These shortages also, allowed nurses to adopt additional clinical tasks in service provision, provided they had undertaken appropriate training and had achieved competence $f$ (Srivastava, et al., 2008, p. 2672). In looking for solutions, experienced cardiology nurses were seen as the ideal personnel who could safely separate low and high risk patients. This was because of their experience dealing with chest pain symptoms and acute coronary syndromes. The process of risk stratifying though has largely been resolved as a consequence of chest pain algorithms which define patient pathways. Nurses were also considered to have some advantages over other disciplines because of their holistic approach towards patients. , They address the social and psychological as well physical elements of the patient•s condition which enables the -one-stop• clinic to cover all aspects of the effect of chest pain on a patient $f$ (Pottle, 2005, p. 231).

Some of the literature describes a devolvement of medical roles with the advent of the ETT nurse. It is more accurate to suggest that partnerships have occurred as a result of nurses working with doctors, and that nurses have naturally gravitated to roles that they are already easily positioned for. As an example, cardiac nurses are commonly trained and experienced analysing ECGs and are competent and qualified to respond to any emergencies. The ability to prescribe medications is one limitation but slowly many services are moving towards treatment protocols that include administering approved medications. Examples include where nurses may administer thrombolytic medications for acute myocardial infarctions (Thompson \& Stewart, 2002). The only time where ETT nurses may be required to administer medications is during a sudden and adverse event of which advanced certification in resuscitation covers this. Despite the introduction of nurses as ETT supervisors, they are still constrained in their roles by medical authority and influence related to treatment prescriptions. Responses from participant interviews and the technician survey indicated that there is reliance on doctors for final decision making and this is a limitation. One participant acknowledged that utilisation of doctor's time was a major precipitant to nurse involvement. There is 
some evidence that nurse•s time has made an impact on service delivery as evidenced by the more efficient running of clinics. Participants perceived though that hospital politics were a barrier to their progression within the role.

\section{Variability}

Variability between ETT nurse roles were seen nationally in the areas of length of time in the role; scope within the role; training and assessment and level of autonomy. Nurses have been reported to be supervising ETTs since 1979 in Australia (Zecchin, et al., 1999), and yet my data shows that cardiac nurses have only been supervising ETTs in New Zealand since 1996. New Zealand has a small population coupled with unique geographical characteristics and this may explain the relatively short history of nurse involvement in ETT services alongside other factors such as medical and nursing cultures. The national questionnaire reports that 49 nurses are working as ETT nurses in 12 of the 19 hospitals in New Zealand. National data does not take into account the number of nurses who have trained as ETT nurses and then subsequently left services nor ETT nurses working in the private sector. Finding appropriately trained staff may be an issue in smaller centres, including access to a cardiologist. Having access to a cardiologist remains a recommendation in international guidelines.

Data from the national New Zealand survey show the predominant trend is that cardiac nurses are supervising ETTs in most cardiac centres. As a consequence this role could be described as a specialty area with a specific focus for nurses. The exceptions are Auckland; Whakatane; Gisborne, Wellington and Grey Base hospitals where nurses are reported to be not supervising ETTs. It is unknown why nurses are not supervising ETTs in some of these hospitals although a lack of qualified staff might explain the type of personnel in smaller hospitals. In addition, smaller hospitals are only providing ETT service for between two and three days a week. This may be because those days coincide with a visiting cardiologist. Waikato and Christchurch Hospitals are nurse-led in their services and run a seven day ETT service. Other centres with a larger pool of ETT nurses such as North Shore and Hawkes Bay Hospitals are only running five day a week services.

Considerable variability has been described in titles and status of ETT nurses internationally. Initially ETT nurses were employed as nurse specialists and educational 
qualifications were reflective of nurses engaged in post graduate education (Lem, et al. 1985: Pottle, 2005: Maier, et al., 2007). The ETT nurses at one regional hospital reported that nurse specialist status should be a prerequisite experience to working in the ETT role. One participant in another regional hospital expressed considerable surprise that the level of responsibility was not reflected by a more advanced level of practice title. Describing a specialty area of nursing can raise some interesting questions as to whether the focus of the role is sufficient enough for ETT nurses to be recognised as specialist nurses. Some of the responding hospitals reported that their ETT nurses are already in nurse specialist roles but that those individual nurses were also performing other specialty roles in addition to supervising ETTs. Respondents from one regional hospital also reported that having a post graduate qualification was a desirable prerequisite qualification in order to be an ETT nurse. None of the respondents thought that an ETT nurse should have Masters Degree. This is in contrast with early literature around supervising ETT personnel that described nurses as having advanced qualifications to a post-graduate level (Lem, et., 1985). In New Zealand a specialist nurse is one who is practising at a particular level and a nurse practitioner refers to , expert registered nurses who work within a specific area of practice incorporating advanced knowledge and skillsf (New Zealand National Nursing Organisations, 2009). In contrast a registered general nurse can practice in a wide variety of areas up to a level of advanced practice. The term •expanded practice more appropriately fits with an ETT nurse who practices with increased autonomy and responsibility whilst constantly expanding their own role.

Variability amongst practices within the ETT nurse•s role was seen nationally. ETT nurses in eight New Zealand hospitals reported that they were formally interpreting results of tests. This is an extension to beyond just knowing when to stop a test. Formal interpretation includes making final analysis, ongoing recommendation and conveying this information to patients. Historically, this has been a medical responsibility. Nurses in six of those eight hospitals took responsibility for referral for other tests. The national data also reports variability in the type and number of other tests in addition to ETTs. These included involvement with dobutamine and persantin stress echo, tilt table tests and medical vascular clinics. ETT nurses in two hospitals were reported to be involved in nurse-led clinics. ETT nurses were also reported to be involved in a number of tests 
that technicians are commonly involved with such as holter monitor analysis and resting ECGs.

Cardiac technicians are reported to be working with nurses in only five of the hospitals surveyed. Those hospitals are larger centres and therefore have a greater pool of personnel. Nurses were reported to be working with medical staff in other hospitals. Nurse participants who were interviewed commented on the collaborative nature of their relationship with the cardiac technicians. They also acknowledged that they had learnt a great deal from the technicians around the process of supervising ETTs. Both the nurses who were interviewed and technicians surveyed commented on the positive aspect of team work and the collaborative way in which they worked together. This is in contrast with the perceived lack of established relationships between medical staff and technicians prior and was due to a high rotation in medical staff. The technicians identified many advantages of having nurses supervising tests and these included; strong focus; increased efficiency; constant presence and positive relationships. The limitations were seen as ETT nurses having to rely on doctors for •final call• in tests and emergencies. It is unknown whether the combination of ETT nurse and technician personnel contributes to some of the quality aspects of patient outcomes, including quality and consistency of tests. There are of course distinct differences in scope of practice between medical, nursing and technician personnel.

In expanding and advanced roles nurses are seen to be, developing skills beyond the recognition of abnormalities and are moving towards independent diagnosis and management $f$ (Riley, et al., 2005). Despite the advances seen in cardiovascular nursing, a mixed picture is seen in the literature and this New Zealand study. ETT nurses in five New Zealand hospitals were reported to be assessing patients by conducting full cardiac examination. No nurses were working alone and independently in any New Zealand hospital. In contrast, one Australian publication describes a clinical setting where nurses are solely supervising tests although still within the hospital setting (Zecchin, et al., 1999). Several of the respondents reported themselves as being in advanced roles but for the most part this national data reports on the degree of expansion that ETT nurses are practising to in each hospital nationally.

There was some minor variation seen in the national data in regards to processes in place for training and competency assessment. Data from the national questionnaire 
show that two hospitals do not have training documents and two hospitals are in progress of developing some. Three hospitals are reported to not have documents for competency assessment. Nurses had been working at those hospitals for between four and ten years. It is important to note that quality documents refer to those that have been

authorised by a quality committee. Smaller centres may lack those inter-professional structures regarding quality processes and thus it is possible that training was very informal and $\bullet$ on the job• Participating hospitals were not asked about where they sourced apparent training documents and what process did they have alternatively in certifying cardiac nurses to supervise ETTs. All hospitals except two reported referring to the Cardiac Society of Australia and New Zealand as a reference point for guidelines. The issue of formalised training and competency assessment remains largely unresolved in New Zealand. This might account for why nurses are not working in the ETT role in some hospitals. In addition there appears to be no national body coordinating ETT nurses in the public sector although there is a voluntary professional sector representing the interests of affiliates within the Cardiac Society of Australia in New Zealand.

\section{Developmental Process for the ETT Nurse}

Collaboration and a team based approach are perceived to contribute to better patient outcomes although little has been written about this aspect in regards to the ETT setting (Leonard, Graham \& Bonacum, 2004; Clements, et al., 2007). Participants who were interviewed reported the positive aspects of collaborating with the cardiac technicians Collaboration between differing disciplines involves perspectives that are shared from differing and similar view points but primarily has the same patient goal. Whilst both the nurses and technicians identified clear defined boundaries in terms of clinical responsibility, there was a strong sense that shared decision-making enhanced the service. Some of the nurse participants alluded though to conceding some of their autonomy in deference to more expert knowledge of the technicians around ECG knowledge, particularly when they were new in the role. The clinical director has suggested that the future of patient care will be team based and that nurses will undoubtedly offer a valuable contribution to service delivery. Collaboration requires that team members are conscious of team process and the development of relationships occurs through communication and education (personal philosophy). 
Autonomy was described as an important precipitant to working in the role by the nurses interviewed. Autonomy can be seen as the freedom and mandate to make decisions which have clinical impact on patients or the service as a whole (personal philosophy). Autonomy can also be seen as a distinguishing trait of expanding and advanced roles. Considerable literature has been written about professional satisfaction from clinical roles where there is a high degree of autonomy (Daly \& Carnwell, 2003; Furlong \& Smith, 2005). However, in this setting, the degree of autonomy for individual ETT nurses was not measured. Increased autonomy is also associated with increased skills in complex decision making and collaboration with others. Whilst the participants only touched on this briefly, this was identified as an important aspect of working in the role and contributing to individual role development. One participant also felt that nurses who worked in patient wards were prevented from being autonomous in practice and this was an incentive to working in the ETT role. Despite participants expressing autonomy as an important precipitant, they saw their autonomy limited by doctors who still had overriding responsibility for tests. This limitation was also noted by the technicians who commented on the differences between the two disciplines. International literature provides some evidence that nurses who are working at advanced level are taking final responsibility for the outcome of ETTs and are making subsequent referrals for other investigations (Pottle, 2005). Six respondents reported that ETT nurses in respective hospitals are making referrals for other investigations.

The nurses described their induction as a process of just beginning to supervise tests and that they were largely guided by the cardiac technicians. The clinical director also identified that doctors also had no formalised training and were probably reliant on the technicians for technical and test procedure advice. Prior to nurse involvement doctors were called to supervise tests only as required and the medical rotation of doctors was high. The consequence was that no one doctor has developed any real expertise as reported by one of the participants interviewed. The result was that the level of experience amongst doctors was variable. Whilst the introduction and initial training for nurses was very ad hoc, nurses had more opportunity to familiarise in a dedicated role. The introduction of nurses supervising ETTs resulted in less doctors having experience in some areas and this was a visible change in roles. 
All the participants identified anxiety beginning in their role because they assumed that the external perception saw nursing involvement as still experimental. Generally, nurses who enter into new clinical roles engage in some form of mentoring in the initial period. In this study, nurse described that they began their development into the role on their own and in an ad hoc way. The participants identified that accumulative experience in this setting contributed to their increasing sense of confidence which facilitated integration into the role. The clinical director also echoed that experience comes from -doing and that there were barriers to learning technical aspects from a text book. The concept of confidence, experience and expertise are interlinked closely in specialty areas. Participants described individual confidence grew as a result of making the right decisions and increasing exposure to differing clinical situations. None of these participants described a formal process of critical reflection and instead described informal discussions with the technicians. There is a consensus that nurses entering into this role have appropriate cardiology experience. Defining exactly what experience is most useful can be difficult because of the unpredictable nature of the tests and variation in patient characteristics. Experience comes not only through clinical practice and workplace relationships, but through an engaged process of ongoing learning.

One of the crucial factors identified by participants who were interviewed is the concept of $\bullet$ knowing when to stop a test. This was reported by cardiologists as an important decision- making skill to have, particularly if the tests are to have clinical credibility and ensure a high level of patient safety (Fuller \& Movahed, 1987 cited in Franklin, et al., 1997). In addition, knowing when not to commence a test relies on the supervising personnel being very aware of test protocols and understanding implications of test variables (Ramamurthy, Kerr, Harsha \& Tavel, 1998). Nurses also reported confidence and a sense of knowing came from repeated exposure to tests and experience with responding to adverse events. Diminishing concentration though, was seen as one disadvantage supervising tests continuously and this was accentuated further by environmental limitations and lack of sufficient breaks. One nurse described the importance of making decisions under an unpredictable and sometimes constant pressure.

Developing expertise as a result of ongoing experience has been an important progression for those participants regularly supervising tests. Currently there is no way 
to measure the level of expertise in the actual role. All ETT nurses are required to have regular recertification of advanced resuscitation skills but there is no national competency reassessment process. The national data shows that ETT nurses in only five hospitals thought it was important to have competency update days. Nurses might argue that there are a variety of ways to provide evidence of ongoing competence which include both hours of clinical practice and ongoing education for registration. ETT nurses in eight of the hospitals from national data reported that attending relevant cardiology study days was important. Access to a centre that can facilitate such days may be an issue in New Zealand. ETT nurses in two hospitals reported that ongoing training for the role was done with doctors.

\section{Implications for Clinical Practice}

Data from this study show that although the role is relatively new in New Zealand, the actual role for ETT nurses has not evolved further. There is no evidence that ETT nurses are increasingly having more autonomy than other registered nurses in other areas of practice with a specialised focus. While their title is more widely recognised, there is no evidence that this a protected title as is for other nurses who work in specialist areas. One could argue that ETT nurses are not performing beyond the expansion of the broad boundaries for a registered nurse. Nurses who were interviewed acknowledged that nurses are forever changing and adapting to service demands. Having increased autonomy and authority might change the status for ETT nurses but ETT nurses themselves would have to work collaboratively with each other to create a policy on national standards. The purpose of this would be an opportunity for ETT nurses collectively to decided how expanded the role might be and whether clinical indicators determine specialist status.

Establishing some consensus about training and competency assessment for ETT nurses in New Zealand may be fraught with difficulty. While a national programme would be expected to provide greater clarity and uniformity in service delivery, it may unintentionally prevent nurses from working in this role in smaller centres. It is important that any national programme does not impose rigid guidelines that would cause restrictions and a lack of flexibility in the more rural areas. The benefits of having an established training programme may assist in breaking down barriers to accepting nurses in this role. One of the implications of lack of consistency is that the ETT role 
does not evolve further and individual positions are reliant on regional support from respective organisations.

Developing a national framework will also provide some credibility in the international cardiovascular arena. One of the notions about nurses who are in advanced or expanded roles is that they are reflexive to the needs of a community (Holloway, Baker \& Lumby, 2009). It is recognised now that nurses are providing increasing leadership in primary health strategies and a team approach in tertiary services (Hughes, 2006; Callaghan, 2007). One participant who was interviewed expressed some enthusiasm for the role to develop further and emphasised that there were real risks in maintaining the status quo. Another participant reported that ETT nurses could make significant contribution to future service development if they were consulted. A lack of consultation might mean that nursing contribution is not factored into the total real cost of service delivery.

One of the possible dilemmas in having a nationally accredited training programme for ETT nurses is that $\bullet$ one size does not fit all•. The data shows that most of the cardiology centres are in the North Island where the population is greater although some centres such Whangarei and Gisborne are geographically isolated (National Health Committee, 2010). Geographic isolation is one of the factors perceived to be contributing to health work force shortages (Goodyear-Smith \& Janes, 2005). Three New Zealand hospitals rely on one ETT nurse and three only have two ETT nurses. In general most of the hospitals had five nurses in order to provide a five to seven day service. These numbers are relatively small if annual, sick and education leave are to be taken into account. Smaller centres may very well rely on nurses who are sharing a variety of roles within a hospital. Nurses at smaller centres may have to train outside their areas and there would be a cost factor associated.

There are advantages and disadvantages in standardising clinical practice for ETT nurses. Uniformity in the standards of tests is one benefit. Standardised competency assessment certificates would offer portability for ETT nurses between hospitals. Having an established training programme will undoubtedly make induction for new ETT nurses easier because there would be established training process and documents. Development of consensus statements around level of practice may also serve to position the ETT nurse alongside other nurse specialist roles. The disadvantages may be the level of resources required to bring uniformity for ETT nurses. Currently there is 
fragmentation and lack of role definitions between ETT nurses nationally. Some hospitals have been utilising nurses for a period of time on a level similar to other registered nurse positions while some ETT nurses are working at nurse specialist level. Managers may argue that there is little evidence for promoting ETT nurses to a level where remuneration reflects a higher level of responsibility without sufficient evidence. Those hospitals surveyed did not suggest that ongoing postgraduate education be a requirement for this role. However other disciplines such as technicians and technologists are required to have a postgraduate qualification in order to lead ETT services. Nurses are working in an era where they need to demonstrate and articulate theory to practice, particularly if they are advancing in practice levels, (Donnelly, 2006). A suggestion of ETT nurses completing an accredited post graduate course may be a solution to enhance consistency in standards. Releasing nurses to undertake study may pose difficulties where services heavily rely on their presence. If ETT nurses wish to scope their role to a specific advanced level, then they need to validate their role through appropriate documentation and evidence.

There is an opportunity with the growing number of nurses who are working as ETT nurses to engage in national discussion around status, competency assessment and more boldly a career pathway within the role. Fourteen years of experience in New Zealand would suggest that nurse involvement in ETTs is no longer an experiment and that those involved in ETT services should move from debate around suitability of nurses in the role to reflection about service strengths. Some authors suggest that having consistent standards around competencies may ensure standards of safety are upheld to a high level (Riley et al., 2005). They also emphasise that it is the ongoing maintenance of competency which is important in nursing practice and not a once only certification. Part of maintaining ongoing competencies could also include a mixture of self directed learning and service related activities such as conferences and study days. Responses in the national survey reflect that ETT nurses see the relevance of attending cardiology study days and conferences. It would be interesting to conduct further research with ETT nurses at each hospital about the frequency and description of cardiology focused study days. ETT nurses from smaller centres may have difficulty accessing appropriate learning centres and liaising with other ETT nurses. Organisational support for ongoing professional development is considered important in nurturing nurses in expanded and advanced roles, particularly if those nurses are to be retained in the health work force 
(Pryse-Hawkins, 2001). This would require that managers also see the importance and relevance of ongoing professional development for nurses in those roles.

Encouraging ETT nurses to reflect on practice experience is an important part of nursing. The adoption of keeping a reflective journal and opportunity for professional and clinical mentoring will also assist nurses in ETT positions to advance clinically. Without some process of contribution to service review, ETT nurses risk being seen as lone health workers who cannot justify how they contribute to patient outcomes. Without opportunity for a national forum on the subject, ETT nurses may well lose the opportunity to develop this role further. The implication is that the ETT nursing role becomes one of many expected nursing duties.

One positive outcome from the change in supervising personnel is that ETT nurses may have a more enhanced relationship with doctors. While cardiac nurses have entered a traditionally medical area as a result of service demands, this may well have served to reduce the traditional hierarchy between cardiac nurses and doctors working in cardiology. Shared understanding of clinical goals in regards to service expectation may have resulted in more collaboration as a result of division of labour and technical skill. Participants acknowledged that their relationship with doctors improved with a sharing of knowledge over time.

Without some progression within the ETT nurse role, there is the potential that the ETT role will not evolve further. There is a real possibility that technicians will assume more responsibility in ETT services in the future as they have done in other areas. Just over half the technicians in the local survey had been working in the department prior to the introduction of nurses supervising ETTs. They were able to compare and contrast the differences and impact on the team and service delivery. The technicians also commented on the positive nature of their relationship with the ETT nurses and that the service had improved as a consequence. Despite this, some of the technicians indicated that there would be changes in the future of ETT services if demands continued. Those changes would include both an expansion of services and the possibility that technicians may very well supervise ETTs alone. Those technicians also suggested that their level of training would have to advance, particularly in the area of emergency resuscitation. The implication for nurses is that their role may become obsolete if technicians supervise tests alone. 


\section{Limitations of this Study}

While the focus of this study has been about role development for ETT nurses, the small sample size gives only a small insight into individual processes. There are limitations with results from the national survey because it is unknown whether the results reflect the total picture of ETT activity in New Zealand. A specific limitation of this study was that it did not include data from the private sector. Obtaining responses for the national survey was reliant on one person completing the questionnaire for each area. A further study with a larger sample group would be necessary to tease out the multi-layered facets to individual role development. A follow up survey with all hospitals previously surveyed might include additional questions that focus on individual responses from ETT nurses that work in each hospital. Questions might include asking about length of time in nursing and educational experiences as well as other professional influences to that particular role. In regards to gaining more in-depth understanding about individual role development, a number of additional questions may have enhanced findings from the interviews. Those questions may have included asking about specific influences to decision making and ongoing learning and development.

\section{Contribution of this Study}

This study provides some insights into aspects of role development and additional findings provide a new multidisciplinary perspective to current literature. Interviewing ETT nurses in a local setting provides an historical first story telling of their experiences and journey. This is the first attempt to gather national data in New Zealand which gives us a valuable insight into ETT services in New Zealand. This may serve as a platform for a national forum around $\bullet$ where to from here?• This is important as services will undoubtedly change and develop to meet the health needs of a population. The question will be whether external influences will contribute to the ETT nurse role evolving further or importantly whether there is impetus from within ETT nurses as a group to develop the role further?

\section{Conclusion}

The overall aim of this study was to gain greater understanding of how ETT nurses have developed in New Zealand and what their process of development has been. Considerable variability between ETT services in New Zealand was found. The variability relates to work place practices, training and assessment. A number of 
evolutionary factors help explain how the ETT nurse•s role was constructed over time. The evolutionary factors are multifactorial and include socio political and geographical influences. The process of role development for individual ETT nurses has been a journey of individual and shared learning in the local setting. A mixed methods approach provided a multi†layered and multidisciplinary perspective to understanding the factors contributing to individual development for ETT nurses. Collaborative team relationships in this study were seen as contributory to the role development for each nurse participant. Exploring individual role development provides useful insight for other nurses who may consider developing other nurse initiated services. In addition, this study offers a new perspective to the international literature about ETT nurses. Finally, the findings from this study will provide a challenge for ETT nurses in New Zealand in how they proceed forward and position themselves globally with other ETT nurses. 


\section{References}

Agrawal, S., Danbauchi, S., Goodfellow, J., Robson, S. (1999).Technician run open access exercise electrocardiography. Heart, 82, 378-382.

Aroney, C., Dunlevie, H., \& Bett, N. (2003). Use of an accelerated chest pain assessment protocol in patients at intermediate risk of adverse cardiac events. Medical Journal of Australia, 178, 370- 374.

Anonymous. (2005). Nurse-led cardiac clinics for adults with coronary heart disease. Best Practice, 9 (1), 1329-1874.

Arnold, J., Goodacre, S., \& Morris, F. (2007). Structure, process and outcomes of chest pain units established in the escape trial. Journal of Emergency Medicine, 24, 462-466.

Bobay, K., Gentile, D., \& Hagle, M. (2009). The relationship of nurses• professional characteristics to levels of clinical nursing expertise. Applied Nursing Research, 22, 48-53.

Bremer, M., Monahan, K., Stussy, V., Miller. (1998). Safety of dobutamine stress echocardiography supervised by registered nurse sonographers. Journal of the American Society of Echocardiography, 11 (6), 601-605.

British Cardiovascular Society. (2008). Clinical guidance by consensus. Recommendations for clinical exercise tolerance testing. Retrieved January 1, 2009 from http://www.scst.org.uk/clin_guidance/ETT\%20consensus\%20March\%202008.pdf

Buchanan, J. (2009). The nursing workforce and global economic recession. Collegian, 16, $1-2$.

Callaghan, L. (2007). Advancing nursing practice: An idea whose time has come. Journal of Clinical Nursing, 17, 205-213.

Cardiac Society of Australia and New Zealand. (2008). Safety and performance guidelines for clinical exercise stress testing. Retrieved January 1, 2009 from http;//www.munatha.com.au/ANZAPNM/stressGL_2006.pdf.

Clements, D., Dault., \& Priest, A. (2007). Effective teamwork in healthcare: Research and reality. Healthcarepapers, 7 (Sp), 26-34.

Crotty, M. (1996).The case of nursing research. In: Phenomenology and nursing research (pp.9-25). Australia: Churchill Livingston.

Daly, W \& Carnwell, R. (2003). Nursing roles and levels of practice: a framework for differentiating between elementary, specialist and advancing nursing practice. Journal of Clinical Nursing, 12 (2), 158-167.

Davis, G., Ortloff, S., Reed, A., Worthington, G. (1998). Evaluation of technician supervised treadmill exercise testing in a cardiac chest pain clinic. Heart, 79 (6), 613-615. 
Donnelly, G, 2006. The essence of advanced nursing practice. The internet Journal of Advanced Nursing Practice, 8 (1), 1-12.

Duffield, C., Gardner, G., Chang, A., \& Catling-Paull, C. (2009). Advanced nursing practice: A global perspective. Collegian, 16, 55-62.

Edmond, J., French, J., Henny, H., Belz, L. (2002). Prospective evaluation of a chest pain pathway at Green Lane Hospital. The New Zealand Medical Journal, 115, (1158), 103-112.

Fletcher, G., Balady, G., Amersterdam, E., Chaitman, B., Eckel, R., Fleg, J., et al. 2001). Exercise standards for testing and training: A statement for healthcare professionals from the American Heart Association. Circulation, 104, 1694-1740.

Franklin, B., Fern, A., Fowler, A., Spring, T. (2009). Exercise physiologist•s role in clinical practice. British Journal of Sports Medicine, 43, 93-98.

Franklin, B., Gordon, S., Timmis, G., \& O•Neill, W. (1997). Is direct physician supervision of exercise stress testing routinely necessary? Chest, 111, 262-265.

Froelicher, V., \& Myers, J. (2007). Manual of exercise testing ( $3^{\text {rd }}$ ed.) (pp.17-47). Philadelphia: Mosby Elsevier.

Furlong, E., \& Smith, R. (2005). Advancing nursing practice: Policy, education and role development. Journal of Clinical Nursing, 14, 1059-1066.

Gearing, R. (2004). Bracketing in research: A typology. Qualitative Health Research, 14, 1429-1449.

Gibbons, R., Balady, G., Bricker, T., Chaitman, B., Fletcher, G., Froeichlicher, V., et al. (2002). ACC/AHA 2002 guideline update for exercise testing: A report of the American college of cardiology/American heart association task force on practice guidelines (committee to update the 1997 exercise testing guidelines). Circulation, 106, 1883-1892.

Goodacre, S., Morris, F., Campbell, S., F., Arnold, J. (2002). A prospective, observational study of a chest pain observation unit in a British hospital. Journal of Emergency Medicine, 19, 117-121.

Goodyear-Smith., \& Janes, R. (2005). New Zealand rural primary health care workforce in 2005; more than just a doctor shortage. Australian Journal of Rural Health, 16 (1), 4046.

Head, M. (2009). Expanded RN roles $\dagger$ A policy perspective. Kai Tiaki Nursing New Zealand, $15(6), 25$.

Health Practitioners Assurance Act 2003, 48, New Zealand. Retrieved on August 5, 2010 from http://www.legislation.govt.nz/act/public/2003/0048/latest/DLM203312.html 
Heath, H. (1998). Reflections and patterns of knowing in nursing. Journal of Advanced Nursing, 27, 1054-1059.

Heart Foundation. (2010). General Statistics. Retrieved August 5, 2010, from http://www.heartfoundation.org.nz/index.asp?pageID=2145831169

Hill, J., \& Timmis, A. (2002). ABC of clinical electrography; Exercise tolerance testing. BMJ, 324, 1084-1087.

Holloway, K., Baker, J., \& Lumby, J. (2009). Specialist nursing framework for New Zealand: A missing link in workforce planning. Policy, Politics \& Nursing Practice, 10 (4), 270-273.

Hughes, F, 2006. Nurses at the forefront of innovation. International Nursing Review, 53 (2) 94-101.

Karnieli-Miller, O., Strier, R., \& Pessach, L. (2009). Power relations in qualitative research. Qualitative Health Research, 19, 279-287.

Johnson, R., Onwuegbuzie, J., \& Turner, 1. (2007). Toward a definition of mixed methods research. Journal of Mixed Methods Research, 1, 112-130.

Jones, M. (2005). Role development and effective practice in specialist and advanced practice roles in acute hospital settings: A systemic review and meta-synthesis. Journal of Advanced Nursing, 49 (2), 191-209.

Kane, G., Hepinstall, M., Kidd, G., Kuehl, C., Murphy, A., Nelson, J., et al. (2008). Safety of stress echocardiography supervised by registered nurses: Results of a 2-year audit of 15,404 patients, Journal of American Society of Echocardiography, 21 (4), 337-341.

Kirk, J., Turnipseed, S., Diercks, D., London, D. (2000). Interpretation of immediate exercise treadmill: Interreader reliability between cardiologist and noncardiologist in a chest pain evaluation unit. Annals of Emergency Medicine, 36 (1), 10-14.

Knight, J., Laubach, C., Butcher, R., Menapace, F. (1995). Supervision of clinical exercise testing by exercise physiologists. The American Journal of Cardiology, 75, 390-391.

Latus, K., \& Underwood, R. (2001). Clinical considerations in cardiac testing. Journal of Nuclear Cardiology, 8 (3), 410-414.

Lem, V., Krivokapich, J., \& Child, J. (1985). A nurse-supervised exercise stress testing laboratory. Heart and Lung, 14 (3), 280-284.

Lyneham, J., Parkinson, C., \& Denholm, C. (2008). Explicating Benner•s concept of expert practice: Intuition in emergency nursing. Journal of Advanced Nursing, 64 (4), 380387. 
Leonard, M., Graham., \& Bonacum. (2004). The human factor: the critical importance of effective teamwork and communication in providing safe care. Quality Safe Health Care, 13, 85-90.

Maier, E., Jensen, L., Sonnenberg, B., Archer, S. (2008). Interpretations of exercise stress test recordings: Concordance between nurse practitioner and cardiologist. Heart and Lung, (2), 144-151.

Muir, D., Jummun, M., Stewart, D., Clark, A. (2002). Diagnostic accuracy of technician supervised and reported exercise tests. Heart, 87, 381-382.

Myers, J., Voodi, L., Umann, T., Froelicher, V. (2000). A survey of exercise testing: Methods, utilization, interpretation, and safety in the VACHS. Journal of Cardiopulmonary Rehabilitation, 20 (4), 251-258.

National Health Committee. (2010). Rural Health: Challenges of distance; opportunities for innovation. Wellington: New Zealand.

New Zealand National Nursing Organsisations. (2009). Glossary of terms. Retrieved May 13, 2010 , http://www.nzcmhn.org.nz/uploads/21290/files/118085/National_Nursing_Organisatio ns_Glossary_June09.pdf_

Nursing Council of New Zealand, (2009).Nursing council to consult on extended practice for registered nurses. News Update.

Onwuegbuzie, A., \& Leech, N. (2005). Linking research questions to mixed methods data analysis procedures. The Qualitative Report, 11 (3), 474-498.

Portney, L., \& Watkins, M. (2009). Descriptive Research, In: Foundations of clinical research applications to practice ( $3^{\text {rd }}$ ed.) (pp.301-324). New Jersey: Pearson Education Inc.

Pottle, A. (2005). A nurse-led rapid access chest pain clinic- experience from the first 3 years. European Journal of Cardiovascular Nursing, 4 (3), 227-233.

Pryse-Hawkins, H. (2001). Commentary: Evolution of the nurse specialist; an unfinished business. International Journal of Cardiology, 84, 89-90.

Ramamurthy, G., Kerr, J., Harsha, D., Tavel, M. (1998). The treadmill test-where to stop and what does it mean? Chest, 115, 4, 1096-1102.

Richards, D. (1986, January). [Letter to the editor]. Heart and Lung, 15 (1), 110.

Riley, J., Brodie, L., \& Shuldham, C. (2005). Achieving competent practitioners. European Journal of Cardiovascular Nursing, 4, 15-21. 
Riley, J., Bullock, I., West, S., Shuldham, C. (2003). Practical application of educational rhetoric: A pathway to expert cardiac nurse practice? European Journal of Cardiovascular Nursing, 4, 283-290.

Ross, J. (1999). The development of the advanced role of rural nurses in New Zealand. Australian Journal of Rural Health, 7 (4), 253-357.

Sandelowski, M. (2000). Focus on research methods whatever happened to qualitative description? Research in Nursing \& Health, 23, 334-340.

Sandelowski, M. (2010). What॰s in a name? Qualitative description revisited. Research in Nursing \& Health, 33, 77-84

Smith, K. (2002). Increasing roles for nurses. European Journal of Cardiovascular Nursing, 1, 19-21.

Srivastava, N., Tucker, J., Draper, E., Milner, M. (2008). A Literature review of principles, policies and practice in extended nursing roles related to UK intensive care settings. Journal of Clinical Nursing, 17, 2671-2680.

Sheer, B., \& Wong, K. (2008). The development of advanced nursing practice globally. Journal of Nursing Scholarship, 3, 204-209.

Starks, H., \& Brown Trinidad, S. (2007) Choose your method: A comparison of phenomenology, discourse analysis, and grounded theory. Qualitative Health Research, 17, 1372-1380.

Stein, R., Chaitman, B., Balady, G., Fleg, J., Limacher, M., Pina, I., et al. (2000). Safety and utility of exercise testing in emergency room chest pain centres. An advisory from the committee on exercise, rehabilitation, and prevention, council on clinical cardiology, American Heart Association. Circulation, 102, 1463-1467.

Thompson, D., Quinn, T., \& Stewart, S. (2002). Effective nurse-led interventions in heart disease. International Journal of Cardiology, 8, 233-237.

Thompson, D., \& Stewart, S. (2002). Special editorial: Nurse-directed services: How can they be made more effective? European Journal of Cardiovascular Nursing, 1, 7-10.

Thompson, D. (2009). Meeting the challenges in cardiovascular nursing. European Journal of Cardiovascular nursing, 8, 83-84.

Wilkinson, J. (2008). Constructing consensus: Developing an advancing nurse practice role. Nursing Praxis in New Zealand, 24 (3), 17-26.

Wilkinson, J. (2008). The ministerial taskforce on nursing: A struggle for control. Nursing Praxis in New Zealand, 24 (3), 5-16.

Zecchin, R., Chai, Y., Roach, K., Speerin, R., Lindsay, G., Squire, J., et al. (1999). Is nursesupervised exercise stress testing safe practice? Heart \& Lung, 28 (3), 175-184. 


\section{Appendix 1: Information Sheet - Nurses}

\section{Role Development of nurses Supervising Exercise Tolerance Tests}

Researchers

Principal Researcher

Judith Ward

Registered Nurse

Candidate for Masters of Health Science

University of Canterbury

College of Education

Private Bag 4800

Christchurch

jaw171@student.canterbury.ac.nz

(03) 3813494

0276659714

\author{
Academic Supervisors \\ Jeffrey Gage PhD \\ Health Sciences Centre \\ University of Canterbury \\ Private Bag 4800 \\ Christchurch 8140 \\ jeffrey.gage@canterbury.ac.nz \\ (03) 3667001 ext 7401 \\ Paul Watson PhD \\ School of Nursing and Human \\ Services, CPIT \\ PO Box 540 \\ Christchurch 8140 \\ watsonp@cpit.ac.nz
}

\section{Introduction and aims of the study:}

You are invited to take part in a research study that will explore the role development of nurses who supervise Exercise Tolerance Tests (ETTs). I propose to interview the ETT nurses and the Director of Cardiology at Christchurch Hospital. I also propose to survey the ECG technicians at Christchurch Hospital and Cardiology Departments nationally. This study will contribute towards completion of a Masters of Health Science Degree. I am interested in varying perspectives about how nurses have developed in this role in a local setting. Role Development refers to the process of beginning and integrating in the clinical role of supervising ETTs. Nurses in New Zealand have been performing this role for the past approximately six years and thus their involvement in this role is relatively new. Findings from this study will contribute to the international literature on nurses in this role and may offer a new perspective.

My research question is $\bullet$ What is the process of role development for cardiac nurses who supervise exercise tolerance tests•

\section{Aims:}

- Determine what is currently known about the practice of nurses supervising ETTs

- Describe the role development of nurses who supervise ETTs in a specific locality

- Gather an interdisciplinary perspective about the role development of nurses who supervise ETTs

- Determine the extent to which nurses are involved in the supervision of ETTs within the public sector in New Zealand 


\section{Interview:}

I invite you to participate in a semi-structured interview that explores aspects of role development regarding nurses who supervise Exercise Tolerance Tests. The interview is expected to take 30 to 60 minutes of your time. This interview will be conducted in a place that is convenient to you. All tape-recorded interviews will be transcribed verbatim by myself as the principal researcher. The proposed study has been discussed with your on-line manger and permission has been given for this study to be carried out.

Only my supervisors and I will have access to this data. All recorded information and completed questionnaires will remain confidential at all times. It is hope that final findings of this study will be published in an academic journal. However, no material that could identify you personally will be used in any reports of this study. The data will be securely stored for 10 years after completion of this study and then destroyed. Individuals who are taped may have their tapes on request.

There are no immediate or direct benefits to you taking part in this study. However, your participation will contribute to a new focus around personnel who supervise Exercise Tolerance Tests.

Participation in this study is entirely your choice. Reading this information sheet does not mean that you have to take part in this study. You may withdraw from this study at any point without having to give a reason. Withdrawal from this study will have no impact on your employment.

I note that this study has been reviewed and approved by both the Upper South B Regional Ethics Committee. Reference: URB/09/08/035, and the University of Canterbury Human Ethics Committee. Reference: 2009/133.

Please contact the researcher any time if you have queries about this study and would like to discuss further.

If you agree to take part in this study, please contact Judy Ward (details provided) 


\section{Appendix 2: Consent Form - Nurses}

\section{Role Development of Nurses Supervising Exercise Tolerance Tests}

\begin{tabular}{|l|l|l|l|}
\hline English & I wish to have an interpreter & Yes & No \\
\hline M• ori & $\begin{array}{l}\text { E hiahia ana ahau ki tetahi kaiwhaka M• ori/kaiwhaka pakeha } \\
\text { korero }\end{array}$ & Ae & Kao \\
\hline $\begin{array}{l}\text { Cook Island } \\
\text { M• ori }\end{array}$ & Ka inangaro au i tetai tangata uri reo & Ae & Kare \\
\hline Fijian & Au gadreva me dua e vakadewa vosa vei au & lo & Sega \\
\hline Niuean & Fia manako au ke fakaaoga e taha tagata fakahokohoko kupu & E & Nakai \\
\hline S• moan & Ou te manaø ia i ai se faamatala upu & loe & Leai \\
\hline Tokelaun & $\begin{array}{l}\text { Ko au e fofou ki he tino ke fakaliliu te gagana Peletania ki na } \\
\text { gagana o na motu o te Pahefika }\end{array}$ & loe & Leai \\
\hline Tongan & Oku ou fiemaru ha fakatonulea & lo & Ikai \\
\hline & $\begin{array}{l}\text { Other languages to be added following consultation with } \\
\text { relevant communities. }\end{array}$ & & \\
\hline
\end{tabular}

Researchers

Principal Researcher

Academic Supervisors

Judith Ward

Jeffrey Gage PhD

Registered Nurse

Health Sciences Centre

Candidate for Masters of Health Science

University of Canterbury

University of Canterbury

Private Bag 4800

College of Education

Christchurch 8140

Private Bag 4800

Christchurch

jaw@student.canterbury.ac.nz

(03)3813494

0276659714

jeffrey.gage@canterbury.ac.nz

Paul Watson PhD

School of Nursing and

Human Services, CPIT

PO Box 540

Christchurch 8140

watsonp@cpit.ac.nz

I have read and understood the description of the above named study.

I have had opportunity to discuss this study with 
I am aware that this study contributes to completion of a Masters of Health Science Degree.

On this basis, I agree to participate in this study, and I consent to the publication of the final results with the understanding that personal information about myself may be identified by my position. However, in doing so, I would expect to review material before it is published.

I wish to receive a summary of results.

Yes $\quad$ No

I would like the researcher to discuss findings of this study with me.

Yes $\quad$ No

I understand also that I may at any time withdraw from the project, including withdrawal of any information I have given.

I note that the project has been reviewed and approved by both the Upper South B Regional Ethics Committee. Reference: URB/09/08/035, and the University of Canterbury Human

Ethics Committee. Reference: 2009/133.

I hereby consent to take part in this study:

Name (please print):

Signature:

Signature of Researcher:

Date:

(Note: A copy of the consent form may be retained by participant) 


\section{Appendix 3: Interview Guide - Nurses}

These interviews will be semi structured as individual nurses may wish to talk more in depth on themes that they have identified. Questions may include:

- How long have you been registered as a nurse?

- How long have you been working in Cardiology?

- How long have you been working as an ETT nurse?

- What interested you in wanting to be in this role?

- How did you feel in the first six months of working in this role?

- What have been the benefits to working in this role?

- What have been some of the challenges of working in this role?

- Describe important aspects to working in this role

- How do you see the nursing role fitting in with other disciplinary groups involved in ETTs?

- How do you feel about working in this role now?

- What contributed to your development in the role?

- How do you see your role developing in the future?

- Would you like to make any final comments? 


\section{Appendix 4: Information Sheet - Clinical Director of Cardiology}

\section{Role Development of nurses Supervising Exercise Tolerance Tests}

$\underline{\text { Researchers }}$

\section{Principal Researcher}

Judith Ward

Registered Nurse

Candidate for Masters of Health Science

University of Canterbury

College of Education

Private Bag 4800

Christchurch

jaw171@student.canterbury.ac.nz

(03) 3813494

0276659714

\author{
Academic Supervisors \\ Jeffrey Gage PhD \\ Health Sciences Centre \\ University of Canterbury \\ Private Bag 4800 \\ Christchurch 8140 \\ jeffrey.gage@canterbury.ac.nz \\ (03) 3667001 ext 7401 \\ Paul Watson PhD \\ School of Nursing and Human \\ Services, CPIT \\ PO Box 540 \\ Christchurch 8140 \\ watsonp@cpit.ac.nz
}

You are invited to take part in a research study that will explore the role development of nurses who supervise Exercise Tolerance Tests (ETTs). I propose to interview the ETT nurses and the Director of Cardiology at Christchurch Hospital. I also propose to survey the ECG technicians at Christchurch Hospital and Cardiology Departments nationally. This study will contribute toward completion of a Masters of Health Science Degree. I am interested in varying perspectives about how nurses have developed in this role in a local setting. Role Development refers to the process of beginning and integrating in the clinical role of supervising ETTs. Nurses in New Zealand have been performing this role for the past approximate six years and thus their involvement in this role is relatively new. Findings from this study will contribute to the international literature on nurses in this role and may offer a new perspective.

My research question is ,What is the process of role development for cardiac nurses who supervise exercise tolerance tests?•

Aims:

- Determine what is currently known about the practice of nurses supervising ETTs 
- Describe the role development of nurses who supervise ETTs in a specific locality

- Gather an interdisciplinary perspective about the role development of nurses who supervise ETTs

- Determine the extent to which nurses are involved in the supervision of ETTs within the public sector in New Zealand

\section{Interview:}

I invite you to participate in a semi-structured interview that explores aspects of role development regarding nurses who supervise Exercise Tolerance Tests. The interview is expected to take 30 to 60 minutes of your time. This interview will be conducted in a place that is convenient to you. In your capacity as Director of Cardiology, I seek a managerial perspective about the nurse $\bullet$ involvement in this service.

The tape-recorded interviews will be transcribed in verbatim by myself as the principal researcher. Only my supervisors and I will have access to this data. All recorded information and will remain confidential at all times. It is hope that final findings of this study will be published in an academic journal. It is acknowledged that your personal identity may be identified by your position. The data will be securely stored for 10 years after completion of this study and then destroyed. Individuals who are taped may have their tapes on request.

There are no immediate or direct benefits to you taking part in this study. However, your participation will contribute to a new focus around personnel who supervise Exercise Tolerance Tests.

Participation in this study is entirely your choice. Reading this information sheet does not mean that you have to take part in this study. You may withdraw from this study at any point without having to give a reason.

I note that this study has been reviewed and approved by both the Upper South B Regional Ethics Committee. Reference: URB/08/09/035, and the University of Canterbury Human Ethics Committee. Reference: 2009/133.

Please contact the researcher any time if you have queries about this study and would like to discuss further.

If you agree to take part in this study, please contact Judy Ward (details provided) 


\section{Appendix 5: Consent Form - Clinical Director of Cardiology}

\section{Role Development of Nurses Supervising Exercise Tolerance Tests}

\begin{tabular}{|l|l|l|l|}
\hline English & I wish to have an interpreter & Yes & No \\
\hline M• ori & $\begin{array}{l}\text { E hiahia ana ahau ki tetahi kaiwhaka M• ori/kaiwhaka pakeha } \\
\text { korero }\end{array}$ & Ae & Kao \\
\hline $\begin{array}{l}\text { Cook Island } \\
\text { M• ori }\end{array}$ & Ka inangaro au i tetai tangata uri reo & Ae & Kare \\
\hline Fijian & Au gadreva me dua e vakadewa vosa vei au & lo & Sega \\
\hline Niuean & Fia manako au ke fakaaoga e taha tagata fakahokohoko kupu & E & Nakai \\
\hline S• moan & Ou te manaø ia i ai se faamatala upu & loe & Leai \\
\hline Tokelaun & $\begin{array}{l}\text { Ko au e fofou ki he tino ke fakaliliu te gagana Peletania ki na } \\
\text { gagana o na motu o te Pahefika }\end{array}$ & loe & Leai \\
\hline Tongan & Oku ou fiemaru ha fakatonulea & lo & Ikai \\
\hline & $\begin{array}{l}\text { Other languages to be added following consultation with } \\
\text { relevant communities. }\end{array}$ & & \\
\hline
\end{tabular}

\section{$\underline{\text { Researchers }}$}

Principal Researcher

Judith Ward

Registered Nurse

Candidate for Masters of Health Science

University of Canterbury

College of Education

Private Bag 4800

Christchurch

jaw@student.canterbury.ac.nz

(03)3813494

0276659714
Academic Supervisors

Jeffrey Gage PhD

Health Sciences Centre

University of Canterbury

Private Bag 4800

Christchurch 8140

jeffrey.gage@canterbury.ac.nz

$\underline{\text { Paul Watson } \mathrm{PhD}}$

School of Nursing and

Human Services, CPIT

PO Box 540

Christchurch 8140

watsonp@cpit.ac.nz

I have read and understood the description of the above named study.

I have had opportunity to discuss this study with

I am aware that this study contributes to completion of a Masters of Health Science Degree. 
On this basis, I agree to participate in this study, and I consent to the publication of the final results with the understanding that personal information about myself may be identified by my position. However, in doing so, I would expect to review the material before it is published.

I wish to receive a summary of results.

Yes No

I would like the researcher to discuss findings of this study with me.

Yes No

I understand also that I may at any time withdraw from the project, including withdrawal of any information I have given.

I note that the project has been reviewed and approved by both the Upper South B Regional Ethics Committee. Reference: URB/09/08/035, and the University of Canterbury Human Ethics Committee. Reference: 2009/133.

\section{I hereby consent to take part in this study:}

Name (please print)

Signature:

Signature of Researcher:

Date:

(Note: A copy of the consent form may be retained by participant) 


\section{Appendix 6: Interview Guide - Clinical Director of Cardiology}

- When were nurses first involved in the supervision of ETT tests at Christchurch Hospital?

- Why were nurses established as the personnel to supervise these tests?

- Who was involved in establishing nurses as supervisors of ETTs? E.g. Charge nurses, Cardiologists, service manager, nurse specialist, nurses themselves, other etc

- What processes were established to prepare nurses for this role?

- How has the introduction of nurses supervising ETTs, impacted on service provision?

- How has the multidisciplinary team felt about the nurse•s involvement in this role?

- How do you see the role of nurses supervising ETTs developing in the future? 


\section{Appendix 7: Information Sheet • Technicians}

\section{Role Development of nurses Supervising Exercise Tolerance Tests}

\section{$\underline{\text { Researchers }}$}

Principal Researcher

Judith Ward

Registered Nurse

Candidate for Masters of Health Science

University of Canterbury

College of Education

Private Bag 4800

Christchurch

jaw171@student.canterbury.ac.nz

(03) 3813494

0276659714

\author{
Academic Supervisors \\ Jeffrey Gage PhD \\ Health Sciences Centre \\ University of Canterbury \\ Private Bag 4800 \\ Christchurch 8140 \\ jeffrey.gage@canterbury.ac.nz \\ (03) 3667001 ext 7401 \\ Paul Watson PhD \\ School of Nursing and Human \\ Services, CPIT \\ PO Box 540 \\ Christchurch 8140 \\ watsonp@cpit.ac.nz
}

You are invited to take part in a research study that will explore the role development of nurses who supervise Exercise Tolerance Tests (ETTs). I propose to interview the ETT nurses and the Director of Cardiology at Christchurch Hospital. I also propose to survey the ECG technicians at Christchurch Hospital and Cardiology Departments nationally. This study will contribute towards completion of a Masters of Health Science Degree. I am interested in varying perspectives about how nurses have developed in this role. Role Development refers to the process of beginning and integrating in the clinical role of supervising ETTs. Nurses in New Zealand have been performing this role for the past approximate six years and thus their involvement in this role is relatively new. Findings from this study will contribute to the international literature on nurses in this role and may offer a new perspective.

My research question is: ,What is the process of role development for cardiac nurses who supervise exercise tolerance tests?•

Aims:

- Determine what is currently known about the practice of nurses supervising ETTs

- Describe the role development of nurses who supervise ETTs in a specific locality

- Gather an interdisciplinary perspective about the role development of nurses who supervise ETTs

- Determine the extent to which nurses are involved in the supervision of ETTs in the public sector in New Zealand 


\section{Questionnaire:}

I invite you to complete a questionnaire that seeks information about Exercise Tolerance Testing and involvement of nurses as the supervisors. This questionnaire will take approximately 10 to 15 minutes of your time.

There are no immediate or direct benefits to you taking part in this study and participation in this study is entirely your choice. Reading this information sheet does not mean that you are required to complete the questionnaire. A summary of data collected will be shared with all staff in the ECG department at Christchurch Hospital

I note that this study has been reviewed and approved by both the Upper South B Regional Ethics Committee. Reference: URB/09/08/035, and the University of Canterbury Human Ethics Committee. Reference: 2009/133.

Please contact the researcher any time if you have queries about this study and would like to discuss further.

Thank you for taking time to reading this information sheet 


\section{Appendix 8: Questionnaire -Technicians}

The following questions seek to understand your perceptions about role development of nurses supervising exercise tolerance tests.

Your answers will contribute to a completion of a Dissertation, being submitted for a Masters of Health Science Degree.

This questionnaire should only take approximately 10-15 minutes of your time.

On completion, analysis of questions will be shared with participants who would like to receive a summary of findings.

1. How many years have you been working in the ECG Department?

$$
\text { 0-2 years } \quad 2-5 \text { years } \quad 5-10 \text { years } \quad 10 \text { years }+
$$

2. Have you been working at a time when there were no dedicated ETT nurses, and a doctor supervised tests

Yes

No Go to question 4

3. If yes, what were the strengths and limitations of the way the ETT service was delivered when doctors supervised tests?

Strengths:

Limitations: 
4. What are the strengths and limitations of the way the ETT service is delivered now that nurses are supervising ETTs?

Strengths:

Limitations:

5. How do you see the ETT service developing in the future?

6. What would this mean for the role of the technicians?

7. What would this mean for the role of the nurses?

8. What role do technicians play in the role development of nurses who supervise Exercise Tolerance tests?

Please feel free to add any additional comments that you think may be relevant.

Thank-you for completing this questionnaire

Please place in the box provided

\author{
Judy.ward@cdhb.govt.nz
}




\section{Appendix 9: Information Sheet - National}

\section{Role Development of Nurses Supervising Exercise Tolerance Tests}

\section{$\underline{\text { Researchers }}$}

Principal Researcher

Judith Ward

Registered Nurse

Candidate for Masters of Health Science

University of Canterbury

College of Education

Private Bag 4800

Christchurch

jaw171@ student.canterbury.ac.nz

(03) 3813494

0276659714

\author{
Academic Supervisors \\ Jeffrey Gage $\mathrm{PhD}$ \\ Health Sciences Centre \\ University of Canterbury \\ Private Bag 4800 \\ Christchurch 8140 \\ jeffrey.gage@canterbury.ac.nz \\ (03) 3667001 ext 7401 \\ $\underline{\text { Paul Watson PhD }}$ \\ School of Nursing and Human \\ Services, CPIT \\ PO Box 540 \\ Christchurch 8140 \\ watsonp@cpit.ac.nz
}

You are invited to take part in a research study that will explore the role development of nurses who supervise Exercise Tolerance Tests (ETTs).I propose to interview the ETT nurses and the Director of Cardiology at Christchurch Hospital. I also propose to survey the ECG technicians at Christchurch Hospital and Cardiology Departments nationally. This study will contribute towards completion of a Masters of Health Science Degree. I am interested in varying perspectives about how nurses have developed in this role. Role Development refers to the process of beginning and integrating in the clinical role of supervising ETTs. Nurses in New Zealand have been performing this role for the past approximate six years and thus their involvement in this role is relatively new. I am hoping to identify various themes that are unique to nurses in this role. Findings from this study will contribute to the international literature on nurses in this role and may offer a new perspective.

My research question is, What is the process of role development of for cardiac nurses who supervise exercise tolerance tests?•

Aims:

- Determine what is currently known about the practice of nurses supervising ETTs

- Describe the role development of nurses who supervise ETTs in a specific locality

- Gather an interdisciplinary perspective about the role development of nurses who supervise ETTs

- Determine the extent to which nurses are involved in the supervision of ETTs within the public sector in New Zealand 


\section{Questionnaire:}

I invite you to complete a questionnaire that seeks information about Exercise Tolerance Testing and involvement of nurses as the supervisor in your area. This questionnaire will take approximately 10 to 15 minutes of your time.

There are no immediate or direct benefits to you taking part in this study and participation in this study is entirely your choice. Reading this information sheet does not mean that you are required to complete the questionnaire. A summary of data collected will be sent to those areas that have requested.

I note that this study has been reviewed and approved by both the Upper South B Regional Ethics Committee. Reference: URB/09/08/035, and the University of Canterbury Human Ethics Committee. Reference: 2009/133.

Please contact the researcher any time if you have queries about this study and would like to discuss further.

Thank you for taking time to reading this information sheet 


\section{Appendix 10: Questionnaire - National}

\section{Role Development of Nurses Supervising Exercise Tolerance Tests}

The following questions seek to find information about the status of nurses supervising exercise tolerance tests in New Zealand. Your answers will contribute to completion of a Dissertation, being submitted for a Masters of Health Science Degree.

The questionnaire should only take approximately 10 -15 minutes to complete.

Analysis of questionnaires will be shared with participants who would like to receive a summary of findings

On completion, please place your completed questionnaire in the stamped addressed envelope.

1. Are exercise tolerance tests performed in your cardiac department?

Yes

No If no, please go to question 14

2. How many days of the week are ETTs performed in your department?

days per week

3. Which of the following personnel supervise exercise tolerance tests in your department?

Cardiologists

Registered Nurses

Technicians

Registrars

Other (Please specify)

*If nurses do not supervise exercise tolerance tests, please go to Question 14

4. How many nurses are involved supervising ETTs in your department?

Number of nurses involved in supervising ETTs

5. In what year did nurses become involved in the supervision of

ETTs in your department? 
6. What prior experience are nurses required to have before they supervise ETTs? (Please tick as many boxes as you like)

None

Specific cardiology experience

Other (Please specify)

7. What qualifications are nurses required to have before supervising ETTs? (Please tick as many boxes as you like)

None

Advanced life support certificate

Graduate certificate in Cardiology

Post Graduate Certificate

Post Graduate Diploma

Masters Degree

Other (Please specify)

8. What ongoing training/education do you see as being relevant for nurses supervising ETTs?

e.g. specific cardiology study days, attending conference, competency update days

9. Do you have quality documents in regards to training ETT nurses in your department?

Yes

No

In progress 
10. Do you have quality documents in regards to assessing competencies of nurses who supervise ETTs?

Yes

No

In progress

11. Are ETT nurses in your area involved in other tests?

Dobutamine Stress Echo

Other (Please specify)

12. Do technicians work along side nurses supervising ETT tests?

Yes

No

13. Which of the following additional roles to supervising ETTs are nurses involved in? (Please tick as many boxes as you like)

Patient education

Interpretation of ETT results (formally)

Health promotion

Referral for other tests

Cardiac examination

Other (Please specify)

14. Does your area apply the guidelines (for supervision of Exercise Tolerance Testing) as set down by the Cardiac Society of Australia and New Zealand (CSANZ, 2008)?

Yes

No 
15. Please tick the box that best describes your position

Clinical Director of Cardiology

Clinical Nurse Manager

Clinical Nurse Specialist

ETT Nurse

Other

I would like to receive a summary of findings of this study

Yes

No

Address you would like summary sent to:

Thank you for completing this questionnaire

Please return in the free post envelope provided

Judy Ward (judy.ward@cdhb.govt.nz) 


\title{
Appendix 11: Maori Health - Consultation
}

\author{
Canterbury \\ District Health Board \\ Te Poari Hauora o Waitaha
}

Thursday, 30 July 2009

Judith Ward

Registered Nurse

Cardiology

Christchurch Hospital

$\mathrm{CDHB}$

\section{Re: Role Development of Nurses Supervising Exercise Tolerance Tests}

Tena koe Judy

Ka nui te mihi tenei ki a koe me tou roopu o ka Kairapukorero ki te hapai o te kaupapa whakahirahira mou, moku mo tatou katoa. Ko Rapuka Korero te mea nui. No reira tena koe me te roopu o ka Kairapukorero, tena koutou katoa.

Thank you for submitting your research for assessment by Te Komiti Whakarite. We have made several recommendations and comments for you to consider. We do not require a response as the final decision is with the Upper South Island Ethics Committee.

- In order for us to build on-going relationships with researchers and to improve Māori health we would appreciate if feedback on your findings could be provided to us.

- We appreciate that you acknowiedge your research will be of interest to Mãori especially when we have more Maori nurses who will benefit from your study.

- Although we have been consulted it is important that other ethnic groups, especially ethnic groups with significant numbers in New Zealand are also consulted.

Te Komiti Whakarite recognises the effort you have made with regards to the following:

- A literature search will identify current knowledge about nurses who supervise ETTs.

- Semi-structured interviews will be conducted with ETT nurses and the Director of Cardiology at Christchurch Hospital around the focus of nurse's role development. 
- Cardiac Technicians at Christchurch Hospital will be invited to complete a questionnaire on nurses' development in the role.

- Questionnaires will be sent to all cardiology services within the 21 District Health Boards to collect national data.

- This study aims to increase understanding of nurses preparing for such roles and their ongoing role development.

- Dissemination of the study/research findings in a summary form to participants and consultation groups including the Cardiac Society of Australia and New Zealand as well as the Cardiac meeting at Christchurch Hospital.

- The benefits of your research/study for participants and the general population make for positive reading.

- I would also like to acknowledge the consultation that you undertook with me as chairperson of Te Komiti Whakarite as it was very informative.

The findings from this study may contribute to the development of future research hypotheses or projects and it is important that you disseminate your findings to the Maori community.

Heoi ano

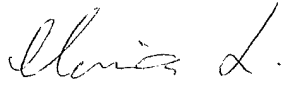

Tahu Potiki Stirling

Chairperson

Te Komiti Whakarite 


\section{Appendix 12: Ethics Approval}

Human Ethics Committee

Tel: +643364 2241, Fax: +643364 2856, Email: human-ethics(a)canterbury.ac.nz

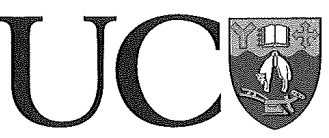

UNIVERSITY OF

CANTERBURY

Te Whare Wänanga o Waitaha

Ref: HEC $2009 / 133$

22 September 2009

Judith Ward

Hcalth Scicnces Centre

UNIVERSITY OF CANTERBURY

Dear Judith

The Human Ethics Committee advises that your research proposal "Role development of nurses supervising exercise tolerance tests" has been considered and approved.

Please note that this approval is subject to the incorporation of the amendments you have provided in your email of 18 September 2009.

Best wishes for your project.

Yours sincerely

Meveldueg

Dr Michael Grimshaw

T. Chair, Human Ethics Committee 


\section{Appendix 13: Ethics Approval}

\author{
Health \\ and \\ Disability \\ Ethics \\ Committees
}

17 August 2009

Ms Judith Ann Ward

University of Canterbury

27 Sheldon Street

Woolston

Christchurch 8023

Dear Ms Ward

Ethics Reference Number: URB/09/08/035

Role Development of Nurses Supervising Exercise Tolerance Tests

Investigator: Ms Judith Ann Ward

Locality: Christchurch Hospital

The above study has been given ethical approval by the Upper South B Regional Ethics Committee.

Approved Documents

Information Sheet and Consent Form dated 1 July 2009

National Questionnaire dated 1 July 2009

Interview Guide dated 1 July 2009 (Nurses) dated 1 July 2009

Interview Guide dated 1 July 2009 (Director of Cardiology) dated 1 July 2009.

Accreditation

The Committee involved in the approval of this study is accredited by the Health Research Council and is constituted and operates in accordance with the Operational Standard for Ethics Committees, April 2006.

\section{Final Report}

The study is approved until 30 June 2010. A final report is required at the end of the study and a form to assist with this is available at http://www.ethicscommittees.health.govt.nz. If the study will not be completed as advised, please forward a progress report and an application for extension of ethical approval one month before the above date.

\section{Amendments}

It is also a condition of approval that the Committee is advised of any adverse events, if the study does not commence, or the study is altered in any way, including all documentation eg advertisements, letters to prospective participants. 
Please quote the above ethics committee reference number in all correspondence.

It should be noted that Ethics Committee approval does not imply any resource commitment or administrative facilitation by any healthcare provider within whose facility the research is to be carried out. Where applicable, authority for this must be obtained separately from the appropriate manager within the organisation.

The committee would like to take this opportunity to wish you all the best with your study.

Yours sincerely

Dicationip

Mrs Diana Whipp

Upper South B Regional Ethics Committee Administrator

Email: diana_whipp@moh.govt.nz 